\title{
Heterogeneous Nanostructured Electrode Materials for Lithium-Ion Batteries - Recent Trends and Developments
}

\author{
Xiangfeng Guan ${ }^{1}$, Guangshe Li1 ${ }^{1}$ Jing Zheng², Chuang $\mathrm{Yu}^{2}$, \\ Xiaomei Chen 1 , Liping $\mathrm{Li}^{2}$ and Zhengwei $\mathrm{Fu}^{1}$ \\ ${ }^{1}$ State Key Laboratory of Structural Chemistry and \\ ${ }^{2}$ Key Laboratory of Optoelectronic Material Chemistry and Physics, \\ Fujian Institute of Research on the Structure of Matter, \\ Chinese Academy of Sciences, Fuzhou,
} China

\section{Introduction}

Developing highly efficient, low cost, and environmentally benign energy storage devices and related materials is a key issue to meet the challenge of global warming, the finite nature of fossil fuels, and city pollution. Among the various available storage technologies, lithium-ion batteries (LIBs) currently represent the state-of-the-art technology in small rechargeable batteries because it can offer the largest energy density and output voltage of all known rechargeable battery technologies. A typical commercial lithium-ion battery consists of a negative electrode (anode, e.g., graphite) and a positive electrode (cathode, e.g., $\mathrm{LiCoO}_{2}$ ), both of which are separated by a lithium-ion-conducting electrolyte. When the cell is charged, Li ions are extracted from the cathode, pass through the electrolyte, and are inserted into the anode. Discharge reverses the procedure. Although such batteries are commercially successful, these cells are still required to improve their performance to satisfy an increasing demand for portable and miniaturized electronics, uninterrupted power supplies for technological and rural needs, power tools, and even stationary storage batteries.

Since the recharging is completed with the lithium ion insertion/extraction process in both electrodes, the nature of two electrode materials is crucial to the performance improvement of batteries (Liang et al., 2009). At present, commercial batteries are mostly based on micrometer-size electrode materials, which are limited by their kinetics, lithium-ion intercalation capacities, and structural stability. The performance of currently available LIBs can only meet the requirements of applications to some degree (Guo et al., 2008). These have placed renewed demands on new and improved electrode materials for LIBs with a high energy density, high power density, longer cycle life, and improved safety.

Nanostructured approaches have been recently demonstrated to be highly effective in greatly improving the electrochemical performance of electrode materials. For instances, nanostructured materials decrease the diffusion length of lithium ion in the insertion/extraction process, which results in the higher capacities at high charge/discharge 
rates. Nanostructured materials can also increase the surface/interface storage due to the high contact between electrode material and electrolyte. Additionally, nanostructured materials can buffer the stresses caused by the volume variation occurring during the charge/discharge process, alleviating the problem of capacity fade and poor rate capability associated with the material breaking away into the electrolyte. However, nanostructured materials, especially single-phased nanostructured materials, are not an ultimate solution to meet the requirements of future LIBs. One of the primary reasons is that some of the intrinsic material properties of bulk phase, such as low conductivities, low energy densities at high charge/discharge rates, and weak mechanical stabilities, cannot be simply altered or improved by just transforming them into nanostructured materials (Liu et al., 2011). Moreover, without some surface protection, nanostructured materials may magnify the safety issues due to a high surface reactivity and may aggravate capacity fade due to aggregation.

Recently, heterogeneous nanostructured approaches have been introduced to overcome the above mentioned limitations when using single component nanostructured electrode materials. The heterogeneous nanostructured materials are composed of multinanocomponents, each of which is tailored to address a different demand (e.g. high lithiumion/electrical conductivity, high capacity, and excellent structural stability) (Liu et al., 2011). There exists a synergistic effect by the interplay between particle shape, properties, and possible association of the individual components, which can be regulated to explore the full potential of the materials in terms of the performance (e.g. high energy density, high power density, longer cycle life, and improved safety). For instances, concentration-gradient coreshell nanostructured cathode material composed of $\mathrm{Li}\left[\mathrm{Ni}_{0.8} \mathrm{Co}_{0.1} \mathrm{Mn}_{0.1}\right] \mathrm{O}_{2}$ and $\mathrm{Li}\left[\mathrm{Ni}_{0.46} \mathrm{Co}_{0.23} \mathrm{Mn}_{0.31}\right] \mathrm{O}_{2}$ have been reported to exhibit a very high reversible capacity, excellent cycling, and safety characteristics, which are attributed to the synergic effects of core and shell components (Sun et al., 2009). Novel nanonet constructed by $\mathrm{SnO}_{2}$ nanoparticles and ploy (ethylene glycol) chains has been prepared. The synergic properties and functionalities of both materials enable this composite material to exhibit unexpectedly high lithium storage over the theoretical capacity of $\mathrm{SnO}_{2}$ (Xiong et al., 2011). Graphene anchored with $\mathrm{Co}_{3} \mathrm{O}_{4}$ nanoparticles have been synthesized and utilized as anode materials, which exhibits a large reversible capacity, excellent cyclic performance, high Coulombic efficiency, and good rate capability due to a strong synergic effect between $\mathrm{Co}_{3} \mathrm{O}_{4}$ nanoparticles and graphene nanosheet (Wu et al., 2010).

Therefore, developing the heterogeneous nanostructured electrode materials is considered to be the most promising avenue towards future LIBs with high energy density, high power density, longer cycle life, and improved safety. Even so, it is necessary first of all to know how heterogeneous nanostructured materials have impacts on the performance of the LIBs and what kinds of synergic effects these materials exhibit. In this chapter, we focus on the recent trends and developments of heterogeneous nanostructured electrode materials for uses in LIBs and provide an overview of the synthesis, synergic mechanism of heterogeneous nanostructured components, and a survey of promising candidates based on heterogeneous nanostructured materials for LIBs.

\section{Heterogeneous nanostructured cathode materials}

Heterogeneous nanostructured cathode materials are of great interest for LIBs because of the synergic properties arising from the intergrated multi-nanocomponents, each of which is 
tailored to address a different demand like high lithium-ion/electrical conductivity, high capacity, and excellent structural stability. In this section, we describe these heterogeneous cathode nanomaterials based on the type of void spaces available for lithium ion insertion: one-dimensional, two-dimensional, and three-dimensional transition-metal-oxide-based nanocomposites (Figure 1).

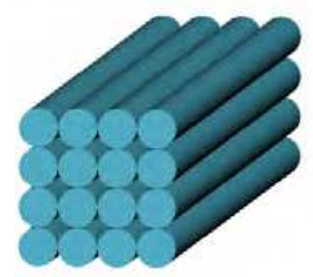

(a)

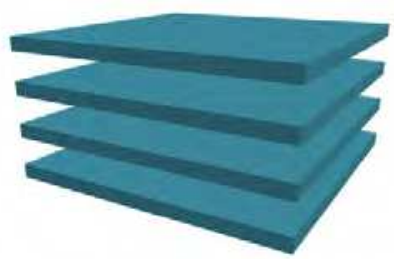

(b)

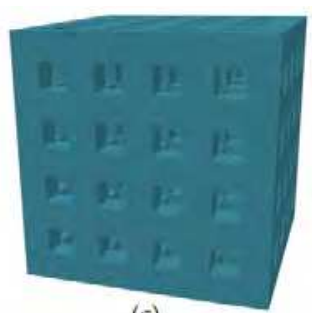

(c)

Fig. 1. Schematic representation of void spaces in a) one-dimensional, b) two-dimensional, and c) three-dimensional transition-metal-based oxides. (Redrawn from Ref.(Winter et al., 1998))

\subsection{One-dimensional cathode nanocomposites}

Since the first report by Padhi et al. (1997) on reversible electrochemical lithium insertionextraction in $\mathrm{LiFePO}_{4}$, olivine structured lithium transition metal phosphates, $\mathrm{LiMPO}_{4}(\mathrm{M}$ $=\mathrm{Fe}, \mathrm{Mn}, \mathrm{Co}, \mathrm{Ni}$ ), have attracted much attention as the promising candidate cathode materials for LIBs. As shown in Figure 2, the structure of $\mathrm{LiMPO}_{4}$ consists of a distorted hexagonal close-packed (hcp) oxygen framework with $1 / 8$ of the tetrahedral holes occupied by $\mathrm{P}$, and $1 / 2$ of the octahedral holes occupied by various metal atoms ( $\mathrm{Li}$ and $\mathrm{M}$ ).

(a)

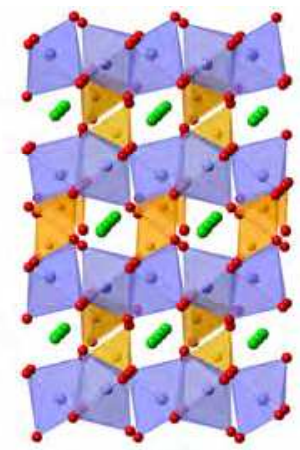

(b)

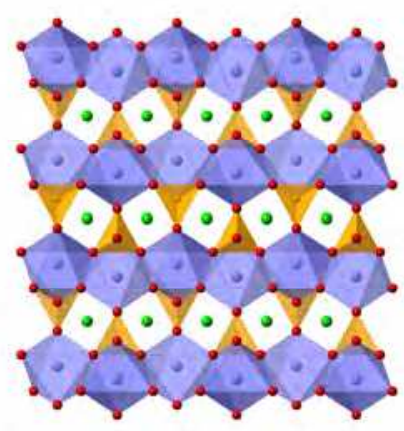

Fig. 2. Polyhedral representation of the structure of $\mathrm{LiMPO}_{4}$ (space group Pnma) viewed a) along $b$-axis and $\mathrm{b}$ ) along $c$-axis. $\mathrm{MO}_{6}$ octahedra are shown in blue, phosphate tetrahedra in yellow, and lithium ions in green.

Crystalline $\mathrm{LiMPO}_{4}$ has an orthorhombic unit cell (space group Pmnb). Layers of $\mathrm{MO}_{6}$ octahedra are corner-shared in the bc plane and linear chains of $\mathrm{LiO}_{6}$ octahedra are edge shared in a direction parallel to the b-axis. These chains are bridged by edge and corner shared phosphate tetrahedra, creating a stable crystal structure (Ellis et al., 2010). Because 
oxygen atoms are strongly bonded by both $\mathrm{M}$ and $\mathrm{P}$ atoms, the structure of $\mathrm{LiMPO}_{4}$ is stable at high temperatures. The high lattice stability guarantees an excellent cyclic performance and operation safety for $\mathrm{LiMPO}_{4}$. However, the strong covalent oxygen bonds lead to a low ionic diffusivity and poor electronic conductivity. Additionally, the Li diffusion in $\mathrm{LiMPO}_{4}$ is widely believed to be one dimensional along the b-axis, as shown in Figure 3. These limit the high rate performance of olivine $\mathrm{LiMPO}_{4}$. In this family compounds, lithium iron phosphate $\left(\mathrm{LiFePO}_{4}\right)$ and lithium manganese phosphate $(\mathrm{LiMnPO})$ are more promising because they operate at $3.4-4.1 \mathrm{~V}$ versus $\mathrm{Li} / \mathrm{Li}^{+}$, which is not so high as to decompose the organic electrolyte but is not so low as to scarify the energy density.

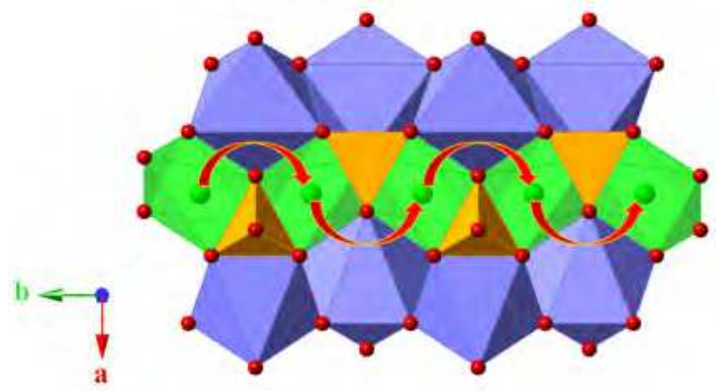

Fig. 3. Structure of $\mathrm{LiMPO}_{4}$ that depicts the curved trajectory of $\mathrm{Li}$ ion transport along $b$-axis, shown with red arrows. The colour scheme is the same as that in Figure 2. (Redrawn from Ref. (Ellis et al., 2010))

\subsection{1 $\mathrm{LiFePO}_{4}$}

$\mathrm{LiFePO}_{4}$ is one of the most promising cathode materials because of its high operating voltage $\left(\sim 3.5 \mathrm{~V}\right.$ vs. $\left.\mathrm{Li} / \mathrm{Li}^{+}\right)$and large theoretical gravimetric capacity $(\sim 170 \mathrm{mAh} / \mathrm{g})$, as well as its low cost, environmental friendliness, particularly high thermal stability, and strong overcharge tolerance as compared to other cathode materials. One impediment to the wider use of $\mathrm{LiFePO}_{4}$, however, is its low lithium ion conductivity (lithium ion diffusion coefficient (DLi) is $\left.10^{-14} \mathrm{~cm}^{2} \mathrm{~s}^{-1}\right)$ and electrical conductivity $\left(10^{-9} \mathrm{Scm}^{-1}\right)$. The slow lithium diffusion can be addressed by decreasing the particle dimensions to nanometer scale to reduce the diffusion paths. To overcome the low electronic conductivity, many conductive agents such as carbonaceous materials and polymers have been reported to extend the performance of $\mathrm{LiFePO}_{4}$.

\subsubsection{Carbonaceous materials}

Carbonaceous materials such as amorphous carbon, carbon nanotube, and graphene have been used to form composites with $\mathrm{LiFePO}_{4}$ to improve the electronic conductivity of electrodes. Amorphous carbon coating is one of the most important techniques used to improve the specific capacity, rate performance, and cycling life of $\mathrm{LiFePO}_{4}$. The main role of amorphous carbon coating is to enhance the surface electronic conductivity of $\mathrm{LiFePO}_{4}$ particles so that the active materials can be fully utilized at high current rates. The beneficial effects of carbon coating have been shown to be strongly related to the morphology. For example, Wang et al. (2008) coated $\mathrm{LiFePO}_{4}$ nanoparticles with a carbon shell by in situ polymerization. As shown in Figure 4, these composites are composed of $20-40 \mathrm{~nm} \mathrm{LiFePO} 4$ 
nanoparticles covered with 1-2 nm thick carbon shells. The $\mathrm{LiFePO}_{4} / \mathrm{C}$ composite delivered a discharge capacity of $169 \mathrm{mAh} / \mathrm{g}$ at a $0.6 \mathrm{C}$ rate, which is extremely closer to the theoretical value of $170 \mathrm{mAh} / \mathrm{g}$ for $\mathrm{LiFePO}_{4}$. Even at a high discharge rate of $60 \mathrm{C}$, it still delivered a respectable specific capacity of $90 \mathrm{mAh} / \mathrm{g}$. The composite also exhibits an excellent cycling performance, with less than 5\% discharge capacity loss over 1100 cycles. These authors have proposed that an ideal core-shell network of $\mathrm{LiFePO}_{4} / \mathrm{C}$ composites should contain nano-size $\mathrm{LiFePO}_{4}$ particles completely coated with a thin layer of porous conductive carbon, which serves as the electron pathway and porous nature that allow lithium ions to diffuse through.
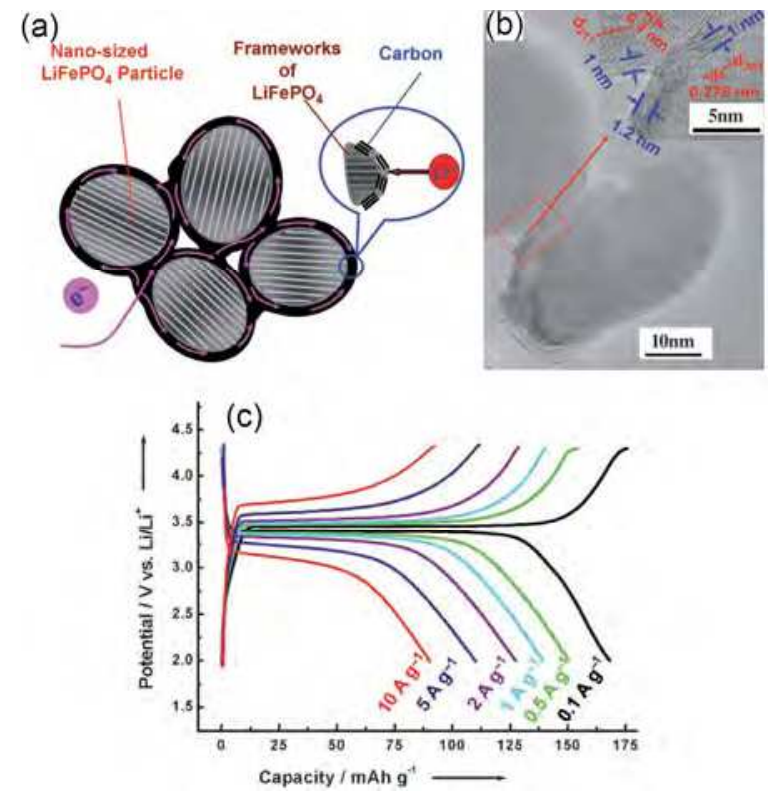

Fig. 4. a) Designed ideal structure for $\mathrm{LiFePO}_{4}$ particles with nano-sizes and a complete carbon coating, b) a typical TEM image for some $\mathrm{LiFePO}_{4} / \mathrm{C}$ primary particles, c) charge/discharge tests for $\mathrm{LiFePO}_{4} /$ carbon composites at different current densities in a potential window of 2.0-4.3 V (vs. Li/ $\mathrm{Li}^{+}$) (Wang et al., 2008).

In-situ formed amorphous carbon coating layer can not only reduce the particle size of $\mathrm{LiFePO}_{4}$ by inhibiting particle growth during the sintering (Huang et al., 2001), but also act as a reducing agent to suppress the oxidation from $\mathrm{Fe}^{2+}$ to $\mathrm{Fe}^{3+}$ during the sintering and thus simplify the atmosphere requirement in synthesis (Pent et al., 2011).

The beneficial effect of carbon coating has also been observed to depend on the uniformity, thickness, loading, and precursor of the coating. For instance, Konarova et al. (2008) prepared $\mathrm{LiFePO}_{4} / \mathrm{C}$ composites with different amounts of carbon by ultrasonic spray pyrolysis followed by a heat treatment. They have found that the discharge capacity is strongly affected by the amount of carbon residue and sintering temperature. After optimization, $\mathrm{LiFePO}_{4} / \mathrm{C}$ composites with $1.87 \mathrm{wt} \%$ of carbon exhibited a best electrochemical performance with capacities of $140 \mathrm{mAh} / \mathrm{g}$ at C/10 and $84 \mathrm{mAh} / \mathrm{g}$ at $5 \mathrm{C}$. 
$\mathrm{Vu}$ et al. (2011) synthesized monolithic, three-dimensionally ordered macroporous and meso-/microporous $(3 \mathrm{DOM} / \mathrm{m}) \mathrm{LiFePO}_{4} / \mathrm{C}$ composite cathodes by a multiconstituent, dual templating method. In this composite, $\mathrm{LiFePO}_{4}$ is dispersed in a carbon phase around an interconnected network of ordered macropores. The carbon phase enhances the electrical conductivity of the cathode and maintains $\mathrm{LiFePO}_{4}$ as a highly dispersed phase during the synthesis and even the electrochemical cycling. The capacity of the composites is as high as $150 \mathrm{mAh} / \mathrm{g}$ at a rate of C/5,123 mAh/g at $1 \mathrm{C}, 78 \mathrm{mAh} / \mathrm{g}$ at $8 \mathrm{C}$, and $64 \mathrm{mAh} / \mathrm{g}$ at $16 \mathrm{C}$, showing no capacity fading over 100 cycles.

Carbon nanotubes (CNT) and graphene have advantages of high conductivity, nanotexture, and resiliency, which are very beneficial for LIBs, and therefore have been introduced to improve the electrochemical performances of $\mathrm{LiFePO}_{4}$ cathodes. For example, recently, Zhou et al.(2010) synthesized hierarchically structured composites based on porous $\mathrm{LiFePO}_{4}$ with CNT networks. Porous $\mathrm{LiFePO}_{4}-\mathrm{CNT}$ composites were synthesized via a facile in-situ sol-gel method, where the carbon nanotubes were functionalized using a mixed acid method to ensure an uniform dispersion into the aqueous sol. As shown in Figure 5, $\mathrm{LiFePO}_{4} / \mathrm{CNT}$ composites showed a significantly improved specific capacity and rate performance in comparison to the unmodified porous $\mathrm{LiFePO}_{4}$. This performance enhancement is attributed to an improved electrochemical accessibility and a decrease in inert "dead" zones provided by the interpenetrating conductive CNT networks present in the composite structure.

\section{(a)}

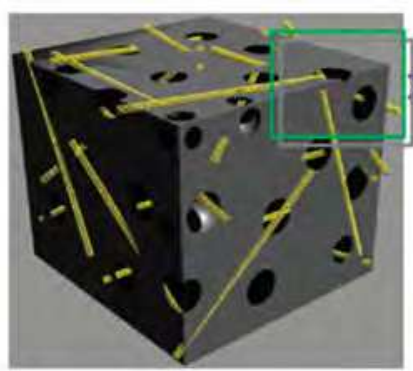

(c)

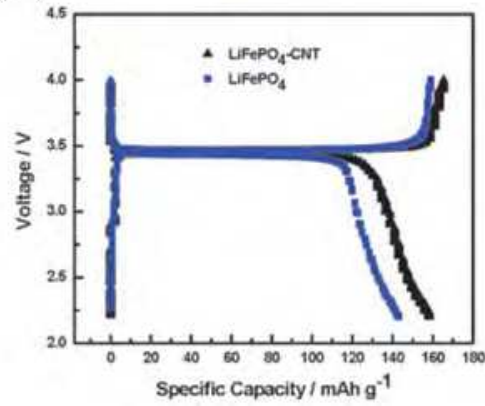

(b)

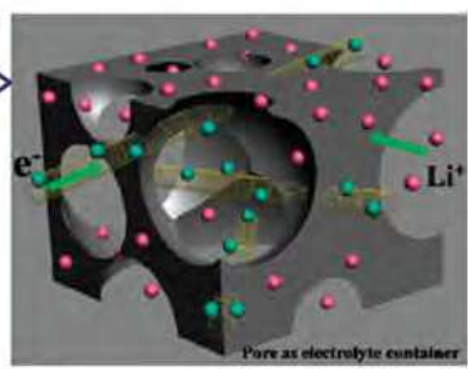

(d)

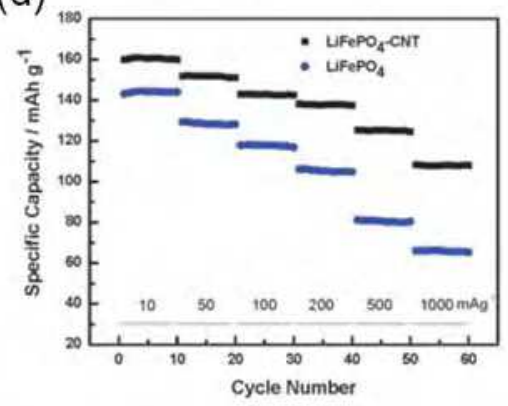

Fig. 5. a) Schematic illustrations of porous $\mathrm{LiFePO}_{4}-\mathrm{CNT}$ composite, b) an enlarged zone from (a), showing the corresponding electron transport and ion diffusion mechanisms, c) charge/discharge profiles; and d) rate performance of porous $\mathrm{LiFePO}_{4}$ (blue) and $\mathrm{LiFePO}_{4}$ CNT composite (black). (Zhou et al., 2010) 
More recently, Zhou et al. (2011) synthesized graphene-modified $\mathrm{LiFePO}_{4}$ composites with $\mathrm{LiFePO}_{4}$ nanoparticles and graphene oxide nanosheets by spray-drying and annealing processes. As indicated in Figure 6, the $\mathrm{LiFePO}_{4}$ primary nanoparticles embedded in microsized spherical secondary particles were wrapped homogeneously and loosely with a graphene 3D network. Such a special nanostructure facilitates the electron migration throughout the secondary particles, while the presence of abundant voids between the $\mathrm{LiFePO}_{4}$ nanoparticles and graphene sheets is beneficial for $\mathrm{Li}^{+}$diffusion. The composite cathode material could deliver a capacity of $70 \mathrm{mAh} / \mathrm{g}$ at $60 \mathrm{C}$ discharge rate and showed a capacity decay rate of $<15 \%$ when cycled under $10 \mathrm{C}$ charging and $20 \mathrm{C}$ discharging for 1000 times.

\section{(a)}
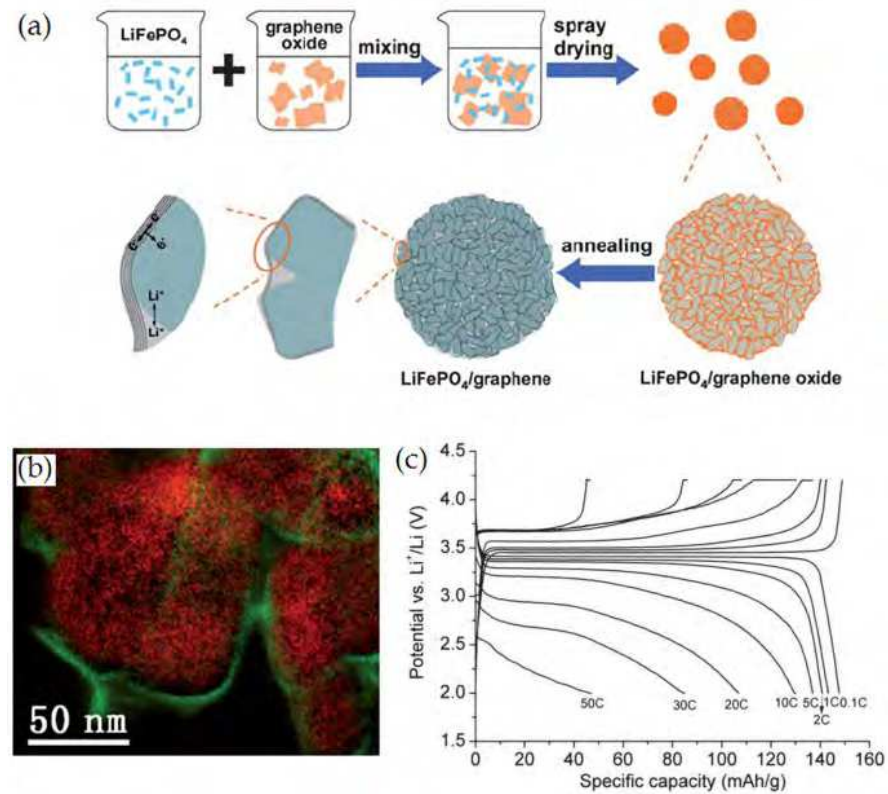

Fig. 6. a) Illustration of the preparation process and microscale structure of $\mathrm{LiFePO}_{4}$ /graphene composites; b) the corresponding elemental map of the same area showing graphene-sheets wrapped on $\mathrm{LiFePO}_{4}$ nanoparticles, where red represents the $\mathrm{LiFePO}_{4}$ nanoparticles, and the green represents graphene sheets; and c) rate discharge curves of $\mathrm{LiFePO}_{4}$ /graphene composite. (Zhou et al., 2011)

Though carbonaceous materials have showed some positive effects in improving the electrochemical performance of $\mathrm{LiFePO}_{4}$ cathode, higher conductive carbon loading also needs more binder which generally reduces the energy density of the cells. Therefore, the influence of particle size, loading content, and mixing procedure of conductive carbonaceous materials on the performance of battery cells needs further attentions.

\subsubsection{Polymers}

Polymers have been proven to be an effective substance to improve the electrochemical properties of $\mathrm{LiFePO}_{4}$ when forming composites with $\mathrm{LiFePO}_{4}$. Huang and Goodenough 
(2008) proposed a strategy of substituting the inactive carbon and Teflon (PTFE) binder with an electrochemically active polymer like polypyrrole (PPy) or polyaniline (PANI) to enhance the electrochemical performance of $\mathrm{LiFePO}_{4}$. Significantly improved capacity and rate capability are achieved in such $\mathrm{LiFePO}_{4}$ /polymer composite cathodes, because polymers can increase the specific capacity and rate capability and lower the overpotential at high discharge rates. Recent work reported by Chen et al. (2011) also indicates that PANI can serve as a binder to make the carbon-coated $\mathrm{LiFePO}_{4}$ (C-LFP) electrode surface smoother to endure a long cycling. In their work, they modified C-LFP with PANI: C-LFP was synthesized via a solid state reaction, whereas PANI was formed in situ by chemical oxidative polymerization of aniline with ammonium persulfate as an oxidizer to achieve the C-LFP/PANI composites. Specific capacities as high as $165 \mathrm{mAh} / \mathrm{g}$ at $0.2 \mathrm{C}, 133 \mathrm{mAh} / \mathrm{g}$ at 7 $\mathrm{C}$, and $123 \mathrm{mAh} / \mathrm{g}$ at $10 \mathrm{C}$ are obtained in C-LFP/7 wt.\% PANI composite.

(a)
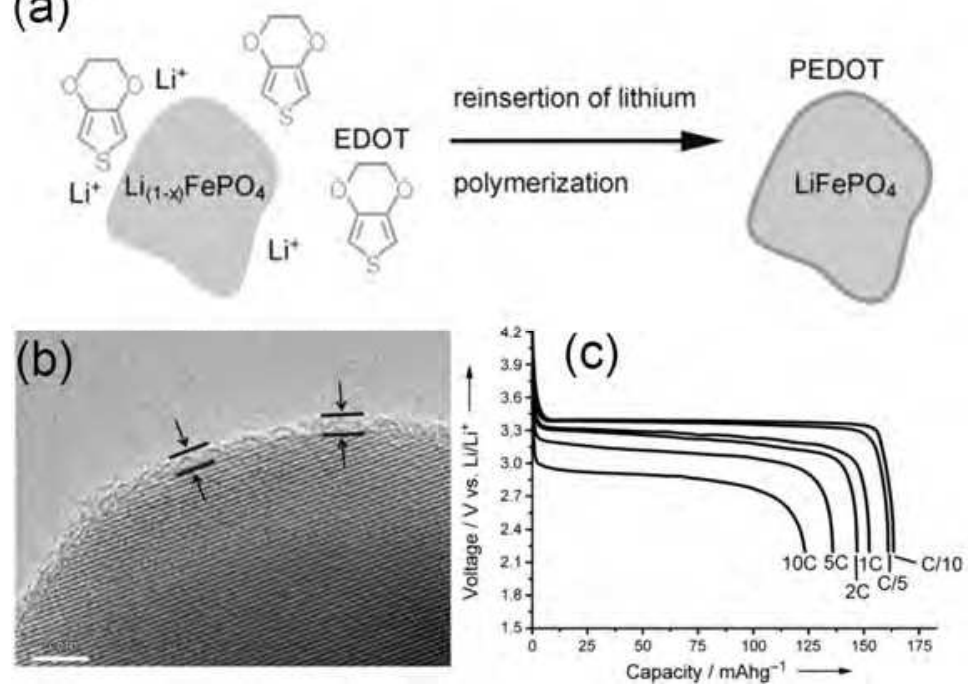

Fig. 7. a) Polymerization reaction. The reinsertion of lithium into $\mathrm{Li}_{1-x} \mathrm{FePO}_{4}$ leads to the oxidation of EDOT deposited on the solid surface as a conducting polymer PEDOT; $b$ ) TEM of PEDOT-LiFePO 4 ; and c) discharge curves of PEDOT/LiFePO $/$ PVDF 5.9 : 86.6 : 7.5 in wt.\%. (Charge conditions are 2.2-4.2 V, versus $\mathrm{Li}^{+} / \mathrm{Li}$ ). (Lepage et al., 2011)

Other means have also been used to synthesize polymer $/ \mathrm{LiFePO}_{4}$ composites, including electropolymerization from a suspension of $\mathrm{LiFePO}_{4}$ particles (Boyano et al., 2010), polymerization using a chemical oxidant in the presence of the particle (Wang et al., 2005), or formation of a colloidal suspension of the polymer immediately before the introduction of $\mathrm{LiFePO}_{4}$ particles (Murugan et al., 2008). However, coating $\mathrm{LiFePO}_{4}$ with homogeneous polymer thin layer is still very difficult. This problem can possibly be solved by the soft chemistry approach reported by Lepage et al. (2011), which relies on the intrinsic oxidation power of $\mathrm{Li}_{1-x} \mathrm{FePO}_{4}$ rather than on an external oxidant as the driving force for the polymerization process, as shown in Figure 7a. The polymerization propagation requires the reinsertion of lithium into the partially delithiated $\mathrm{LiFePO}_{4}$, as well as the transport of $\mathrm{Li}^{+}$ ions and electrons through the deposited polymer coating like PEDOT. In the resultant 
PEDOT $/ \mathrm{LiFePO}_{4}$, a very thin PEDOT layer is homogeneously covered on surface of $\mathrm{LiFePO}_{4}$ nanoparticles (Figure $7 \mathrm{~b}$ ). PEDOT/ $\mathrm{LiFePO}_{4}$ shows a capacity of $163 \mathrm{mAh} / \mathrm{g}$ at C/10, which is similar to the theoretical capacity of $170 \mathrm{mAh} / \mathrm{g}$ for $\mathrm{LiFePO}_{4}$. At higher rates of discharge, more specifically at $10 \mathrm{C}$ (at constant current for a discharge in $6 \mathrm{~min}$ ), the capacity is 123 $\mathrm{mAh} / \mathrm{g}$, approximately $70 \%$ of the theoretical capacity.

\subsection{2 $\mathrm{LiMnPO}_{4}$}

Encouraged by the success of $\mathrm{LiFePO}_{4}$, much research is now focused on the olivine $\mathrm{LiMPO}_{4}\left(\mathrm{M}=\mathrm{Mn}, \mathrm{Co}\right.$, and Ni) structures. Among them, $\mathrm{LiMnPO}_{4}$ is of particular interest as it offers a higher potential of $4.1 \mathrm{~V} \mathrm{vs} \mathrm{Li}^{+} / \mathrm{Li}$ compared to $3.4 \mathrm{~V} \mathrm{vs} \mathrm{Li}^{+} / \mathrm{Li}$ of $\mathrm{LiFePO}_{4}$, the expected safety features, and abundant resources. Hence, $\mathrm{LiMnPO}_{4}$ can be an ideal cathode material. Unfortunately, besides a low ionic conductivity $\left(D_{\mathrm{Li}}<10^{-14} \mathrm{~cm}^{2} \mathrm{~s}^{-1}\right)$, $\mathrm{LiMnPO}_{4}$ also shows an electronic conductivity of $<10^{-10} \mathrm{Scm}^{-1}$ much lower than that of $\mathrm{LiFePO}_{4}$ (i.e., $1.8 \times 10^{-9} \mathrm{Scm}^{-1}$ at $25{ }^{\circ} \mathrm{C}$ ), rendering it difficult to obtain decent electrochemical activity. Similar to the $\mathrm{LiFePO}_{4}$ electrode, a leading approach to improve the performance of $\mathrm{LiMnPO}_{4}$ cathode materials is to use nanosized particles and a carbon coating. For instances, Drezen et al. (2007) synthesized $\mathrm{LiMnPO}_{4}(140 \sim 200 \mathrm{~nm})$ using a sol-gel method followed by carbon coating through a dry ball milling. The $\mathrm{LiMnPO}_{4} / \mathrm{C}$ nanocomposites could deliver reversible capacities of 156 and $134 \mathrm{mAh} / \mathrm{g}$ at C/100 and $\mathrm{C} / 10$, respectively. At faster charging rates, the electrochemical performance was further improved when smaller $\mathrm{LiMnPO}_{4}$ particles were used. Martha et al. (2009) synthesized $\mathrm{LiMnPO}_{4} / \mathrm{C}$ nanocomposites with a polyol method followed by ball-milling. The nanocomposites were composed of 25-30 nm platelet-like $\mathrm{LiMnPO}_{4}$ particles covered by a carbon film about $15 \mathrm{~nm}$ thick. The $\mathrm{LiMnPO}_{4} / \mathrm{C}$ cathode showed a good rate capability and delivered a practical capacity of $140 \mathrm{mAh} / \mathrm{g}$ and $120 \mathrm{mAh} / \mathrm{g}$ at $0.1 \mathrm{C}$ and $0.5 \mathrm{C}$, respectively.
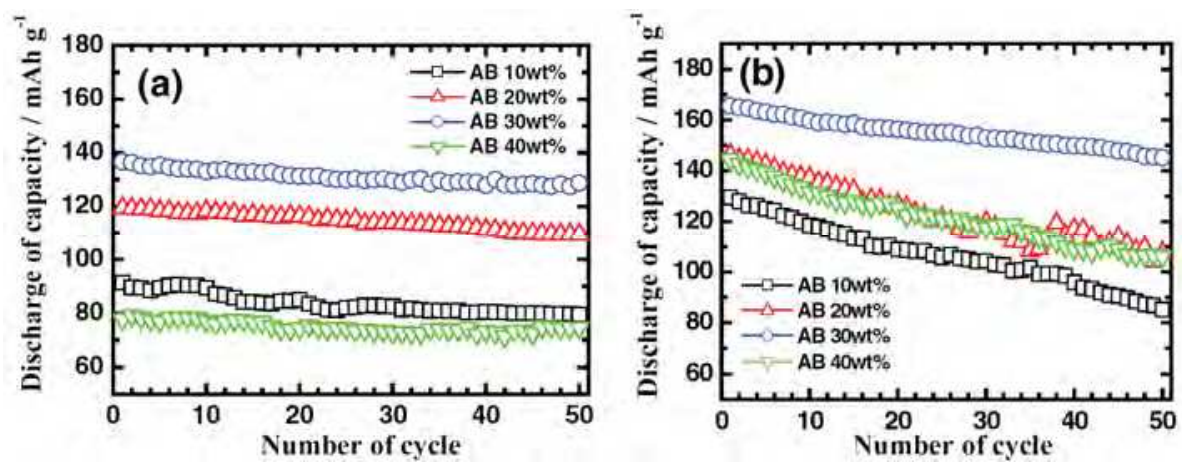

Fig. 8. Cycling stability of $\mathrm{Li} / \mathrm{C}-\mathrm{LiMnPO}_{4}$ cells with different amounts of acetylene black at $0.5 \mathrm{C}$ rate: a) cycled at $25^{\circ} \mathrm{C}$ and b) cycled at $55^{\circ} \mathrm{C}$. The cell was charged at a constant current rate of $\mathrm{C} / 20$ to $4.5 \mathrm{~V}$ and kept at $4.5 \mathrm{~V}$ until C/100. (Oh et al., 2010)

Recently, Baknev et al. (2010) prepared a $\mathrm{LiMnPO}_{4} / \mathrm{C}$ composite cathode by a combination of spray pyrolysis and a wet ball milling. The composite cathode delivered discharge capacities of $153 \mathrm{mAh} / \mathrm{g}$ at $0.05 \mathrm{C}$ and $149 \mathrm{mAh} / \mathrm{g}$ at $0.1 \mathrm{C}$ at room temperature and exhibited initial discharge capacities of 132 and $80 \mathrm{mAh} / \mathrm{g}$ at 1 and $5 \mathrm{C}$ at $50{ }^{\circ} \mathrm{C}$. These 
authors also demonstrated that particle size and homogeneity of the carbon distribution are critical in determining the reversible capacity and rate capability of $\mathrm{LiMnPO}_{4}$. More recently, Oh et al. (2010) prepared nanostructured $\mathrm{C}-\mathrm{LiMnPO}_{4}$ powders by ultrasonic spray pyrolysis followed by a ball milling and found that the content of acetylene black (AB) carbon has a great influence on the electrochemical properties of the C-LiMnPO $\mathrm{P}_{4}$ nanocomposites. As shown in Figure 8, when $\mathrm{AB}$ carbon content is $30 \mathrm{wt} \%$, the C-LiMnPO 4 composites exhibited a best electrochemical performance, delivering discharge capacities of $158 \mathrm{mAh} / \mathrm{g}$ and 107 $\mathrm{mAh} / \mathrm{g}$ at rates of $1 / 20 \mathrm{C}$ and $2 \mathrm{C}$, respectively. Additionally, the capacity retention of the $30 \mathrm{wt} \% \mathrm{AB}$ electrode after 50 cycles was $94.2 \%$ at $25^{\circ} \mathrm{C}$ and $87.7 \%$ at $55^{\circ} \mathrm{C}$, with its initial capacity at $0.5 \mathrm{C}$ rate being $137 \mathrm{mAh} / \mathrm{g}$ and $166 \mathrm{mAh} / \mathrm{g}$, respectively. While, an excessive amount of carbon causes the carbon particles to segregate and decreases the electrochemical properties of the C-LiMnPO 4 .

(a)

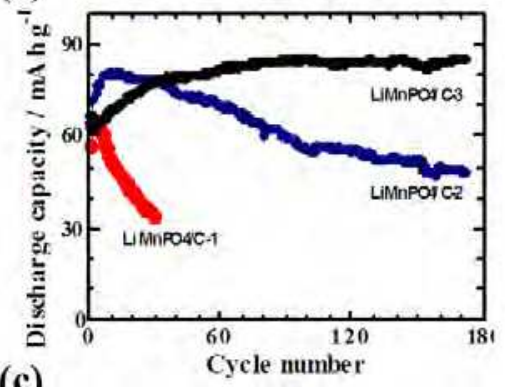

(c)

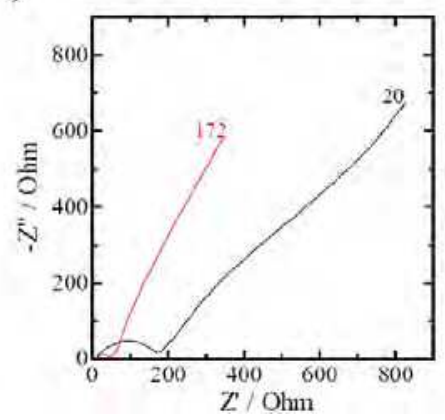

(b)

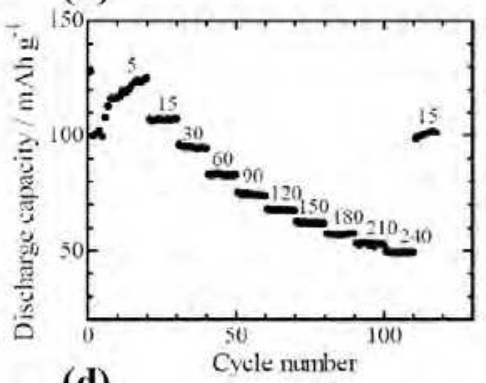

(d)

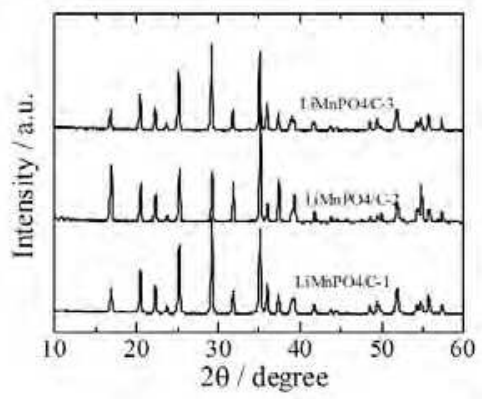

Fig. 9. a) Cycle performances of the samples; b) discharge capacity of $\mathrm{LiMnPO}_{4} / \mathrm{C}-3$ at different current densities; c) impedance results of $\mathrm{LiMnPO}_{4} / \mathrm{C}-3$ after 20 and 172 cycles; and d) XRD patterns of the samples.

In our recent experiments, we have found that the procedures of mixing and annealing treatments significantly affect the electrochemical performance of $\mathrm{LiMnPO}_{4} / \mathrm{C}$ cathode. We prepared $\mathrm{LiMnPO}_{4}$ nanoparticles by a hydrothermal method, the same as the method described by our previous work (Fang et al., 2007) except that $\mathrm{LiOH}$ was used as $\mathrm{pH}$ modifier instead of $\mathrm{NH}_{3} \bullet \mathrm{H}_{2} \mathrm{O}$. Then, the $\mathrm{LiMnPO}_{4} / \mathrm{C}$ composites were synthesized by three ways: (1) hydrothermally synthesized $\mathrm{LiMnPO}_{4}$ was milled with $20 \mathrm{wt} \%$ of carbon black for $4 \mathrm{~h}$ to obtain carbon-LiMnPO 4 composites, named as $\mathrm{LiMnPO}_{4} / \mathrm{C}-1$; (2) hydrothermally synthesized $\mathrm{LiMnPO}_{4}$ was milled with $20 \mathrm{wt} \%$ of carbon black for $4 \mathrm{~h}$ and 
followed by annealing at $700{ }^{\circ} \mathrm{C}$ for $2 \mathrm{~h}$ in $\mathrm{N}_{2}$. The obtained composites were ball-milled for $4 \mathrm{~h}$ again to obtain carbon- $\mathrm{LiMnPO}_{4}$ composites, named as $\mathrm{LiMnPO}_{4} / \mathrm{C}-2$; (3) hydrothermally synthesized $\mathrm{LiMnPO}_{4}$ was milled with $20 \mathrm{wt} \%$ of carbon black for $4 \mathrm{~h}$ and followed by annealing at $700{ }^{\circ} \mathrm{C}$ for $2 \mathrm{~h}$ in $\mathrm{N}_{2}$ to obtain $\mathrm{LiMnPO}_{4} / \mathrm{C}-3$. As indicated by Figure 9a, among three samples, $\mathrm{LiMnPO}_{4} / \mathrm{C}-3$ exhibited the best electrochemical properties, which delivered a discharge capacity of $80 \mathrm{mAh} / \mathrm{g}$ after 180 cycles at a current density of $30 \mathrm{~mA} / \mathrm{g}$. $\mathrm{LiMnPO}_{4} / \mathrm{C}-3$ also showed an excellent capacity retention at different charge/discharge current density (Figure 9b). The excellent electrochemical performance of $\mathrm{LiMnPO}_{4} / \mathrm{C}-3$ may result from the decreased internal impedance during the charge/discharge cyclings, as shown in Figure 9c. In order to study the influence of different synthetic procedures on crystallinity of $\mathrm{LiMnPO}_{4} / \mathrm{C}$, the samples were characterized by X-ray diffraction (XRD). As shown in Figure 9d, $\mathrm{LiMnPO}_{4} / \mathrm{C}-1$ and $\mathrm{LiMnPO}_{4} / \mathrm{C}-2$ showed a broad noncrystalline peaks in the diffraction range of 15 40。, which is not observed in $\mathrm{LiMnPO}_{4} / \mathrm{C}-3$. It indicates that $\mathrm{LiMnPO}_{4} / \mathrm{C}-3$ shows a highest crystallinity. Therefore, annealing in $\mathrm{N}_{2}$ could effectively reduce the surface defects as produced by ball-milling and improve the crystallinity, which may result in a higher discharge capacity and enhance the electrode stability through suppressing the internal impedance of the electrode from increasing. Similar phenomenon has also been observed in other cathodes (Dimesso et al., 2011). Therefore, the influence of particle size, loading content, mixing procedure of conductive carbons on the performance of battery cells needs further detailed investigations.

\subsection{Two-dimensional cathode nanocomposites}

Layered-type transition metal oxides $\left(\mathrm{LiMO}_{2}, \mathrm{M}=\mathrm{V}, \mathrm{Mn}, \mathrm{Fe}, \mathrm{Co}\right.$, and $\left.\mathrm{Ni}\right)$ is an important two-dimensional insertion compound for cathode materials. It adopts the $\alpha-\mathrm{NaFeO}_{2}$-type structure, which can be regarded as a distorted rock salt superstructure, as shown in Figure 10. In a cubic close-packed oxygen array, lithium and transition-metal atoms are distributed in the octahedral interstitial sites. $\mathrm{MO}_{2}$ layers are formed consisting of edge-sharing $\left[\mathrm{MO}_{6}\right]$ octahedra. In between these $\mathrm{MO}_{2}$ layers, lithium resides in octahedral [ $\mathrm{LiO}_{6}$ ] coordination, leading to the alternating planes (111) of the cubic rock-salt structure. (Winter et al, 1998).

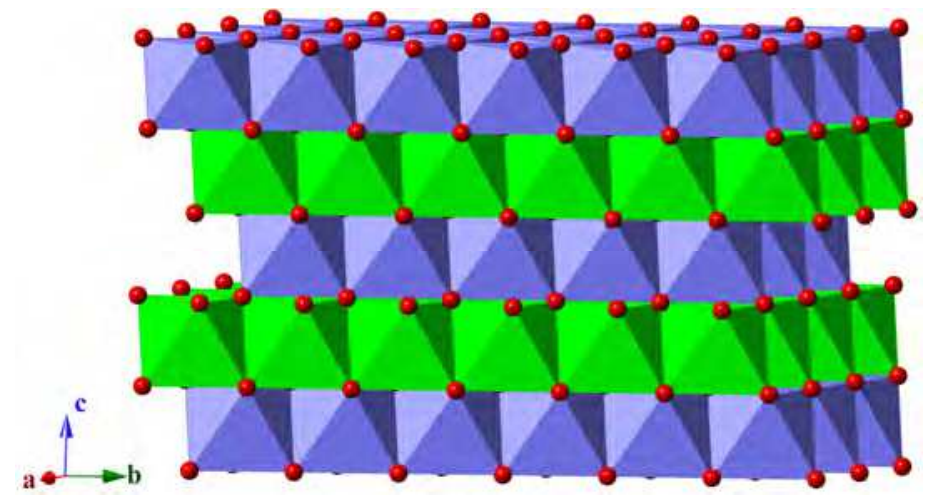

Fig. 10. Two-dimensional crystal structure of $\mathrm{LiMO}_{2}(\mathrm{M}=\mathrm{Ni}, \mathrm{Co}, \mathrm{V})$ of a-NaFeO${ }_{2}$-type. $\mathrm{MO}_{6}$ octahedra are shown in blue, $\mathrm{LiO}_{6}$ octahedra in green, and oxygen ions in red. 
Among the above-mentioned isostructural dioxides, particularly lithium cobalt oxide $(\mathrm{LiCoO} 2)$ and mixed manganese-nickel-cobalt dioxide $\left(\mathrm{Li}(\mathrm{Mn}, \mathrm{Ni}, \mathrm{Co}) \mathrm{O}_{2}\right)$ have gained an industrial importance as the electrode materials.

\subsection{1 $\mathrm{LiCoO}_{2}$}

$\mathrm{LiCoO}_{2}$ is the most widely used cathode materials in commercial LIBs owing to its favourable electrochemical attributes, including a good capacity retention, favourable rate capability, and high structural reversibility below $4.2 \mathrm{~V}$ vs. $\mathrm{Li} / \mathrm{Li}^{+}$. Layered $\mathrm{Li}_{x} \mathrm{CoO}_{2}$ materials are typically charged up to $4.2 \mathrm{~V}(0.5<\mathrm{x}<1)$ because further increase in the charge cut-off voltage results in a phase transition from monoclinic to hexagonal. The phase transition leads to an anisotropic volume change of the host lattice, which causes a structural degradation and large capacity fade during the repeated cyclings. In addition, the dissolution of $\mathrm{Co}^{4+}$ when $x>0.5$ is also attributed to the degradation of $\mathrm{LiCoO}_{2}$. Therefore, the specific capacity of this type of material is limited to the range of 137 to $140 \mathrm{mAh} / \mathrm{g}$, although the theoretical capacity of $\mathrm{LiCoO}_{2}$ is $273 \mathrm{mAh} / \mathrm{g}$ (Wang et al., 2008). In this regard, great efforts have been made to increase the specific capacity of $\mathrm{LiCoO}_{2}$ and improve the capacity retention. The construction of heterogeneous nanostructure by coating the chemically stable compounds on the surface of $\mathrm{LiCoO}_{2}$ is the most effective strategy to improve the electrochemical performance of $\mathrm{LiCoO}_{2}$ at high cut-off voltage. There has been extensively research by coating $\mathrm{LiCoO}_{2}$ material with various metal oxides, metal phosphates, and other chemically stable compounds.

\subsubsection{Metal oxide}

Various metal oxide coatings such as $\mathrm{Al}_{2} \mathrm{O}_{3}$ (Oh et al., 2010), $\mathrm{CeO}_{2}$ (Ha et al., 2006), $\mathrm{ZrO}_{2}$ (Liu et al., 2010), $\mathrm{Li}_{4} \mathrm{Ti}_{5} \mathrm{O}_{12}$ (Yi et al, 2011), etc., have been studied. These metal oxides behave as an effective physical protection barrier to prohibit the chemical reactions between the electrolyte and $\mathrm{LiCoO}_{2}$ cathode. They also prevent the structural degradation of $\mathrm{LiCoO}_{2}$ during the cyclings. Therefore, both the cycle life and rate capability of $\mathrm{LiCoO}_{2}$ cathode were improved by coating these oxides. Interestingly, some of them such as $\mathrm{Al}_{2} \mathrm{O}_{3}$ and $\mathrm{ZnO}$ can act as HF scavenger to reduce the acidity of non-aqueous electrolyte, suppressing metal dissolution from the $\mathrm{LiCoO}_{2}$ materials. It is well known that $\mathrm{LiPF}_{6}$, the dominant lithium salt for LIBs, is sensitive to trace of moisture. HF is formed when $\mathrm{LiPF}_{6}$ decomposes in the presence of moisture, which can result in the dissolution of the transition metal and surface corrosion of cathode materials ( $\mathrm{Zhou}$ et al. 2005). For example, $\mathrm{Al}_{2} \mathrm{O}_{3}$ and $\mathrm{ZnO}$ can react with a trace amount of HF in the electrolyte to reduce the active concentration of HF by the formation of $\mathrm{AlF}_{3}$ and $\mathrm{ZnF}_{2}$, suppressing $\mathrm{Co}$ dissolution and $\mathrm{F}$ - concentration in the electrolyte. In general, excess coating leads to a loss of rate or power capability. Therefore, control over the thickness of coating materials is very important. Recently, Scott et al (2011) modified $\mathrm{LiCoO}_{2}$ with coating ultrathin $\mathrm{Al}_{2} \mathrm{O}_{3}$ film as a surface protective layer by atomic layer deposition (ALD) technique. The conformal 1-2 nm thick film which has clearly different lattice fringes from those in the bulk region is clearly observed for $\mathrm{Al}_{2} \mathrm{O}_{3}$ coated $\mathrm{LiCoO}_{2}$ (see Figure 11a). The coated nano- $\mathrm{LiCoO}_{2}$ electrodes with 2 ALD cycles deliver a discharge capacity of $133 \mathrm{mAh} / \mathrm{g}$ with a currents of $1400 \mathrm{~mA} / \mathrm{g}(7.8 \mathrm{C})$, corresponding to a $250 \%$ improvement in reversible capacity compared to the uncoated $\mathrm{LiCoO}_{2}$, as shown in Figure 11b. The simple ALD process is broadly applicable and provides new opportunities for the battery industry to design other novel nanostructured electrodes that are highly durable even while cycling at high rate. 
(a)

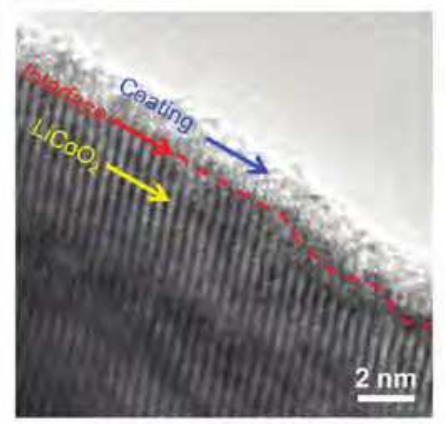

(b)

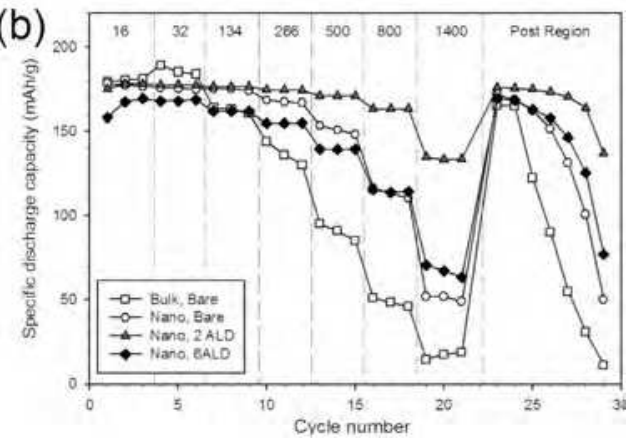

Fig. 11. a) HR-TEM images of the $\mathrm{Al}_{2} \mathrm{O}_{3}$-coated $\mathrm{LiCoO}_{2}$ nanoparticles by 6 ALD cycles on the bare powders; and b) variations in discharge capacities versus charge/discharge cycle number for different $\mathrm{LiCoO}_{2}$ electrodes cycled at different rates between 3.3 and $4.5 \mathrm{~V}$ (vs $\left.\mathrm{Li} / \mathrm{Li}^{+}\right)$at room temperature. Current densities $(\mathrm{mA} / \mathrm{g}$ ) are indicated at the top. (Scott et al.,2011)

\subsubsection{Metal phosphates}

$\mathrm{AlPO}_{4}$ and $\mathrm{LiFePO}_{4}$ have been reported as an effective coating material for improving the electrochemical properties of $\mathrm{LiCoO}_{2}$. $\mathrm{AlPO}_{4}$ can be coated on $\mathrm{LiCoO}_{2}$ by direct dispersing $\mathrm{LiCoO}_{2}$ in $\mathrm{AlPO}_{4}$ precursors and followed by annealing at elevated temperatures. $\mathrm{AlPO}_{4}$ coating can behave as a protective layer to prohibit the chemical reactions between the electrolyte and $\mathrm{LiCoO}_{2}$, suppressing $\mathrm{Co}$ dissolution and the lattice distortion during cycling with a charge cut-off voltage of $4.6 \mathrm{~V}$. The crystallinity of the $\mathrm{AlPO}_{4}$-coating layer and the interdiffusion at the interface can affect the electrochemical properties of the $\mathrm{AlPO}_{4}$-coated $\mathrm{LiCoO}_{2}$ (Kim et al. 2006). The same group also reported that different phases of $\mathrm{AlPO}_{4}$ have great influences on the electrochemical properties of $\mathrm{LiCoO}_{2}$. They coated $\mathrm{LiCoO}_{2}$ with three types of $\mathrm{AlPO}_{4}$ phase, i.e., amorphous, tridymite, and cristobalite phases, by spin coating method. The $\mathrm{LiCoO}_{2}$ thin film coated with amorphous nanoparticles showed the best cycle-life performance by effectively suppressing the degradation of $\mathrm{Li}^{+}$-diffusion kinetics (Kim et al., 2007). Wang et al. (2007) modified $\mathrm{LiCoO}_{2}$ using $\mathrm{LiFePO}_{4}$ coating with a thickness ranging 10 $100 \mathrm{~nm}$ by impregnation method. The coating of $\mathrm{LiFePO}_{4}$ serves as both the protecting layer and the active cathode material with good conductivity. The $\mathrm{LiFePO}_{4}$-coated $\mathrm{LiCoO}_{2}$ exhibited an improved electrochemical performance during the charge/discharge cycles, especially at high potentials and high temperature. For example, at $60{ }^{\circ} \mathrm{C}$ and at a rate of $1 \mathrm{C}, 5.0 \mathrm{wt} . \%$ $\mathrm{LiFePO}_{4}$-coated $\mathrm{LiCoO}_{2}$ cathodes showed a better capacity retention $(132 \mathrm{mAh} / \mathrm{g})$ with a $4.2 \mathrm{~V}$ charge-cutoff after 250 cycles, while the uncoated $\mathrm{LiCoO}_{2}$ cathode showed $5 \%$ capacity retention under the same conditions after only 150 cycles.

\subsubsection{Other chemically stable compounds}

Highly ionic conductive solid electrolytes have been used as the protective layer of $\mathrm{LiCoO}_{2}$. Recently, Choi et al. (2010) modified the surfaces of $\mathrm{LiCoO}_{2}$ with a lithium phosphorus oxynitride (LiPON) glass-electrolyte thin film. Homogeneous LiPON thin films with 0.5 0.7 $\mu \mathrm{m}$ in thickness were deposited on the surfaces of $\mathrm{LiCoO}_{2}$ by a radio frequency (RF) magnetron sputtering method. They found that the LiPON coating improved the rate capability and the thermal stability of the charged $\mathrm{LiCoO}_{2}$ cathode. The ion conducting 
LiPON film enhances the lithium-ion migration through the interface between the surface of $\mathrm{LiCoO}_{2}$ particles and the electrolyte, suppressing the surface reaction between the electrode surface and electrolyte during cyclings.

\subsection{2 $\mathrm{Li}(\mathrm{Mn}, \mathrm{Ni}, \mathrm{Co}) \mathrm{O}_{2}$}

Metals $\mathrm{Mn}, \mathrm{Ni}$, and Co can all be accommodated in the layered metal oxide structure, giving a range of compositions $\mathrm{Li}\left[\mathrm{Mn}_{\mathrm{x}} \mathrm{Ni}_{\mathrm{y}} \mathrm{Co}_{\mathrm{z}}\right] \mathrm{O}_{2}(x+y+z=1)$. A solution of $\mathrm{Li}\left[\mathrm{Mn}_{\mathrm{x}} \mathrm{Ni}_{\mathrm{y}} \mathrm{Co}_{\mathrm{z}}\right] \mathrm{O}_{2}$ may possess improved performances, such as thermal stability due to the synergetic effect of three ions. Recently, intense efforts have been directed towards the development of $\mathrm{Li}\left[\mathrm{Mn}_{\mathrm{x}} \mathrm{Ni}_{\mathrm{y}} \mathrm{Co}_{\mathrm{z}}\right] \mathrm{O}_{2}$ as a possible replacement for $\mathrm{LiCoO}$. However, layered $\mathrm{Li}\left[\mathrm{Mn}_{\mathrm{x}} \mathrm{Ni}_{\mathrm{y}} \mathrm{CO}_{\mathrm{z}}\right] \mathrm{O}_{2}$ structures tend to become unstable at high levels of delithiation, which is attributed largely to the highly oxidizing nature of tetravalent $\mathrm{Co}$ and $\mathrm{Ni}$ that results in the loss of oxygen and the migration of the transition metal ions to the lithium-depleted layer. In spite of numerous valuable works, the cycle life and thermal stability of $\mathrm{Li}\left[\mathrm{Mn}_{\mathrm{x}} \mathrm{Ni}_{\mathrm{y}} \mathrm{Co}_{\mathrm{z}}\right] \mathrm{O}_{2}$ still need further improvement. Several strategies have been used to improve the electrochemical performances of $\mathrm{Li}\left[\mathrm{Mn}_{x} \mathrm{Ni}_{y} \mathrm{Co}_{z}\right] \mathrm{O}_{2}$ cathode, which can be summarized as follows:

\subsubsection{Surface modifications}

Coating of the surfaces of $\mathrm{Li}\left[\mathrm{Mn}_{x} \mathrm{Ni}_{\mathrm{y}} \mathrm{Co}_{\mathrm{z}} \mathrm{O}_{2}\right.$ with $\mathrm{Al}_{2} \mathrm{O}_{3}, \mathrm{LiAlO}_{2}, \mathrm{AlPO}_{4}$, and $\mathrm{ZrO}_{2}$ has been widely attempted, leading to significantly improved electrochemical properties. For example, Hu et al. (2009) coated the surface of $\mathrm{LiNi}_{1 / 3} \mathrm{Co}_{1 / 3} \mathrm{Mn}_{1 / 3} \mathrm{O}_{2}$ with a uniform nanosized layer of $\mathrm{ZrO}_{2}$. $\mathrm{ZrO}_{2}$-coated $\mathrm{LiNi}_{1 / 3} \mathrm{Co}_{1 / 3} \mathrm{Mn}_{1 / 3} \mathrm{O}_{2}$ exhibits an improved rate capability and cycling stability under a high cut-off voltage of $4.5 \mathrm{~V}$, owing to the ability of $\mathrm{ZrO}_{2}$ layer in preventing the direct contact of the active material with the electrolyte. In this case, $\mathrm{ZrO}_{2}$ play a similar role as it does in $\mathrm{ZrO}_{2}$ coated $\mathrm{LiCoO}_{2}$ (Chen et al., 2002).

\subsubsection{Mixing with other layered components}

Thackeray et al. (2007) proposed a strategy to stabilize a layered $\mathrm{Li}\left[\mathrm{Mn}_{\mathrm{x}} \mathrm{Ni}_{\mathrm{y}} \mathrm{Co}_{\mathrm{z}}\right] \mathrm{O}_{2}$ electrode by integrating a structurally compatible component that was electrochemically inactive between 4 and $3 \mathrm{~V}$, aiming to increase the stability of layered electrodes over a wider compositional range without compromising the power or cycle life of the cells. $\mathrm{Li}_{2} \mathrm{MnO}_{3}$ is the best stabilized component for $\mathrm{Li}\left[\mathrm{Mn}_{\mathrm{x}} \mathrm{Ni}_{\mathrm{y}} \mathrm{CO}_{\mathrm{z}}\right] \mathrm{O}_{2}$ electrode because it is electrochemically inactive over a potential window of $2.0 \sim 4.4 \mathrm{~V}$ in which $\mathrm{Li}\left[\mathrm{Mn}_{\mathrm{x}} \mathrm{Ni}_{\mathrm{y}} \mathrm{Co}_{\mathrm{z}}\right] \mathrm{O}_{2}$ component is electrochemically active and operates as a true insertion electrode. In $\mathrm{Li}_{2} \mathrm{MnO}_{3}$, all manganese ions are tetravalent and cannot be oxidized further. Lithium insertion into $\mathrm{Li}_{2} \mathrm{MnO}_{3}$, with a concomitant reduction of the manganese ions, is also prohibited because there are no energetically favourable interstitial sites for the guest ions. Under such conditions, $\mathrm{Li}_{2} \mathrm{MnO}_{3}$ component acts as a stabilizing unit in the electrode structure. (Thackeray et al., 2007) When charged to higher potentials, typically $4.5 \mathrm{~V}$, it is possible to activate the $\mathrm{Li}_{2} \mathrm{MnO}_{3}$ component during the initial charge by removing $\mathrm{Li}^{+}$with a concomitant loss of oxygen. The removal of two $\mathrm{Li}^{+}$from the $\mathrm{Li}_{2} \mathrm{MnO}_{3}$ component and the reinsertion of only one $\mathrm{Li}^{+}$into the resulting $\mathrm{MnO}_{2}$ component, exceptionally high reversible capacities (230-250 mAh/g) can be obtained. For example, Li et al. (2011) synthesized a high-voltage layered $\mathrm{Li}\left[\mathrm{Li}_{0.2} \mathrm{Mn}_{0.56} \mathrm{Ni}_{0.16} \mathrm{Co}_{0.08}\right] \mathrm{O}_{2}$ cathode material, a solid solution between $\mathrm{Li}_{2} \mathrm{MnO}_{3}$ and $\mathrm{LiMn}_{0.4} \mathrm{Ni}_{0.4} \mathrm{Co}_{0.2} \mathrm{O}_{2}$, by co-precipitation method followed by a hightemperature annealing. After the initial decay, no obvious capacity fading was observed when cycling the material at different rates. Steady-state reversible capacities of $220 \mathrm{mAh} / \mathrm{g}$ 
at $0.2 \mathrm{C}, 190 \mathrm{mAh} / \mathrm{g}$ at $1 \mathrm{C}, 155 \mathrm{mAh} / \mathrm{g}$ at $5 \mathrm{C}$, and $110 \mathrm{mAh} / \mathrm{g}$ at $20 \mathrm{C}$ were achieved in long-term cycle tests within the voltage cutoff limits of 2.5 and $4.8 \mathrm{~V}$ at $20 \mathrm{C}$.

\subsubsection{Heterogeneous core-shell structure}

Recently, Sun and co-workers proposed a novel core/shell concept that construct layered structured $\mathrm{LiNi}_{x} \mathrm{Co}_{y} \mathrm{Mn}_{z} \mathrm{O}_{2}$ cathode with a core enriched in $\mathrm{Ni}$ for high capacity and a shell enriched in $\mathrm{Mn}$ for high stability and cycling performance. They reported that core-shell cathode material $\mathrm{Li}\left[\left(\mathrm{Ni}_{0.8} \mathrm{Co}_{0.1} \mathrm{Mn}_{0.1}\right)_{0.8}\left(\mathrm{Ni}_{0.5} \mathrm{Mn}_{0.5}\right)_{0.2}\right] \mathrm{O}_{2}$ exhibited an excellent cyclability and thermal stability (Sun et al., 2005). As shown in Figure 12, the core-shell structure consists of a $\mathrm{Ni}$-rich $\mathrm{LiNi}_{0.8} \mathrm{Co}_{0.1} \mathrm{Mn}_{0.1} \mathrm{O}_{2}$ core that delivered a high capacity and a Mn-rich $\mathrm{Li}\left[\mathrm{Ni}_{0.5} \mathrm{Mn}_{0.5}\right] \mathrm{O}_{2}$ shell that provides a structural and thermal stability in highly delithiated states. After that, Sun et al. (2009) found a structural mismatch between the core and the shell: Voids of tens of nanometres between the core and shell appear in the core-shell powders after cycling. A shell with a gradient in chemical composition was proposed to grow onto the surfaces of a core material, forming a constant chemical composition. The concentration-gradient cathode material $\left(\mathrm{Li}\left(\mathrm{Ni}_{0.64} \mathrm{Co}_{0.18} \mathrm{Mn}_{0.18}\right) \mathrm{O}_{2}\right)$ thus achieved shows a high capacity of $209 \mathrm{mAh} / \mathrm{g}$, which retains $96 \%$ after 50 charge/discharge cycles under an aggressive test profile $\left(55{ }^{\circ} \mathrm{C}\right.$ between 3.0 and $4.4 \mathrm{~V}$ ), as shown in Figure 13. In a latest work by Koenig and Sun (Koenig et al., 2011), particles with internal gradients in transition metal composition was synthesized using a coprecipitation reaction with a control over the process conditions. By this, compositions and structures can be rationally integrated into the synthesis process, and further gradient coreshell structure $\mathrm{LiNi}_{x} \mathrm{Co}_{y} \mathrm{Mn}_{z} \mathrm{O}_{2}$ materials will become a future choice for cathode in LIBs.

(a)

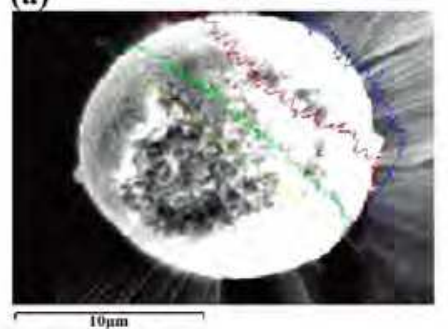

(c)

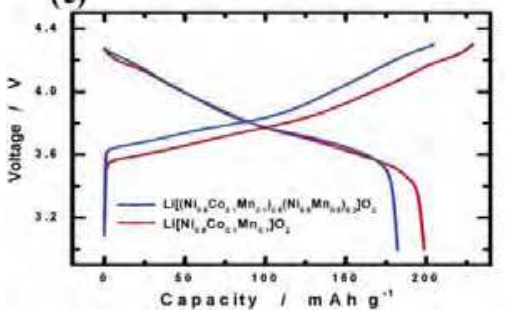

(b)

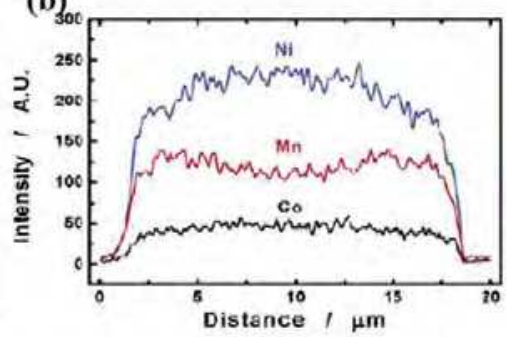

(d)

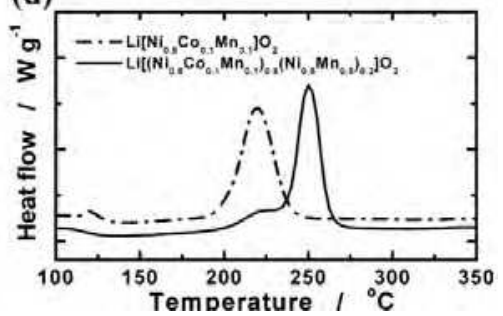

Fig. 12. a) SEM image and b) Energy dispersive spectroscopic line scan of $\mathrm{Li}\left[\left(\mathrm{Ni}_{0.8} \mathrm{Co}_{0.1} \mathrm{Mn}_{0.1}\right)_{0.8}\left(\mathrm{Ni}_{0.5} \mathrm{Mn}_{0.5}\right)_{0.2}\right] \mathrm{O}_{2}$ particles; $\left.\mathrm{c}\right)$ initial charge/discharge curves of $\mathrm{Li} / \mathrm{Li}\left[\mathrm{Ni}_{0.8} \mathrm{Co}_{0.1} \mathrm{Mn}_{0.1}\right] \mathrm{O}_{2}$ and $\mathrm{Li} / \mathrm{Li}\left[\left(\mathrm{Ni}_{0.8} \mathrm{Co}_{0.1} \mathrm{Mn}_{0.1}\right)_{0.8}\left(\mathrm{Ni}_{0.5} \mathrm{Mn}_{0.5}\right)_{0.2}\right] \mathrm{O}_{2}$ cell in a voltage range of 3.0-4.3 V; and d) differential scanning calorimetry traces of $\mathrm{Li}\left[\left(\mathrm{Ni}_{0.8} \mathrm{Co}_{0.1} \mathrm{Mn}_{0.1}\right)_{0.8}\left(\mathrm{Ni}_{0.5} \mathrm{Mn}_{0.5}\right)_{0.2}\right] \mathrm{O}_{2}$ and $\mathrm{Li}\left[\mathrm{Ni}_{0.8} \mathrm{Co}_{0.1} \mathrm{Mn}_{0.1}\right] \mathrm{O}_{2}$ at a charged state to $4.3 \mathrm{~V}$. (Sun et al., 2005) 

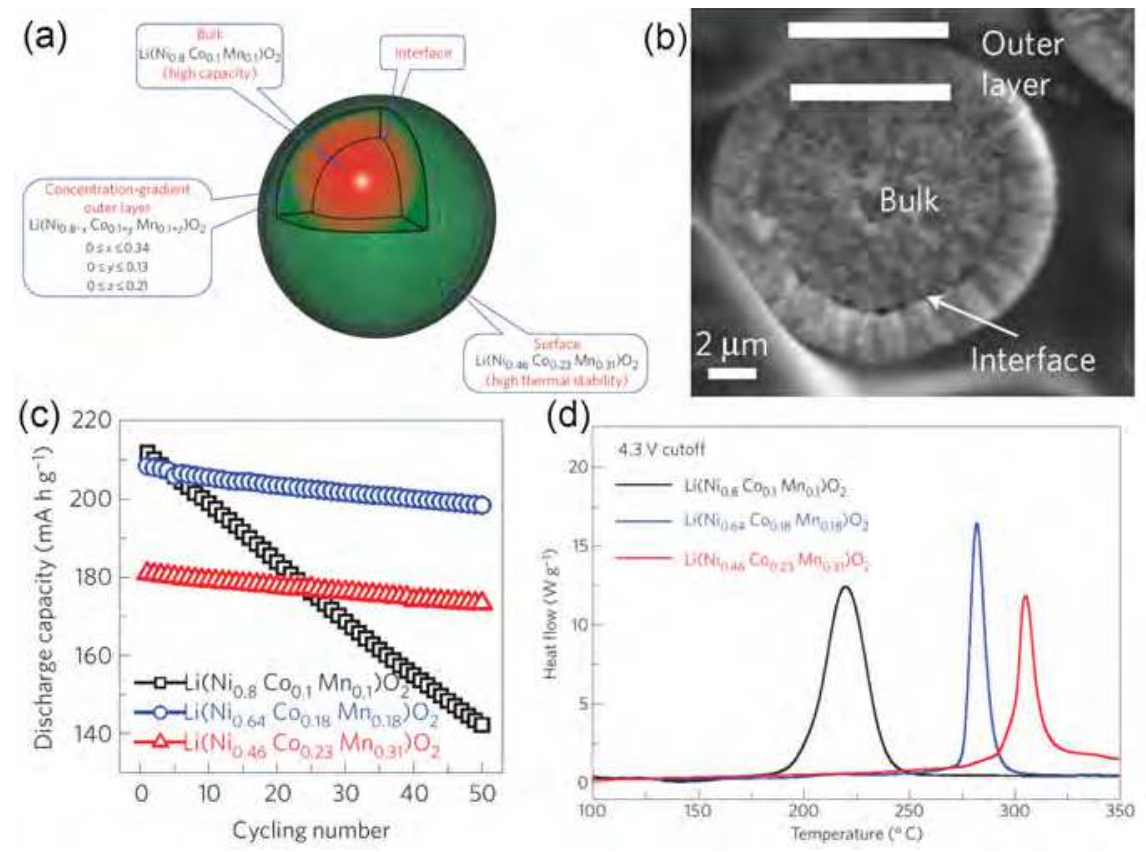

Fig. 13. a) Schematic diagram of cathode particle with Ni-rich core surrounded by concentration-gradient outer layer; b) a scanning electron micrograph of a typical particle; c) cycling performance of half cells based on $\mathrm{Li}\left(\mathrm{Ni}_{0.8} \mathrm{Co}_{0.1} \mathrm{Mn}_{0.1}\right) \mathrm{O}_{2}, \mathrm{Li}\left(\mathrm{Ni}_{0.46} \mathrm{Co}_{0.23} \mathrm{Mn}_{0.31}\right) \mathrm{O}_{2}$ and concentration-gradient material cycled between 3.0 and $4.4 \mathrm{~V}$ at $55{ }^{\circ} \mathrm{C}$ by applying a constant current rate of $0.5 \mathrm{C}(95 \mathrm{~mA} / \mathrm{g})$; and d) differential scanning calorimetry traces showing a heat flow from the reaction between the electrolyte and different electrode materials when charged to $4.3 \mathrm{~V}$. (Sun et al., 2009)

\subsection{Three-dimensional cathode nanocomposites}

Three-dimensional framework structures have many crosslinked channels which must be sufficiently large to accommodate the lithium ion. The advantages of three-dimensional frameworks are represented by i) a possibility of avoiding, for steric reasons, the coinsertion of bulky species such as solvent molecules; and ii) the smaller degree of expansion/contraction of the framework structure upon lithium insertion/extraction (Winter et al., 1998).

\subsection{1 $\mathrm{LiMn}_{2} \mathrm{O}_{4}$}

$\mathrm{LiMn}_{2} \mathrm{O}_{4}$ is regarded as one of the most promising cathodes because of its high output voltage, high natural abundance, low toxicity, and low cost. $\mathrm{LiMn}_{2} \mathrm{O}_{4}$ crystallizes in a spinel structure with the space group of $\mathrm{Fd} 3 \mathrm{~m}$. In the $\mathrm{LiMn}_{2} \mathrm{O}_{4}$ spinel structure, a cubic closepacked (ccp) array of oxygen ions occupy the 32e position, Mn ions are located in the $16 \mathrm{~d}$ site, and $\mathrm{Li}$ in the $8 \mathrm{a}$ site. $\mathrm{Mn}$ ions have an octahedral coordination to oxygen, and the $\mathrm{MnO}_{6}$ octahedra share edges in a three-dimensional host for Li guest ions. The 8a tetrahedral site is 
situated furthest away from the $16 \mathrm{~d}$ site of all the interstitial tetrahedral (8a, $8 \mathrm{~b}$ and $48 \mathrm{f}$ ) and octahedra (16c). Each of the 8a-tetrahedron faces is shared with an adjacent, vacant 16c site. This combination of structural features in the stoichiometric spinel compound constitutes a very stable structure, as shown in Figure $14 . \mathrm{LiMn}_{2} \mathrm{O}_{4}$ has a three-dimensional lithium diffusion path, in which every plane is suitable to exchange lithium ion from active materials to the electrolyte.

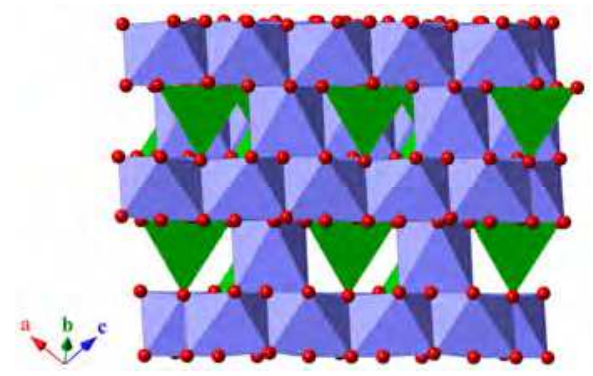

Fig. 14. Three-dimensional crystal structure of $\mathrm{LiMn}_{2} \mathrm{O}_{4} . \mathrm{MnO}_{6}$ octahedra are shown in blue, $\mathrm{LiO}_{4}$ tetrahedra in green, and oxygen ions in red.

$\mathrm{LiMn}_{2} \mathrm{O}_{4}$ has a theoretical capacity of $148 \mathrm{mAh} / \mathrm{g}$ and a voltage plateau of about $4 \mathrm{~V}$. A typical cyclic voltammogram of $\mathrm{LiMn}_{2} \mathrm{O}_{4}$ is shown in Figure 15. Two couples of reversible redox peaks are observed during the charge/discharge processes. The split of the redox peaks into two couples shows that the electrochemical reaction of the extraction and insertion of lithium ions occurs in two stages. The first oxidation peak is ascribed to the removal of $\mathrm{Li}^{+}$from half of the tetrahedral sites in which $\mathrm{Li}-\mathrm{Li}$ interactions exist, whereas the second oxidation peak is attributed to the removal of $\mathrm{Li}^{+}$from the remaining tetrahedral sites where no $\mathrm{Li}-\mathrm{Li}$ interactions exist. The whole process can be described as follows:

$$
\begin{aligned}
& 0.5 \mathrm{Li}^{+}+0.5 e+2 \lambda \mathrm{MnO}_{2} \Leftrightarrow \mathrm{Li}_{0.5} \mathrm{Mn}_{2} \mathrm{O}_{4} \\
& 0.5 \mathrm{Li}^{+}+0.5 e+\mathrm{Li}_{0.5} \mathrm{Mn}_{2} \mathrm{O}_{4} \Leftrightarrow \mathrm{LiMn}_{2} \mathrm{O}_{4}
\end{aligned}
$$

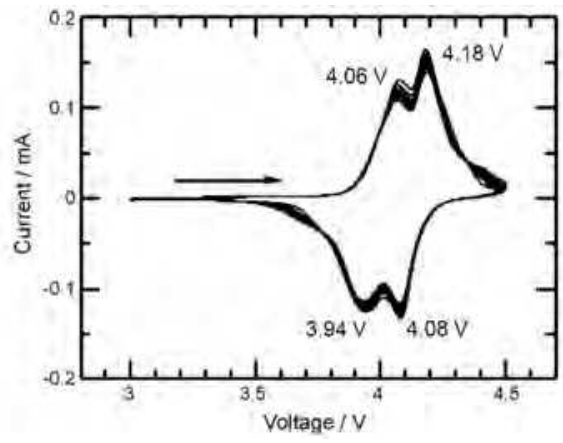

Fig. 15. Cyclic voltammograms of $\mathrm{LiMn}_{2} \mathrm{O}_{4}$ within the voltage range from 3.0 to $4.5 \mathrm{~V}$ versus $\mathrm{Li} / \mathrm{Li}^{+}$. (Fang et al., 2008) 
Since the application of $\mathrm{LiMn}_{2} \mathrm{O}_{4}$ in high power systems requires the development of fast kinetic electrodes which appears nowadays possible thanks to the use of nanostructured morphologies, various synthesis methods have been widely investigated to prepare nanostructured $\mathrm{LiMn}_{2} \mathrm{O}_{4}$ and these nanostructured methods have been demonstrated to be highly effective in greatly enhancing the electrochemical performance of $\mathrm{LiMn}_{2} \mathrm{O}_{4}$ electrode materials. It is found that the electrochemical performance of $\mathrm{LiMn}_{2} \mathrm{O}_{4}$ electrodes strongly depends on the morphology and the crystalline phase. For example, in our previous work (Fang et al., 2008), we verified that the electrochemical performance of $\mathrm{LiMn}_{2} \mathrm{O}_{4}$ could be improved by altering the starting materials, as shown in Figure 16. In particular, a- $\mathrm{MnO}_{2}$ nanorods are proved to be a quite promising starting material for the preparation of highly crystallized and high performance $\mathrm{LiMn}_{2} \mathrm{O}_{4}$. After that, Ding et al. (2011) and Lee et al. (2010) prepared single-crystalline $\mathrm{LiMn}_{2} \mathrm{O}_{4}$ nanotubes and nanowires from $\beta-\mathrm{MnO}_{2}$ and $\alpha-\mathrm{MnO}_{2}$ precursors, respectively, which also leads to an improved electrochemical performance.
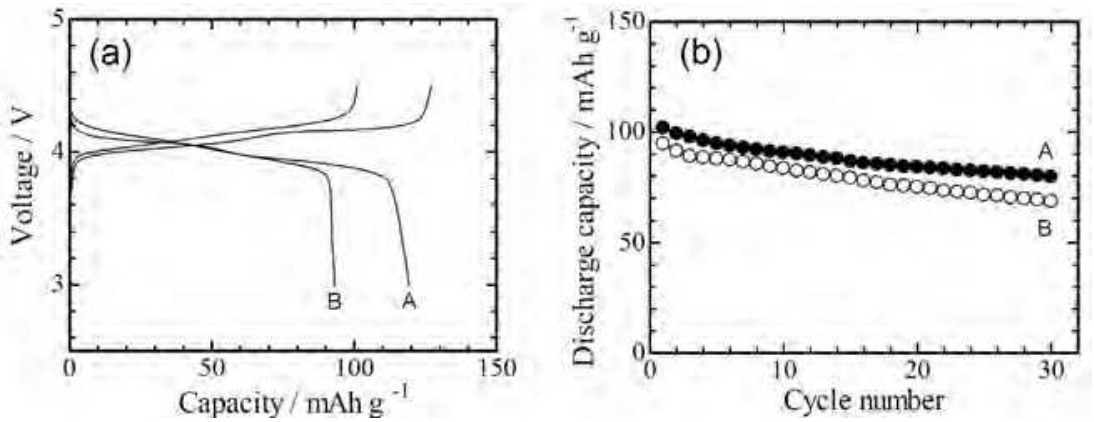

Fig. 16. a) Charge/discharge curves and b) cycling performance of $\mathrm{LiMn}_{2} \mathrm{O}_{4}$ prepared from a- $\mathrm{MnO}_{2}$ nanorods (A) and commercial $\mathrm{MnO}_{2}$ (B) in the voltage range from 3.0 to $4.5 \mathrm{~V}$ versus $\mathrm{Li} / \mathrm{Li}^{+}$at a current density of $20 \mathrm{~mA} / \mathrm{g}$. (Fang et al., 2008)

Unfortunately, $\mathrm{LiMn}_{2} \mathrm{O}_{4}$ shows a fast capacity fading during the cyclings, which cannot be ultimately solved by nanostructured approaches only. The capacity fading of $\mathrm{LiMn}_{2} \mathrm{O}_{4}$ has been ascribed to the dissolution of $\mathrm{Mn}$, Jahn-Teller distortion of $\mathrm{Mn}^{3+}$, and decomposition of electrolyte solution on electrode. Of the above factors, dissolution of surface $\mathrm{Mn}^{3+}$ with the electrolyte is now regarded as the most important reason for the capacity fading. Surface modification of the cathode electrode has been a successful strategy to solve the capacity fading problem, which could decrease the surface area to retard the side reactions between the electrode and electrolyte and to further diminish the Mn dissolution during cycling. In recent years, various types of coating materials, including oxides, metals, fluorides, phosphate, polymers, carbon materials, and other electrode materials have been explored to improve the electrochemical stability of $\mathrm{LiMn}_{2} \mathrm{O}_{4}$ cathodes. For example, Sahan et al. (2008) reported that $\mathrm{Li}_{2} \mathrm{O}-2 \mathrm{~B}_{2} \mathrm{O}_{3}(\mathrm{LBO})$-coated $\mathrm{LiMn}_{2} \mathrm{O}_{4}$ electrode prepared by a solution method shows an excellent cycling behaviour without any capacity loss even after 30 cycles at room temperature and a 1$\mathrm{C}$ rate, as plotted in Figure 17. The improved cycling stability is also achieved by coating with [Li, $\mathrm{La} \mathrm{TiO}_{3}$ (Jung et al., 2011) and $\mathrm{Li}_{4} \mathrm{Ti}_{5} \mathrm{O}_{12}$ (Liu et al., 2007). Recent developments in the surface modification have been reviewed by Yi et al. (2009). Despite the numerous studies in this area, a functional understanding of coated $\mathrm{LiMn}_{2} \mathrm{O}_{4}$ electrodes remains incomplete. In the case of metal oxides, it appears likely that some of the metal oxides such as $\mathrm{MgO}, \mathrm{Al}_{2} \mathrm{O}_{3}, \mathrm{ZrO}_{2}$ 
may act as a physical protection barrier to depress $\mathrm{Mn}^{2+}$ dissolution by forming epitaxial layers on the underlying coated spinel, improving the structural stability of the cathode. It has also been suggested that $\mathrm{ZnO}$ coatings may act as HF scavenger to be capable of neutralizing the acid species. However, it is not yet clear which of these various processes is most important to the stabilization of a $\mathrm{LiMn}_{2} \mathrm{O}_{4}$ electrode surface. Recently, Ouyang et al., (2010) reported the results of ab initio studies of the atomic and electronic structure of clean and $\mathrm{Al}_{2} \mathrm{O}_{3}$ covered $\mathrm{Li}_{\mathrm{x}} \mathrm{Mn}_{2} \mathrm{O}_{4}(001)$ surfaces ( $\mathrm{x}=0$ or 1 ). They gave a clear picture that only $\mathrm{Mn}^{3+}$ ions occur at the clean $\mathrm{LiMn}_{2} \mathrm{O}_{4}$ (001) surfaces due to a lower coordination with $\mathrm{O}$ atoms, while $\mathrm{Mn}$ atoms in bulk $\mathrm{LiMn}_{2} \mathrm{O}_{4}$ exhibit a mixed $\mathrm{Mn}^{3+} / \mathrm{Mn}^{4+}$ oxidation states. An $\mathrm{Al}_{2} \mathrm{O}_{3}$ ad-layer inhibits the formation of $\mathrm{Mn}^{3+}$ at the $\mathrm{Li}_{x} \mathrm{Mn}_{2} \mathrm{O}_{4}$ (001) surfaces and thus has a more complex role than just separating the cathode from the electrolyte as is commonly assumed. Key variables that influence the coating efficacy remain to be identified and optimized for most of the coating materials that have been employed to date.

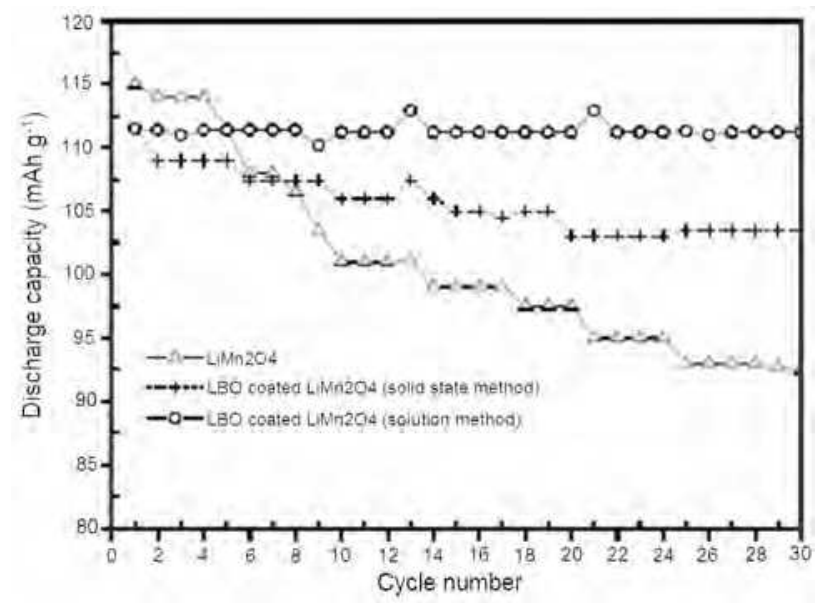

Fig. 17. Cycling performance of different materials at $1 \mathrm{C}$ discharge rate at room temperature. (Sahan et al., 2008)

\subsection{2 $\mathrm{LiNi}_{0.5} \mathrm{Mn}_{1.5} \mathrm{O}_{4}$}

$\mathrm{Ni}$-doped spinel oxide, $\mathrm{LiNi}_{0.5} \mathrm{Mn}_{1.5} \mathrm{O}_{4}$, is another promising three-dimensional cathode material for future high power battery applications due to its large reversible capacity (147 $\mathrm{mAh} / \mathrm{g}$ ) at a high operating voltage around $4.7 \mathrm{~V}$. $\mathrm{LiNi}_{0.5} \mathrm{Mn}_{1.5} \mathrm{O}_{4}$ spinel is fundamentally different from pure spinels as all redox activity takes place on $\mathrm{Ni}$ and $\mathrm{Mn}$ remains in +4 state.

$\mathrm{LiNi}_{0.5} \mathrm{Mn}_{1.5} \mathrm{O}_{4}$ has two different crystal structures of the space groups of $\mathrm{Fd}-3 \mathrm{~m}$ or $\mathrm{P}_{3} 32$ depending on Ni ordering in the lattice. As shown in Figure 18, Fd-3m type $\mathrm{LiNi}_{0.5} \mathrm{Mn}_{1.5} \mathrm{O}_{4}$ is a disordering distribution, the $\mathrm{Ni}$ and $\mathrm{Mn}, \mathrm{Li}$ and $\mathrm{O}$ atoms are occupied in the $16 \mathrm{~d}$ octahedral sites, $8 \mathrm{a}$ tetrahedral sites and 32e sites, respectively. In this case, $\mathrm{Ni}$ and $\mathrm{Mn}$ atoms are randomly distributed in the $16 \mathrm{~d}$ sites. The $P 4_{3} 32$ type $\mathrm{LiNi}_{0.5} \mathrm{Mn}_{1.5} \mathrm{O}_{4}$ is has an ordered distribution, in which $\mathrm{Ni}, \mathrm{Mn}$, and $\mathrm{Li}$ atoms occupythe $4 \mathrm{a}, 12 \mathrm{~d}$, and $4 \mathrm{c}$ sites, respectively. $\mathrm{O}$ ions occupy the $8 \mathrm{c}$ and $24 \mathrm{e}$ sites. In this case, $\mathrm{Ni}$ and $\mathrm{Mn}$ atoms are ordered regularly (Santhanam et al., 2010). It has been reported that $\mathrm{LiNi}_{0.5} \mathrm{Mn}_{1.5} \mathrm{O}_{4}$ with $\mathrm{Fd}-3 m$ space 
group has a better electrochemical performance than that of spinel with $P 4_{3} 32$ space group due to a 2.5 orders of magnitude faster electronic conductivity.

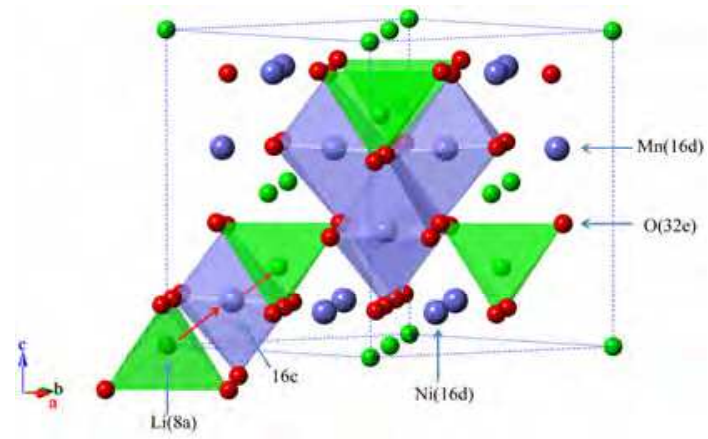

Fig. 18. Spinel structure of $\mathrm{LiNi}_{0.5} \mathrm{Mn}_{1.5} \mathrm{O}_{4}(\mathrm{Fd}-3 \mathrm{~m})$ showing the diffusion path of $\mathrm{Li}^{+}$. (Redrawn from Ref. (Xia et al., 2007))

A typical cyclic voltammogram of $F d-3 m$ type $\mathrm{LiNi}_{0.5} \mathrm{Mn}_{1.5} \mathrm{O}_{4}$ is shown in Figure 19 . Three well-defined reversible peaks are observed during the charge/discharge processes. The appearance of $4 \mathrm{~V}$ peak is due to $\mathrm{Mn}^{3+}$ which is formed by oxygen loss during the hightemperature calcinations. Two major peaks appearing between 4.5 and $5 \mathrm{~V}$ during charge/discharge cyclings are due to the redox couples $\mathrm{Ni}^{2+} / \mathrm{Ni}^{3+}$ and $\mathrm{Ni}^{3+} / \mathrm{Ni}^{4+}$ or ordering of lithium and vacancies at $\mathrm{x}=0.5$. For the ordered spinel, the $4 \mathrm{~V}$ peaks are absent because oxidation states of $\mathrm{Ni}$ and $\mathrm{Mn}$ were +2 and +4 , respectively (Santhanam, et al., 2010).

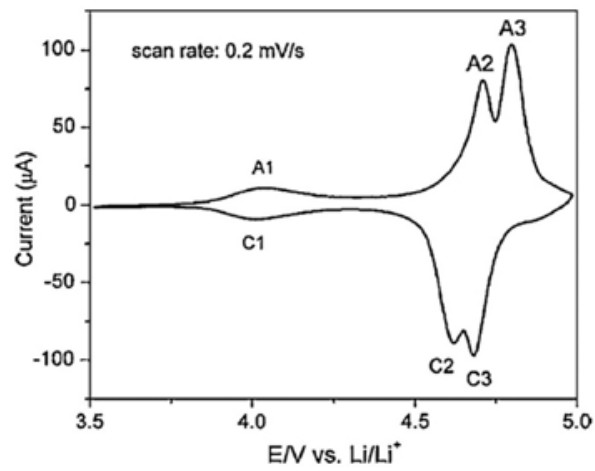

Fig. 19. Cyclic voltammogram of $\mathrm{LiNi}_{0.5} \mathrm{Mn}_{1.5} \mathrm{O}_{4}$ electrode cycled between 3.5 and $5 \mathrm{~V}$ vs. $\mathrm{Li} / \mathrm{Li}^{+}$at $0.2 \mathrm{mVs}^{-1}$ scan rate (Xia et al., 2007)

There are two main problems with this $\mathrm{LiNi}_{0.5} \mathrm{Mn}_{1.5} \mathrm{O}_{4}$ spinel material: One is that it is difficult to prepare pure spinel $\mathrm{LiNi}_{0.5} \mathrm{Mn}_{1.5} \mathrm{O}_{4}$ due to the formation of $\mathrm{Li}_{x} \mathrm{Ni}_{1-\mathrm{x}} \mathrm{O}$ as a second phase at high calcination temperatures. Developing low-temperature synthesis method of nanostructure $\mathrm{LiNi}_{0.5} \mathrm{Mn}_{1.5} \mathrm{O}_{4}$ is an effective strategy to solve this problem. In our previous work, we discovered a low-temperature solid-state route for single-phase $\mathrm{LiNi}_{0.5} \mathrm{Mn}_{1.5} \mathrm{O}_{4}$ (Fang et al., 2007). As shown in Figure 20, $\mathrm{LiNi}_{0.5} \mathrm{Mn}_{1.5} \mathrm{O}_{4}$ shows a dimension of about $200 \mathrm{~nm}$ and has a cubic spinel structure, which can be indexed in a 
space group of $F d-3 m$. The discharge capacity of $\mathrm{LiNi}_{0.5} \mathrm{Mn}_{1.5} \mathrm{O}_{4}$ reaches up to $134 \mathrm{mAh} / \mathrm{g}$ at a current density of $20 \mathrm{~mA} / \mathrm{g}$, while it retains as high as $110 \mathrm{mAh} / \mathrm{g}$ even at a high current density of $900 \mathrm{~mA} / \mathrm{g}$.
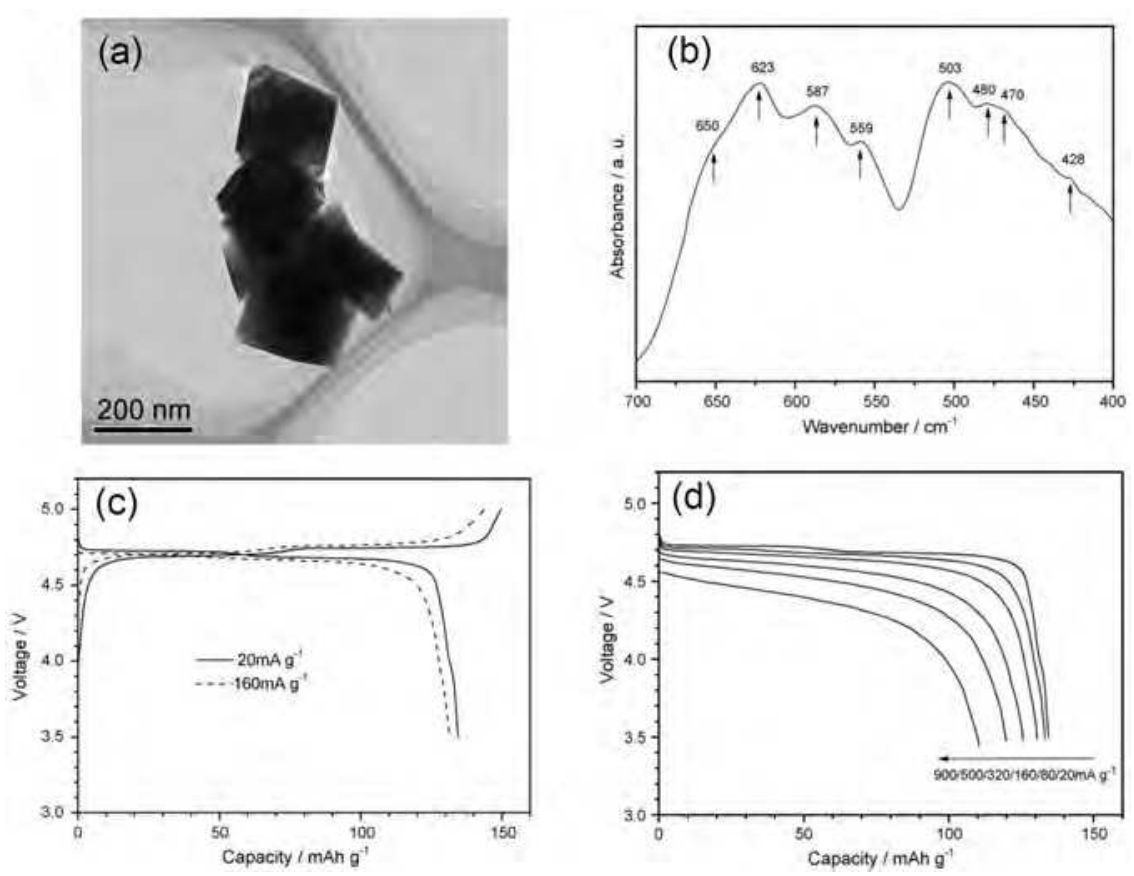

Fig. 20. a) Transmission electron micrograph and b) IR spectrum of $\mathrm{LiNi}_{0.5} \mathrm{Mn}_{1.5} \mathrm{O}_{4}$;

c) Charge/discharge curves of $\mathrm{LiNi}_{0.5} \mathrm{Mn}_{1.5} \mathrm{O}_{4}$ cycled at current densities of $20 \mathrm{~mA} / \mathrm{g}$ (solid line) and $160 \mathrm{~mA} / \mathrm{g}$ (dash line); and d) Discharge curves of the as-prepared $\mathrm{LiNi}_{0.5} \mathrm{Mn}_{1.5} \mathrm{O}_{4}$ at various current densities. (Fang et al., 2007)

The another one problem is that $\mathrm{LiNi}_{0.5} \mathrm{Mn}_{1.5} \mathrm{O}_{4}$ still undergoes decomposition of electrolyte and dissolution of $\mathrm{Mn}$ and $\mathrm{Ni}$, particularly under high voltage and elevated temperature conditions. The construction of heterogeneous nanostructure by coating some chemically stable compounds on $\mathrm{LiNi}_{0.5} \mathrm{Mn}_{1.5} \mathrm{O}_{4}$ is a most widely used strategy to enhance the electrochemical properties of $\mathrm{LiNi}_{0.5} \mathrm{Mn}_{1.5} \mathrm{O}_{4}$. This strategy has the advantages of the delivery of the original capacity due to no reduction in the amount of electrochemically active elements in the parent oxide and the suppression of the corrosion reactions between the high voltage spinel cathode and electrolyte. In this regard, various materials such as metal oxides, metal, fluoride, and carbon have been used to modify the surfaces of $\mathrm{LiNi}_{0.5} \mathrm{Mn}_{1.5} \mathrm{O}_{4}$.

\subsubsection{Coating by metal oxides}

Surface modifications of $\mathrm{LiNi}_{0.5} \mathrm{Mn}_{1.5} \mathrm{O}_{4}$ spinel material by metal oxides such as $\mathrm{ZnO}$ (Arrebola et al., 2010), $\mathrm{ZrO}_{2}$ (Wu et al., 2010), $\mathrm{Bi}_{2} \mathrm{O}_{3}$ (Liu et al., 2009), and $\mathrm{SiO}_{2}$ (Fan et al., 2007) have been investigated. Metal oxides coating act as a protective layer against the attack by HF that generated from the decomposition of $\mathrm{LiPF}_{6}$ salt in the electrolyte, which effectively suppresses the corrosion reaction. For example, Sun et al. (2002) reported that the 
surface modification of $\mathrm{LiNi}_{0.5} \mathrm{Mn}_{1.5} \mathrm{O}_{4}$ by $\mathrm{ZnO}$ significantly improves the capability at elevated temperature. $\mathrm{ZnO}$-coated electrode delivers a capacity of $137 \mathrm{mAh} / \mathrm{g}$ without any capacity loss even after 50 cycles at $55{ }^{\circ} \mathrm{C}$. $\mathrm{ZnO}$ coating layer scavenged fluorine anions by transforming $\mathrm{HF}$ to $\mathrm{ZnF}_{2}$, which keeps the original particle morphology and reduces an increase in interfacial impedance between cathode and electrolyte. Arrebola et al (2010) have also confirmed the role of scavenging $\mathrm{HF}$ of $\mathrm{ZnO}$ coating layer, in which $\mathrm{ZnO}$ coating is beneficial for enhancing the rate capability of $\mathrm{LiNi}_{0.5} \mathrm{Mn}_{1.5} \mathrm{O}_{4}$. In the case of $\mathrm{SiO}_{2}$ coated $\mathrm{LiNi}_{0.5} \mathrm{Mn}_{1.5} \mathrm{O}_{4}$ reported by Fan et al. (2007), $\mathrm{LiNi}_{0.5} \mathrm{Mn}_{1.5} \mathrm{O}_{4}$ spinel is modified by a porous, nanostructured, amorphous $\mathrm{SiO}_{2}$ surface layer, which is a good HF consumer that can neutralize HF and yields Si-F species. Nanocomposites displayed an obviously improved capacity retention rate at $55 \circ \mathrm{C}$, which is beneficial from the lower $\mathrm{HF}$ content in electrolyte resulting from the reaction between $\mathrm{SiO}_{2}$ and $\mathrm{HF}$ and the mechanical separation effect of the $\mathrm{SiO}_{2}$ coating result in relatively lower content of $\mathrm{LiF}$ in the surfaces of the coated $\mathrm{LiNi}_{0.5} \mathrm{Mn}_{1.5} \mathrm{O}_{4}$ cathode materials. Very recently, Liu et al. (2009) modified the surface of the $5 \mathrm{~V}$ cathode material by $\mathrm{Bi}_{2} \mathrm{O}_{3}$ coating, which rendered both excellent rate capability and improved cycling performance. Further investigation indicates that $\mathrm{Bi}_{2} \mathrm{O}_{3}$ is reduced on the cathode surfaces during the electrochemical cycling to metallic $\mathrm{Bi}$, an electronic conductor. Thus, " $\mathrm{Bi}_{2} \mathrm{O}_{3}$ " modified layer acts as a protection shell and a fast electron transfer channel as well, which renders an excellent rate capability and good cycling performance.

\subsubsection{Coating by metals}

Metals such as $\mathrm{Zn}$ (Alcantara et al., 2004), Au (Arrebola et al., 2007) and Ag (Arrebola et al., 2005) have also been coated onto the surfaces of spinel $\mathrm{LiNi}_{0.5} \mathrm{Mn}_{1.5} \mathrm{O}_{4}$ which significantly improves the electrochemical performance. For instance, Arrebola et al. (2007) found that $\mathrm{Au}$ coating on $\mathrm{LiNi}_{0.5} \mathrm{Mn}_{1.5} \mathrm{O}_{4}$ has a beneficial effect in increasing the capacity by hindering the unwanted reactions and simultaneously preventing the active material particles from reacting with the decomposition products such as HF. These authors studied the adverse effect of Ag treatment on the electrochemical performance of $\mathrm{LiNi}_{0.5} \mathrm{Mn}_{1.5} \mathrm{O}_{4}$. It is found that $\mathrm{Ag}$ treatment has only limited benefit at low current densities, while at moderate and high current densities, the capacity delivered is relatively low, even lower than that of the untreated spinel.

\subsubsection{Coating by fluoride}

Coating of spinel $\mathrm{LiNi}_{0.5} \mathrm{Mn}_{1.5} \mathrm{O}_{4}$ with $\mathrm{BiOF}$ can also improve the electrochemical performances (Kang et al., 2010). For instance, BiOF-coated $\mathrm{LiNi}_{0.5} \mathrm{Mn}_{1.5} \mathrm{O}_{4}$ shows a significantly improved capacity retention of $84.5 \%$ for 70 cycles at $55{ }^{\circ} \mathrm{C}$, while the uncoated one exhibits a capacity retention of only $31.3 \%$. The rate capability of the BiOF-coated $\mathrm{LiNi}_{0.5} \mathrm{Mn}_{1.5} \mathrm{O}_{4}$ is also significantly enhanced. Such improvements in electrochemical performance are attributed to the scavenging $\mathrm{HF}$ by BiOF layer from the electrolyte.

\subsubsection{Coating by carbon}

Yang et al. (2011) coated the spinel $\mathrm{LiNi}_{0.5} \mathrm{Mn}_{1.5} \mathrm{O}_{4}$ with a small amount of conductive carbon by the carbonization of sucrose. It is found that carbon coating greatly enhances the discharge capacity, rate capability, and cycling stability of the $\mathrm{LiNi}_{0.5} \mathrm{Mn}_{1.5} \mathrm{O}_{4}$ without degrading the spinel structure. $\mathrm{LiNi}_{0.5} \mathrm{Mn}_{1.5} \mathrm{O}_{4}$ modified with optimal $1 \mathrm{wt} \%$ sucrose can deliver a large capacity of $130 \mathrm{mAh} / \mathrm{g}$ at $1 \mathrm{C}$ discharge rate with a high retention of $92 \%$ after 100 cycles and a high $114 \mathrm{mAh} / \mathrm{g}$ at $5 \mathrm{C}$ discharge rate. The improved electrochemical performances upon carbon-coating are the consequence of the suppression of SEI layer as well as the enhancements in the electronic conductivity and $\mathrm{Li}^{+}$diffusion. 


\subsection{Vanadium pentoxide $\left(\mathrm{V}_{2} \mathrm{O}_{5}\right)$}

$\mathrm{V}_{2} \mathrm{O}_{5}$ is a typical intercalation compound with a layered structure, and therefore is a very promising electrode material for LIBs as it offers the essential advantages of low-cost, abundant sources, high energy density, and better safety. As seen from Figure 21, $\mathrm{V}_{2} \mathrm{O}_{5}$ has an orthorhombic crystal structure which can be described as layers of $\mathrm{VO}_{5}$ square pyramids that share edges and corners. The sixth $\mathrm{V}-\mathrm{O}$ bond in the $c$-direction consists of the weak electrostatic interactions, which facilitates the insertion of various ions and molecules between the layers. Li-ion insertion and electronic transport occur more easily along the $a-b$ plane rather than through the layers of the $c$-axis (Chan et al., 2007). Lithium intercalates along the $a-b$ plane into the interlayer space follows the equation:

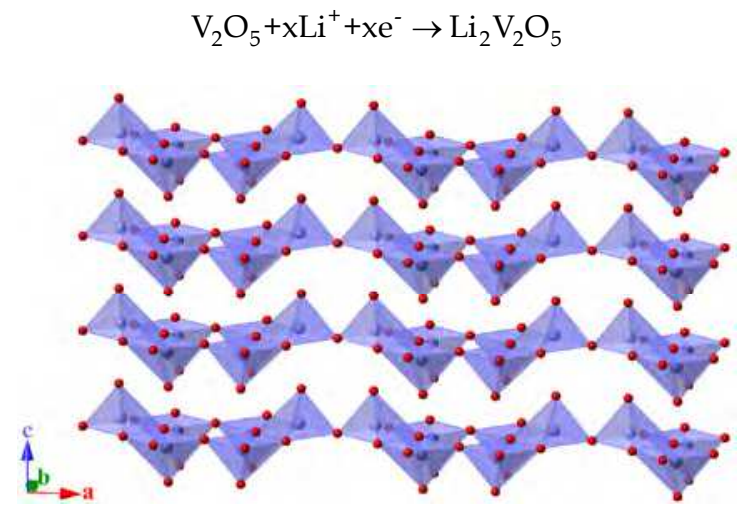

Fig. 21. Layered crystal structure of bulk $\mathrm{V}_{2} \mathrm{O}_{5}$ with boxed region indicating the unit cell. $\mathrm{O}$ atoms are in red and $\mathrm{VO}_{5}$ units in blue.

The theoretical capacity of $\mathrm{V}_{2} \mathrm{O}_{5}$ with two lithium insertions/extractions is about 294 $\mathrm{mAh} / \mathrm{g}$, much higher than those of the commonly used cathode materials like $\mathrm{LiFePO}_{4}(170$ $\mathrm{mAh} / \mathrm{g}$ ), making it a promising cathode material for high power batteries. Since the nanostructured approaches have been recently demonstrated to be highly effective in enhancing the electrochemical performance of electrode materials, various nanostructured $\mathrm{V}_{2} \mathrm{O}_{5}$ has been studied to show the improved electrochemical properties as featured by high capacity and remarkable reversibility. For example, Sides et al. (2005) reported the preparation of monodisperse $\mathrm{V}_{2} \mathrm{O}_{5}$ fibers with an improved electrochemical performance because of the reduced lithium ion diffusion path and increased electrolyte-accessible surface area. Cao et al. (2005) have synthesized $\mathrm{V}_{2} \mathrm{O}_{5}$ with highly ordered superstructures, in which nanoparticles interconnect to form nanorods, and these rods circle around to form hollow microspheres. The specific capacity of these $\mathrm{V}_{2} \mathrm{O}_{5}$ hollow microspheres is 286.4 $\mathrm{mAh} / \mathrm{g}$ at $0.2 \mathrm{C}$ charge/discharge rate, which is very close to the theoretical capacity of $\mathrm{V}_{2} \mathrm{O}_{5}$. However, the Li-ion diffusion coefficient $\left(10^{-12} \mathrm{~cm}^{2} / \mathrm{s}\right)$ and the electronic conductivity $\left(10^{-2}-10^{-3} \mathrm{~S} / \mathrm{cm}\right)$ in crystalline $\mathrm{V}_{2} \mathrm{O}_{5}$ are inherently too low to sustain a large specific capacity at high charge/discharge rates, which cannot be simply altered by the nanostructured strategies mentioned above. In order to improve the electrochemical performance, many heterogeneous nanostructured forms of $\mathrm{V}_{2} \mathrm{O}_{5}$ composites have been reported in the literature, and the usefulness of these designs has been demonstrated. 


\subsubsection{Mixed with conducting secondary phase}

To enhance the high rate capability of $\mathrm{V}_{2} \mathrm{O}_{5}$ cathode materials, the creation of heterogeneous nanostructures from nanoscale $\mathrm{V}_{2} \mathrm{O}_{5}$ and conducting secondary phase is one of the most widely used strategies. There are three kinds of mainly adopted conducting materials, viz. conducting conjugated polymers (CCPS), carbon materials, and various metal oxides. CCPS possess a high inherent conductivity and is able to undergo practically fully reversible redox processes. The heterogeneous nanostructures from $\mathrm{V}_{2} \mathrm{O}_{5}$ and CCPS combine a high capacity and ability to intercalate lithium ions in $\mathrm{V}_{2} \mathrm{O}_{5}$, and high cyclability, conductivity, and other properties of CCPS. For example, Posudievsky et al., (2011) prepared two-component guesthost nanocomposites which are composed of conducting polymers (polyaniline, polypyrrole and polythiophene) and $\mathrm{V}_{2} \mathrm{O}_{5}$. The nanocomposites are capable of reversible cycling as the positive electrode in a lithium ion cell, and retain their capacity over one hundred full charge/discharge cycles. The higher discharge capacity, stability in prolonged charge/discharge cycling, and improved diffusion of lithium ions in the nanocomposites, are the consequences of pillaring by the conducting polymer macromolecules in the layers of the inorganic matrix.

Carbon coating has been applied to $\mathrm{V}_{2} \mathrm{O}_{5}$ cathode to give good electronic conductivity and stability (Odani et al., 2006; koltypin et al., 2007). For example, koltypin et al. (2007) have prepared carbon-coated $\mathrm{V}_{2} \mathrm{O}_{5}$ nanoparticles. The carbon coated $\mathrm{V}_{2} \mathrm{O}_{5}$ electrodes demonstrate a higher capacity, much better rate capability, and very good stability upon cycling and aging at elevated temperatures when compared to the electrodes that comprise the microparticles of $\mathrm{V}_{2} \mathrm{O}_{5}$.

Other than CCPS and carbon, inorganic oxides such as $\mathrm{TiO}_{2}$ (Takahashi et al, 2006) and $\mathrm{WO}_{3}$ (Cai et al, 2011) have been introduced with an aim to improve the electrochemical properties by modifying the crystallinity of $\mathrm{V}_{2} \mathrm{O}_{5}$. For example, Cai et al (2011) found that $\mathrm{V}_{2} \mathrm{O}_{5}-\mathrm{WO}_{3}$ composites films show the enhanced Li-ion intercalation properties compared to pure $\mathrm{V}_{2} \mathrm{O}_{5}$ or $\mathrm{WO}_{3}$ films. At a high current density of $1.33 \mathrm{~A} / \mathrm{g}, \mathrm{V}_{2} \mathrm{O}_{5}-\mathrm{WO}_{3}$ film with a $\mathrm{V}_{2} \mathrm{O}_{5} / \mathrm{WO}_{3}$ molar ratio of $10 / 1$ exhibits the highest capacities of $200 \mathrm{mAh} / \mathrm{g}$ at the first cycle and 132 $\mathrm{mAh} / \mathrm{g}$ after 50 cycles, while pure $\mathrm{V}_{2} \mathrm{O}_{5}$ film delivers discharge capacities of $108 \mathrm{mAh} / \mathrm{g}$ at the first cycle and $122 \mathrm{mAh} / \mathrm{g}$ after 50 cycles. The enhanced Li-ion intercalation properties of the composite films are ascribed to the reduced crystallinity, increased porosity, and the enhanced surface area.

\subsubsection{Thin layer loaded on a continuous conductive matrix}

To improve the high rate electrochemical property of $\mathrm{V}_{2} \mathrm{O}_{5}$, rapid and continuous electronic and ionic transportation path are required. Reducing the dimension of $\mathrm{V}_{2} \mathrm{O}_{5}$ is a most effective method to shorten the $\mathrm{Li}$ ion diffusion path and fasten the $\mathrm{Li}$ ion transportation, since Li-ion diffusion coefficient of $\mathrm{V}_{2} \mathrm{O}_{5}\left(10^{-12} \mathrm{~cm}^{2} / \mathrm{s}\right)$ cannot be altered simply by nanostructure strategy. Also, the disadvantage of the low electronic conductivity $\left(10^{-2}-10^{-3} \mathrm{~S} / \mathrm{cm}\right)$ of $\mathrm{V}_{2} \mathrm{O}_{5}$ can be effectively overcome by the introduction of conductive secondary phase. So, if uniformly ultra thin layer of $\mathrm{V}_{2} \mathrm{O}_{5}$ is formed on a continuous conductive matrix, rapid and continuous electronic and ionic transportation path can be achieved. For example, Yamada et al. (2007) coated thin $\mathrm{V}_{2} \mathrm{O}_{5}$ layer on porous carbon, as shown in Figure 22a. In their work, the porous carbons were prepared using $\mathrm{SiO}_{2}$ colloidal crystals as the templates with three dimensionally interconnected pores, and then $\mathrm{V}_{2} \mathrm{O}_{5}$ /carbon composites were achieved by immersing the 
porous carbons in $\mathrm{V}_{2} \mathrm{O}_{5}$ sol under a reduced pressure. Nanoporous $\mathrm{V}_{2} \mathrm{O}_{5}$ /carbon composites thus prepared exhibit a large capacity of more than $100 \mathrm{mAh} / \mathrm{g}$ and good rate capability of $80 \%$ at $5.0 \mathrm{~A} / \mathrm{g}$ (Figure 22b). The good performance is explained by electric double layer capacitance of large surface area and high rate lithium insertion to $\mathrm{V}_{2} \mathrm{O}_{5}$ gel.
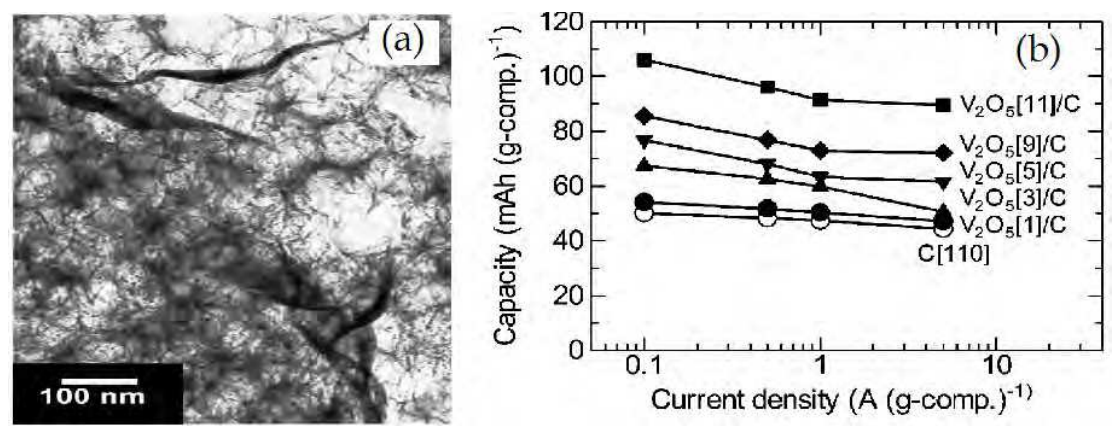

Fig. 22. a) TEM image of $\mathrm{V}_{2} \mathrm{O}_{5} / \mathrm{C}$ composites; and b) rate capability of $\mathrm{V}_{2} \mathrm{O}_{5}[\mathrm{n}] / \mathrm{C}$ composites. (Yamada et al., 2007)
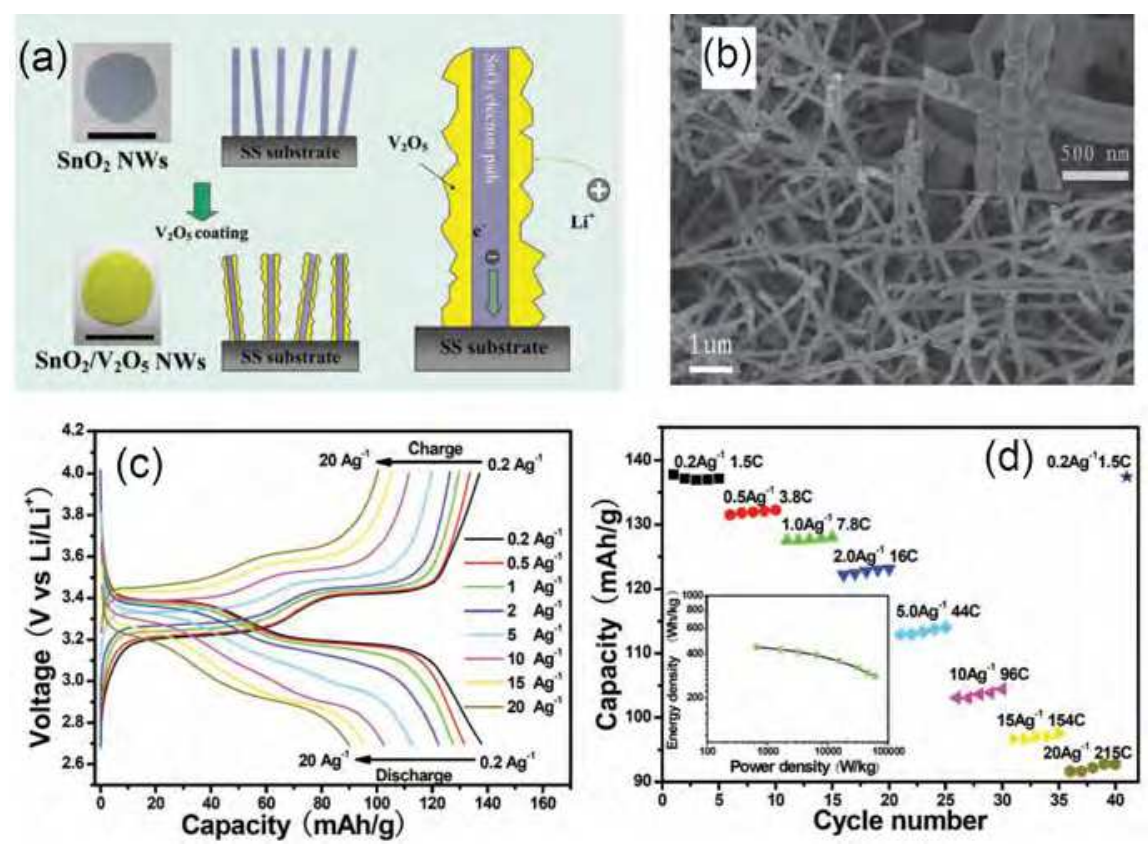

Fig. 23. a) Schematic diagram showing the strategy for coating $\mathrm{V}_{2} \mathrm{O}_{5}$ on $\mathrm{SnO}_{2}$ nanowires (NWs) grown on a stainless-steel (SS) substrate; b) FE-SEM image of the typical $\mathrm{V}_{2} \mathrm{O}_{5}$ loaded $\mathrm{SnO}_{2}$ nanowires; the inset indicates the diameter is about $100 \mathrm{~nm}$; ) the galvanostatic charge/discharge curves of the SVNs electrode at different current densities; and d) rate performance at different current densities, and the inset showing the Ragone plots. (Yan et al., 2011) 
Recently, Yan et al. (2011) have adopted a simple gas-phase-based method to synthesize $\mathrm{V}_{2} \mathrm{O}_{5}$ loaded $\mathrm{SnO}_{2}$ nanowires on the stainless-steel substrate (Figures 23a and b). $\mathrm{V}_{2} \mathrm{O}_{5}$ loaded $\mathrm{SnO}_{2}$ nanowires exhibit a high rate capability and very good cycling stability (Figure 23c). $\mathrm{SnO}_{2} / \mathrm{V}_{2} \mathrm{O}_{5}$ core/shell-nanowires deliver a high power density of about $60 \mathrm{~kW} / \mathrm{kg}$ while the energy density remains at $282 \mathrm{wh} / \mathrm{kg}$ (Figure 23d). The improved electrochemical performance can be ascribed to the synergic effect of $\mathrm{V}_{2} \mathrm{O}_{5}$ thin layer and $\mathrm{SnO}_{2}$ nanowires. $\mathrm{V}_{2} \mathrm{O}_{5}$ layer coated on $\mathrm{SnO}_{2}$ is very thin, which could shorten the ion-diffusion time and enable a high utilization of $\mathrm{V}_{2} \mathrm{O}_{5}$. The free-standing $\mathrm{SnO}_{2}$ nanowires create porous channels, providing effective electrolyte transport and a large contact interface between the electrolyte and active materials. These findings open up new opportunities in the development of highperformance energy-storage devices used for micro-systems, thin-film devices, and other functional devices.

\section{Heterogeneous nanostructured anode materials}

Due to the low theoretical capacity of $372 \mathrm{mAh} / \mathrm{g}$ for graphitic carbon, intensive research has been conducted to search for the alternative anode materials with higher capacities and rate capabilities. Many other anode materials, such as $\mathrm{Sn}, \mathrm{Sb}, \mathrm{Si}, \mathrm{Ge}, \mathrm{SnO}_{2}$, and $\mathrm{Co}_{3} \mathrm{O}_{4}$ have been reported to have larger lithium storage capacities than graphitic carbon via the formation of alloys with lithium or through the reversible reactions with lithium ions. However, these anode materials suffer from the huge volume variation during the lithium insertion/extraction process which leads to the pulverization problem and moreover a rapid deterioration in capacity. Reducing the size of these anode materials to nanometer scale can partially suppress the volume variation, and designing the structure of these anode materials as hollow spheres or porous particles can improve the lithium storage capacity and their initial Coulombic efficiency to a certain degree. Unfortunately, the capacity decay of the electrode along with the charge/discharge cycling still cannot be completely avoided (Liang et al., 2009). Recently, heterogeneous nanostructured anode materials, which are composed of multi-nanocomponents have been shown to exhibit an improved rate and cyclying performance due to the synergic effect between the functional nanocomponents. In this section, we introduced the recent trends and developments of these heterogeneous nanostructured anode materials, including carbonaceous nanocomposites, polymer/inorganic oxides nanocomposites, and binder-free thin-film nanocomposites.

\subsection{Carbonaceous composites anode materials}

Carbonaceous composites materials have been widely used for anodes. Though there are many different types of carbon materials, such as amorphous carbon, carbon nanotubes, and graphene, etc., all of them can not only significantly enhance the electronic conductivity of electrode materials, but also lead to the stabilized SEI films on anodes, which result in the improved rate and cycling performance. However, the synergic effect between carbon materials and other lithium intercalation materials is very complicated. Even when the same carbon material is adopted, the synergic effect could be significantly different due to the varied combination states of nanocomponents.

\subsubsection{Core-shell nanocomposites}

Core-shell nanocomposites for carbon-based anodes refer to a core energy dense nanoparticle coated with a thin amorphous carbon shell, which enhances the electrical 
conductivity, prevents aggregation, improves chemical stability, and buffers the stress of the inner nanoscale active material. Zhang et al. (2008) reported tin nanoparticles encapsulated elastic hollow carbon spheres (TNHCs) with an uniform size. As shown in Figure 24, in the TNHCs composites, multiple tin nanoparticles with a diameter of less than $100 \mathrm{~nm}$ are encapsulated in one thin hollow carbon sphere with a thickness of only $20 \mathrm{~nm}$. This special structure results in both the content of Sn up to $70 \%$ by weight and the void volume in carbon shell as high as $70-80 \%$ by volume. This void volume and elasticity of thin carbon spherical shell efficiently accommodate the volume change of tin nanoparticles due to the Li-Sn alloying-dealloying reactions, and thus prevent the pulverization of electrode. As a result, this composite shows a decent cycle ability with a high initial capacity of more than $800 \mathrm{mAh} / \mathrm{g}$, and after 100 cycles it shows only a moderate decrease in its specific capacity to $550 \mathrm{mAh} / \mathrm{g}$. Coaxial $\mathrm{SnO}_{2} @$ carbon hollow nanospheres have also been reported by Lou et al. (2009). In this new type of nanoarchitecture, the carbon shell is tightly attached to the $\mathrm{SnO}_{2}$ shell, beneficial for the mechanical reinforcement and the enhanced electronic conduction. The composites deliver a discharge capacity of around $460 \mathrm{mAh} / \mathrm{g}$ after 100 cycles with little capacity fade.

(a)

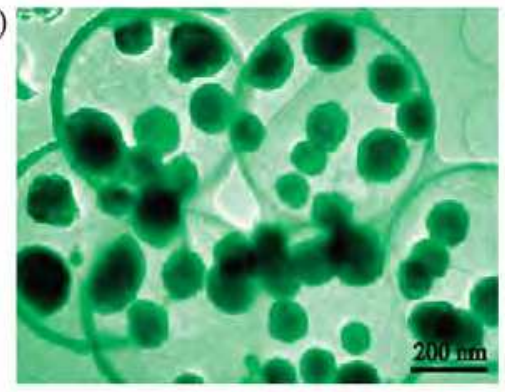

(b)

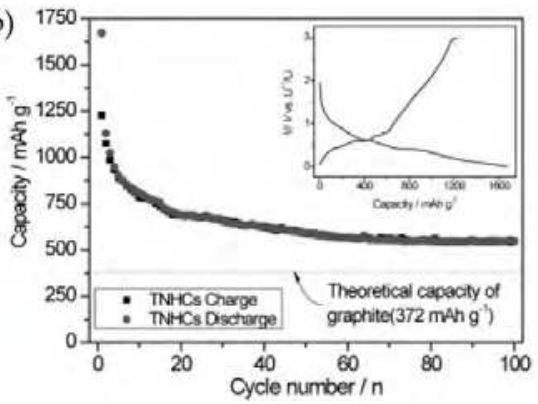

Fig. 24. a) TEM image of TNHCs; b) discharge/charge capacity profiles of TNHCs in $5 \mathrm{mV}-3$ $\mathrm{V}\left(\mathrm{vs}^{\mathrm{Li}} \mathrm{Li}^{+} / \mathrm{Li}\right.$ ) voltage window and $\mathrm{C} / 5$. Inset shows the first discharge/charge profiles of TNHCs cycled at a rate of C/5. (Zhang et al., 2008)

Recently, Yang et al. (2011) reported $\mathrm{TiO}_{2}$ (B) @carbon composite nanowires by a two-step hydrothermal process with subsequent heat treatment in argon. As shown in Figure 25, the nanostructures exhibit a unique feature of having $\mathrm{TiO}_{2}(\mathrm{~B})$ encapsulated inside and an amorphous carbon layer coating outside. The carbon shell accelerates the diffusion of both electrons and lithium ions, ensuring a high electrode-electrolyte contact area and eventually making a greater contribution to the capacity. $\mathrm{TiO}_{2}(\mathrm{~B})$ core also acts as an effective mechanical support to alleviate the stress produced during lithium intercalation/ deintercalation and preserve the one dimensional core/shell structure even after 100 charge/discharge cycles. The composite nanowires exhibit a high reversible capacity of $560 \mathrm{mAh} / \mathrm{g}$ after 100 cycles at a current density of $30 \mathrm{~mA} / \mathrm{g}$, and excellent cycling stability and rate capability.

Above reports have fully demonstrated the benefits of heterogeneous core-shell nanostructures. In this core-shell strategy, the void volume in the core-shell configuration should be optimized according to the actual volume variation of electrode materials during the lithium insertion and extraction, in order to avoid decreasing the volume energy density of LIBs in practical uses. 

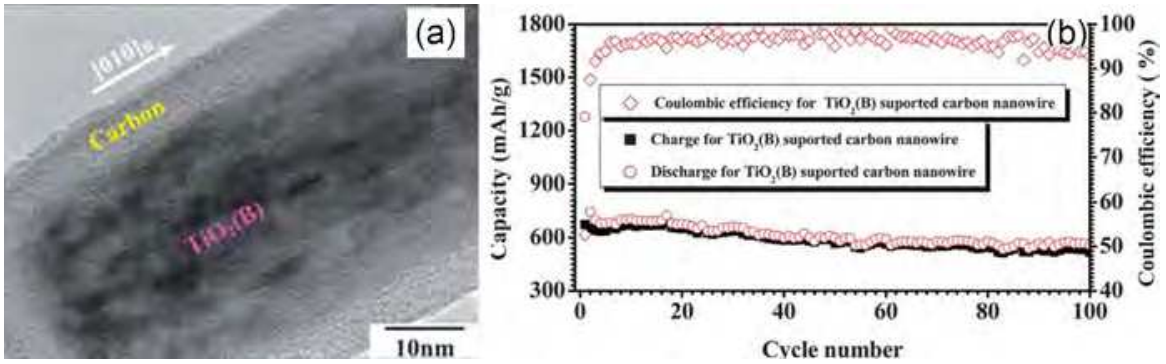

Fig. 25. a) HRTEM image of a section of a $\mathrm{TiO}_{2}(\mathrm{~B}) @$ carbon composite nanowire; b) capacity vs. cycle number curves from the first cycle to the 100th cycle for the $\mathrm{TiO}_{2}(\mathrm{~B}) @$ carbon composite nanowires at a current density of $30 \mathrm{~mA} / \mathrm{g}$. (Yang et al., 2011)

\subsubsection{Carbon-nanotube-based nanocomposites}

Unique properties of carbon nanotube (CNT) such as high conductivity, nanotexture, resiliency, are very helpful for LIBs, where pure CNT and/or their composites play the role of electrode materials. CNT provides an ideal conducting path to ensure a good charge propagation and can serve as a perfect resilient skeleton with stretchable properties that gives a significant improvement in electrochemical cyclability especially when volumetric changes take place during the charge/discharge processes. In this regard, CNTs have been widely used as the conductive additives or conductive matrix for the anode materials. There are two main strategies to synthesize CNT heterogeneous nanostructures: One is interconnecting the electrode materials with the exterior surface of CNT by various mixing procedures. For example, Zhang et al. (2009) prepared $\mathrm{CNT}_{\mathrm{S}} \mathrm{SnO}_{2}$ hybrid nanostructures with excellent lithium storage performance by uniformly loading $\mathrm{SnO}_{2}$ nanoparticles onto a cross-stacked CNT network. Xia et al. (2010) prepared caterpillar-like nanoflaky $\mathrm{MnO}_{2} / \mathrm{CNT}$ nanocomposites, in which highly porous interconnected $\mathrm{MnO}_{2}$ nanoflakes are uniformly coated on the surface of CNT. This nanoflaky $\mathrm{MnO}_{2} / \mathrm{CNT}$ nanocomposite electrode exhibits a large reversible capacity of $801 \mathrm{mAh} / \mathrm{g}$ for the first cycle without capacity fading for the first 20 cycles (Figure 26).
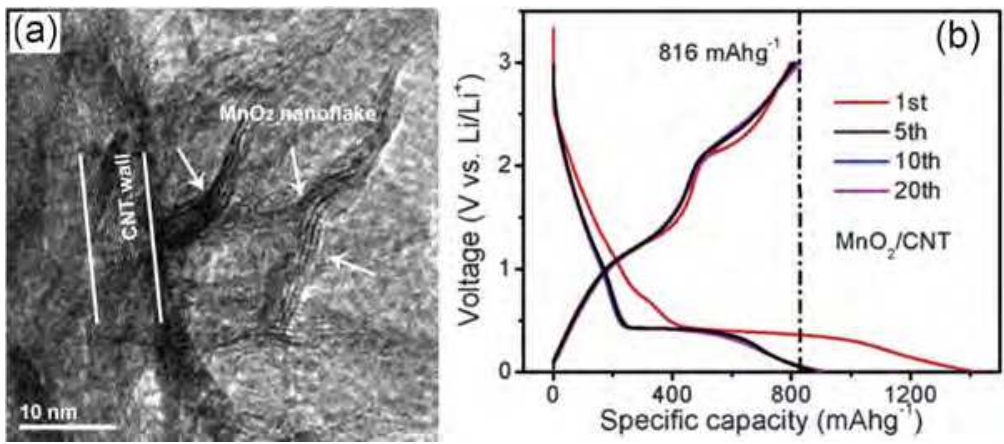

Fig. 26. a) TEM images of one single CNT coated with porous $\mathrm{MnO}_{2}$ layer; and b) voltage profiles of a $\mathrm{MnO}_{2} / \mathrm{CNT}$ nanocomposite electrode cycled between 0.01 and $3 \mathrm{~V}$ at a current density of $200 \mathrm{~mA} / \mathrm{g}$. (Xia et al., 2010) 

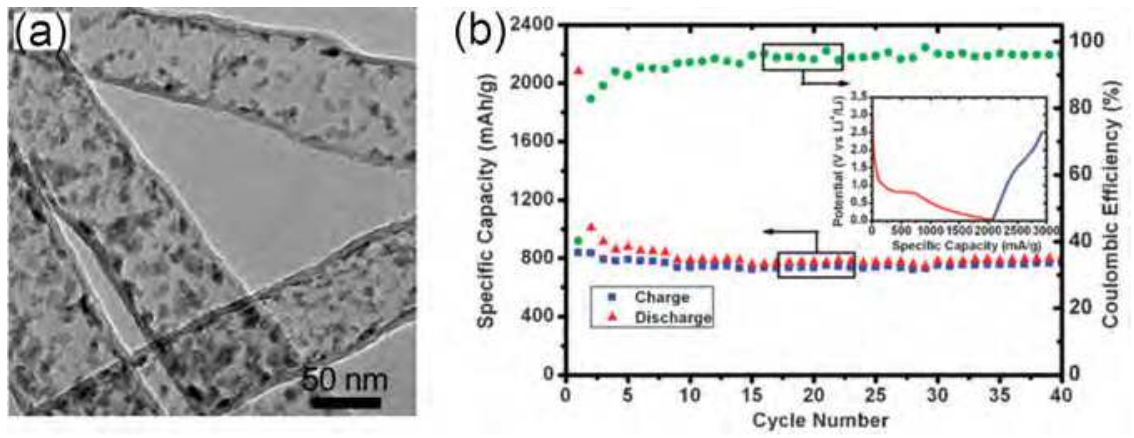

Fig. 27. a) TEM images of the $\mathrm{Fe}_{2} \mathrm{O}_{3}$-filled CNTs; and b) cycling performance of the $\mathrm{Fe}_{2} \mathrm{O}_{3}$-filled CNT measured at a rate of $35 \mathrm{~mA} / \mathrm{g}$ between 0.02 and $2.5 \mathrm{~V}$ (vs. $\mathrm{Li}^{+} / \mathrm{Li}$ ). (Yu et al., 2010)
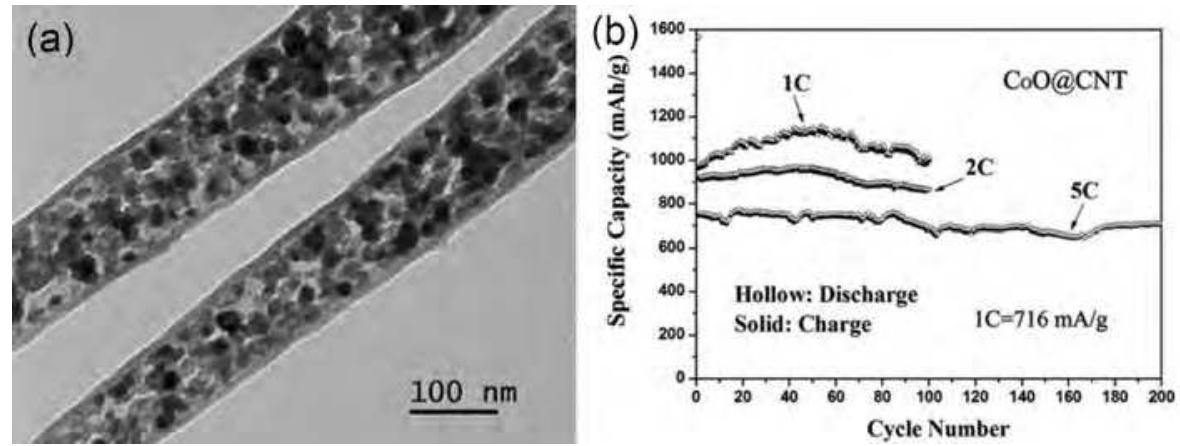

Fig. 28. a) TEM images of CoO@CNT; and b) cycling performance of CoO@CNT at highrates. (Wu et al., 2011)

The other strategy is encapsulating the electrode materials in the interior space of CNT (Wang et al., 2009; Wu et al., 2010; Yu et al., 2010; Wu et al., 2011). For example, Yu et al. (2010) synthesized $\mathrm{Fe}_{2} \mathrm{O}_{3} / \mathrm{CNT}$ nanocomposites by AAO template method. As shown in Figure 27, in this nanocomposite, $\mathrm{Fe}_{2} \mathrm{O}_{3}$ nanoparticles with a mean diameter of $\sim 9 \mathrm{~nm}$ are filled homogeneously into the hollow core of high aspect ratio CNT. The $\mathrm{Fe}_{2} \mathrm{O}_{3}$-filled CNTs exhibit a high initial discharge capacity of $2081 \mathrm{mAh} / \mathrm{g}$, and a reversible capacity of 768 $\mathrm{mAh} / \mathrm{g}$ is obtained after 40 cycles, while the Coulombic efficiency steadily keeps at higher than $95 \%$. $\mathrm{Fe}_{2} \mathrm{O}_{3}$-filled CNTs also show a superior cycling performance and rate capability, which can be attributed to the small size of $\mathrm{Fe}_{2} \mathrm{O}_{3}$ particles and the confinement effect as well as the good electrical conductivity of CNTs. Very recently, Wu et al. (2011) reported a self-assembled echinus-like nanostructure that consists of mesoporous $\mathrm{CoO}$ nanorod@carbon nanotube core-shell materials, as shown in Figure 28a. This core-shell nanostructure shows a high capacity (703-746 mAh/g in 200 cycles) and a long cycle life $(0.029 \%$ capacity loss per cycle) at a high current rate of $3580 \mathrm{~mA} / \mathrm{g}$, as shown in Figure $28 \mathrm{~b}$. The excellent electrochemical energy storage should be attributed to the increased electrical conductivity, mechanical stability and electrochemical activity of porous $\mathrm{CoO}$ materials in the presence of a carbon nanotube overlayer. This core-shell nanostructure not only 
increases the electronic and ionic conductivity due to the presence of highly conductive CNT, but also improves the stability during the repeated ionic intercalation due to the flexible CNT, which act as a buffer to alleviate the volume expansion of metal oxides.

\subsubsection{Graphene-based nanocomposites}

In the family of carbon nanostructures, graphene is the youngest member but has attracted enormous recent interest. Graphene is a two-dimensional macromolecular sheet of carbon atoms with a honey comb structure. It is an excellent substrate to host active nanomaterials for LIBs applications due to its high conductivity, large surface area, flexibility, and chemical stability. In this regard, chemically modified graphene materials have been used to form the heterogeneous nanostructured materials with $\mathrm{Si}$ (Chou et al., 2010), $\mathrm{SnO}_{2}$ (Paek et al., 2009), $\mathrm{Co}_{3} \mathrm{O}_{4}$ (Yang et al., 2010), $\mathrm{TiO}_{2}$ (Li et al., 2011), $\mathrm{Fe}_{2} \mathrm{O}_{3}$ ( $\mathrm{Zhu}$ et al., 2011), $\mathrm{Mn}_{3} \mathrm{O}_{4}$ (Wang et al., 2010), and $\mathrm{SnSe}_{2}$ (Choi et al., 2011). Improved electrochemical performances are thus achieved, owing to the synergic effect between graphene and active nanoparticles. In these nanocomposites, the ultrathin flexible graphene layers can provide a support for anchoring well-dispersed active nanoparticles and work as a highly conductive matrix for enabling good contact between them, which can also effectively prevent the volume expansion/contraction and aggregation of the active nanoparticles during $\mathrm{Li}$ charge/discharge processes. Meanwhile, the anchoring of active nanoparticles on graphene effectively reduces the degree of restacking of graphene sheets and consequently keeps a highly active surface area and to some extent, increases the lithium storage capacity and cyclic performance (Wu et al., 2010). For example, Paek et al. (2009) reported $\mathrm{SnO}_{2}$ /graphene nanocomposites, in which graphene nanosheets are homogeneously distributed between the loosely packed $\mathrm{SnO}_{2}$ nanoparticles. This nanocomposite exhibits a charge capacity of $570 \mathrm{mAh} / \mathrm{g}$ after 30 cycles with about $70 \%$ retention of the reversible capacity. Recently, Zhang et al. (2010) synthesized $\mathrm{Fe}_{3} \mathrm{O}_{4}$ /graphene composites by depositing $\mathrm{Fe}^{3+}$ in the interspaces of graphene sheets. In the composites, $\mathrm{Fe}_{3} \mathrm{O}_{4}$ nanoparticles are dispersed on graphene sheets, which show a high reversible capacity, as well as a significantly enhanced cycling performance (about $650 \mathrm{mAh} / \mathrm{g}$ after 50 cycles) and high rate capabilities ( $350 \mathrm{mAh} / \mathrm{g}$ at $5 \mathrm{C}$ ).

Though graphene sheets can effectively buffer the strain from the volume change of metals or metal oxides during the charge/discharge processes and preserve the high electrical conductivity of the overall electrode, the metal and metal oxide nanoparticles are still prone to strong aggregation during the cycle processes because of non-intimate contact between graphene layers and active nanoparticles, leading to a slow capacity fading. An alternative strategy for solving the aggregation problem of metal and metal oxides is to confine them within individual graphene shells. Yang et al. (2010) reported graphene-encapsulated $\mathrm{Co}_{3} \mathrm{O}_{4}$ nanoparticles prepared by co-assembly between negatively charged graphene oxide and positively charged oxide nanoparticles. This assembly enables a good encapsulation of electrochemically active metal oxide nanoparticles by graphene sheets, thus leading to a remarkable lithium-storage performance such as highly reversible capacity and excellent cycle performance. A very high and stable reversible capacity of about $1100 \mathrm{mAh} / \mathrm{g}$ in the initial 10 cycles, and $1000 \mathrm{mAh} / \mathrm{g}$ after 130 cycles is achieved for the graphene-encapsulated $\mathrm{Co}_{3} \mathrm{O}_{4}$ electrode, which is superior over those of $\mathrm{Co}_{3} \mathrm{O}_{4} /$ graphene composite or bare $\mathrm{Co}_{3} \mathrm{O}_{4}$ electrodes (Figure 29). 

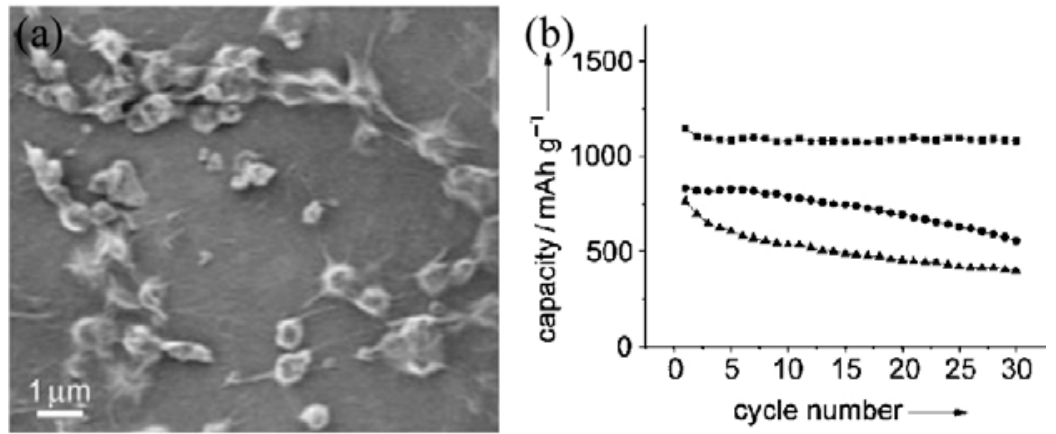

Fig. 29. a) SEM images of graphene-encapsulated $\mathrm{Co}_{3} \mathrm{O}_{4}$ and b) comparison of the cycle performance of graphene-encapsulated $\mathrm{Co}_{3} \mathrm{O}_{4}(\boldsymbol{\bullet})$, mixed $\mathrm{Co}_{3} \mathrm{O}_{4}$ / graphene composite $(\bullet)$, and bare $\mathrm{Co}_{3} \mathrm{O}_{4}$ electrodes $(\boldsymbol{\Delta})$ over 30 cycles (current density=74 mA/g). (Yang et al. 2010)

\subsection{Polymer/inorganic oxides nanocomposites}

Heterogeneous nanostructures that consist of the composites of inorganic oxides and organic conducting polymers have been proven to be an effective approach to improve the high-rate electrochemical properties of LIBs. Organic conducting polymers provide a conducting backbone for the nanoscale inorganic oxides and accelerate the charge transfer between them, limit formation of a surface electrochemical interface (SEI) layer to improve the chemical stability, and buffer the stress of the inner nanoscale inorganic oxides to improve the structural stability.

\subsubsection{Polypyrrole (PPy)}

PPy is a chemical compound formed from a number of connected pyrrole ring structures and it is the first polyacetylene-derivative to show a high conductivity. Chew et al. (2007) reported a novel nano-silicon/PPy composite by chemical ploymerization. The cycling stability of Si/PPy electrodes is significantly improved when compared to that of the bare Si anodes. PPy plays a key role in improving the electrochemical performance of the composites: (i) PPy in the composites is a conducting polymer, which increases the conductivity of the samples. (ii) PPy can act as a conductive binder, increasing the contact among particles, therefore the particle-to-particle resistance will be decreased, thus reducing the irreversible reactions with the electrolyte. (iii) PPy is an effective component that buffers the great volume changes during the cycling process, thus improving the cyclability of the Si electrode. Similarly, Cui et al. (2011) have synthesized $\mathrm{SnO}_{2} @$ PPy nanocomposites by an one-pot oxidative chemical polymerization method. The nanocomposites exhibit high discharge/charge capacities and favourable cycling. For $\mathrm{SnO}_{2} @ P P y$ nanocomposites with 79 $\mathrm{wt} \% \mathrm{SnO}_{2}$, the electrode reaction kinetics is controlled by the diffusion of $\mathrm{Li}^{+}$in the nanocomposite. The calculated diffusion coefficiency of lithium ions in $\mathrm{SnO}_{2} @ \mathrm{PPy}$ nanocomposite with $79 \mathrm{wt} \% \mathrm{SnO}_{2}$ is $6.7 \times 10^{-8} \mathrm{~cm}^{2} \mathrm{~s}^{-1}$, while the lithium-alloying activation energy at $0.5 \mathrm{~V}$ is $47.3 \mathrm{~kJ} \mathrm{~mol}^{-1}$, which is obviously lower than that for the bare $\mathrm{SnO}_{2}$. The enhanced electrode performance with the $\mathrm{SnO}_{2} @ P P y$ nanocomposite is originated from the advantageous nanostructures that allow a better structural flexibility, shorter diffusion length, and easier interaction with lithium. 


\subsubsection{Polyaniline (PANI)}

PANI is a conducting polymer of the semi-flexible rod polymer family. It has the advantages of ease of fabrication, high conductivity, and good flexibility, so it can be used to prepare the composite anode of varied microstructures. Nickel foam-supported NiO/PANI composites with a porous net-like morphology have been prepared by a chemical bath deposition technique (Huang et al., 2008). These composites are constructed by $\mathrm{NiO}$ nanoflakes coated by PANI layer. As an anode for lithium ion batteries, NiO/PANI composites exhibit a weaker polarization as compared to $\mathrm{NiO}$ film. The specific capacity after 50 cycles for $\mathrm{NiO} / \mathrm{PANI}$ film is $520 \mathrm{mAh} / \mathrm{g}$ at $1 \mathrm{C}$, higher than that of $440 \mathrm{mAh} / \mathrm{g}$ for NiO film. These improvements are attributed to the fact that PANI enhances the electrical conduction of the electrode and keeps the NiO film stable during cyclings. Similarly, He et al. (2008) prepared $\mathrm{SnO}_{2}$-PANI composite by microemulsion polymerization method. The composite is composed of amorphous PANI and $\mathrm{SnO}_{2}$ nanoparticles, in which $\mathrm{SnO}_{2}$ is coated with PANI. $\mathrm{SnO}_{2}$-PANI composite to show a reversible capacity of $657.6 \mathrm{mAh} / \mathrm{g}$ with a capacity loss per cycle at only $0.092 \%$ after 80 cycles. Recently, Cai et al. (2010) reported Si/PANI nanocomposite synthesized by chemical polymerization of aniline and nano-silicon. $\mathrm{Si} / \mathrm{PANI}$ composite maintains a capacity of $1870 \mathrm{mAh} / \mathrm{g}$ up to 25 cycles with a slight loss per cycle, showing an excellent rate performance. The high stable cyclability and improved rate performance are attributed to the fact that the nano-silicon particles are electrically connected by the nest-like PANI so that dispersity of the nano-silicon will be greatly enhanced and the conductivity could be improved. Moreover, Si/PANI composite accommodates a large volume expansion because of the flexible nest-like PANI matrix.

\subsubsection{Poly(ethylene glycol) (PEG) /polyethylene oxide (PEO)}

PEG or PEO refers to an oligomer or polymer of ethylene oxide. Two names are chemically synonymous, but historically PEG has tended to refer to oligomers and polymers with a molecular mass below 20,000 g/mol, while PEO to polymers with a molecular mass above $20,000 \mathrm{~g} / \mathrm{mol}$. PEG or PEO has a chain structure of $\mathrm{HO}-\mathrm{CH}_{2}-\left(\mathrm{CH}_{2}-\mathrm{O}-\mathrm{CH}_{2}-\right)_{n}-\mathrm{CH}_{2}-\mathrm{OH}$. PEG and PEO have been widely investigated as the electrolytes in lithium batteries. The ionic transport mechanism is that $\mathrm{Li}^{+}$ions move from one coordination site to another revolved by the polymer chains. On one hand, the reaction between lithium and PEG is not reversible at ambient conditions. On the other, PEO is stable even in contact with lithium at $60{ }^{\circ} \mathrm{C}$. Hence, until very recently, Xiao et al. (2010) and Xiong et al. (2011) reported the improved lithium storage by introduction of PEO and PEG, respectively, there have been no literature reports that ethylene oxide units in polymers are used for reversible lithium storage. In the case of $\mathrm{MoS}_{2} / \mathrm{PEO}$ nanocomposite, $\mathrm{PEO}$ is inserted into the interlay spacing of exfoliated $\mathrm{MoS}_{2}$ to form $\mathrm{Li}_{0.12}(\mathrm{PEO})_{\mathrm{y}} \mathrm{MoS}_{2}$. A small amount of PEO $\left(\mathrm{Li}_{0.12}(\mathrm{PEO})_{0.05} \mathrm{MoS}_{2}\right)$ not only doubles the initial capacity of the pristine $\mathrm{MoS}_{2}$ but significantly improves the capacity retention. This nanocomposite delivers a charge/discharge capacity of above $900 \mathrm{mAh} / \mathrm{g}$ after 50 cycles, as shown in Figure 30, during which PEO stabilizes the disordered structure of the exfoliated $\mathrm{MoS}_{2}$ throughout the cycling regime to accommodate more $\mathrm{Li}^{+}$ions and accelerates the $\mathrm{Li}^{+}$transportation between $\mathrm{MoS}_{2}$ sheets and electrolyte. While higher amounts of PEO may decrease the lithium accessibility and electronic conductivity, resulting in a higher internal resistance and charge transfer. Xiong et al. reported a novel nanonet that is composed of $\mathrm{SnO}_{2}$ nanoparticles and PEG chains. The synergic properties and functionalities of these two components enable this composite to exhibit an 
unexpectedly high lithium storage over the theoretical capacity of $\mathrm{SnO}_{2}$. Lithium is stored in the PEG-SnO $\mathrm{O}_{2}$ nanocomposites, where the crosslinked $\mathrm{SnO}_{2}$ particles pave the electron paths and the revolved EO segments provide the coordination centers. When the composite electrode is charged, those $\mathrm{Li}^{+}$ions coordinated with $\mathrm{EO}$ segments are reduced and deposited, and more $\mathrm{Li}^{+}$ions from electrolytes will be reduced at this site to form the lithium clusters. When the composite electrode is discharged, lithium clusters transform into $\mathrm{Li}^{+}$ions to release the extra capacity.
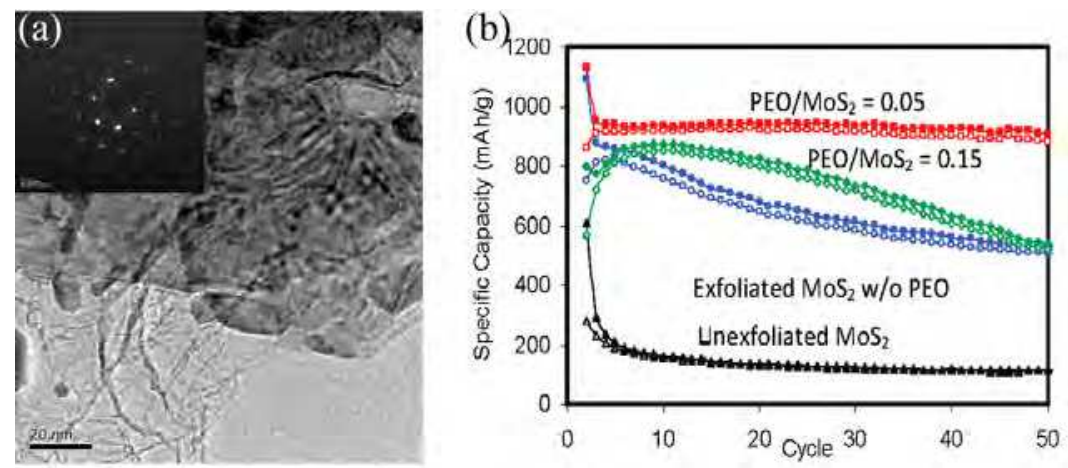

Fig. 30. a) TEM images for exfoliated PEO/ $\mathrm{MoS}_{2}=0.05$ composite; and b) comparison of cycling stability for unexfoliated $\mathrm{MoS}_{2}$ and exfoliated $\mathrm{MoS}_{2}$ with different amounts of PEO. All cells were cycled between 0.01 and $3.0 \mathrm{~V}$ at $50 \mathrm{~mA} / \mathrm{g}$. Solid symbols, Li insertion; open symbols, Li extraction. (Xiao et al., 2010)

\subsection{Heterogeneous nanoarchitectured thin-film electrodes}

Researchers have developed a new structural strategy for high performance electrodes, namely, "nanoarchitectured thin-film electrode," which is composed of a direct growth of highly conductive one-dimensional (1D) metal nanorods onto a metallic current collector followed by attachment of active materials on the surface of 1D metal nanorods. Due to the merit of this unique structure, LIBs can achieve high specific capacities and superior rate capabilities because of the formation of 3D conductive networks by direct connections among active materials, highly conductive 1D pathways, and a metallic current collector. Additionally, the large free space secured by 1D nanostructures effectively alleviates the huge volume changes that occur during $\mathrm{Li}^{+}$insertion/extraction, leading to a suppressed electrode degradation (Park et al., 2011). This strategy obviates the use of binders, electron conducting additives, and solvents traditionally used for electrode fabrication. Following this strategy, many heterogeneous nanoarchitectured electrodes have been synthesized, such as $\mathrm{Sn}$ coated $\mathrm{TiO}_{2}$ nanotube array (Kim et al., 2010), NiO coated silicon nanowire array (Qiu et al., 2010), carbon-coated $\mathrm{ZnO}$ nanorod array (Liu, et al., 2009), $\mathrm{MnO}_{2} /$ carbon nanotube array (Reddy et al., 2009), $\mathrm{Cu}_{6} \mathrm{Sn}_{5}$-coated $\mathrm{TiO}_{2}$ nanotube arrays (Xue et al., 2011), etc. For example, carbon-coated $\mathrm{SnO}_{2}$ nanorod array directly grown on Fe-Co-Ni alloy substrate (Ji et al. 2010) shows a good capacity retention at $585 \mathrm{mAh} / \mathrm{g}$ after 50 cycles at 500 $\mathrm{mA} / \mathrm{g}$ and cyclability (stable $320 \mathrm{mAh} / \mathrm{g}$ at 3,000 mA/g). Ortiz et al. (2010) fabricated nanoarchitectured crystalline $\mathrm{SnO}$ nanowires $/ \mathrm{TiO}_{2}$ nanotubes composites electrodes. As shown in Figure 31, the composites consist of tin and $\mathrm{SnO}$ nanowires grown onto $\mathrm{TiO}_{2}$ 
nanotubes by anodization of titanium and tin electrodeposition. The $2 \mu \mathrm{m}$ length tin-based nanowires supported on self-organized $\mathrm{TiO}_{2}$ provide a real capacities of 95 and $140 \mu \mathrm{A} \mathrm{h}$ $\mathrm{cm}^{-2}(\sim 675 \mathrm{mAh} / \mathrm{g})$ under high rates of $4 \mathrm{C}$ and $2 \mathrm{C}$, keeping 70 and $85 \%$ initial capacity over 50 cycles, respectively.
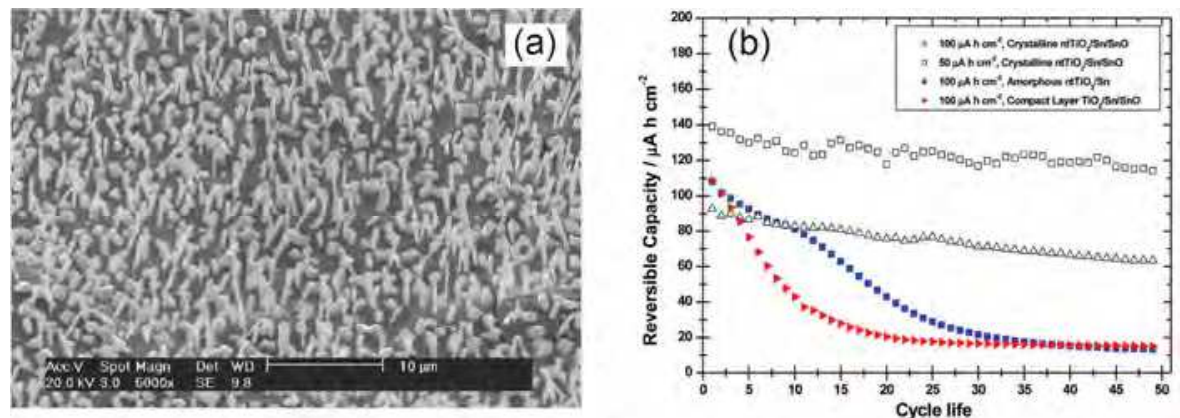

Fig. 31. a) SEM image of tin nanowires supported onto $\mathrm{TiO}_{2}$ nanotube arrays; and b) cycle life performance under galvanostatic regime at a current density of $100 \mu \mathrm{Acm}^{-2}$. (Oritz et al., 2010)

These heterogeneous nanoarchitectured thin-film electrodes have demonstrated to display a stable capacity over many cycles, whereas an increase in film thickness is urgently required to provide the sufficiently active material because stress-induced cracking would lead to a poor cycling performance and rate capability owing to an increase in film thickness. An alternative strategy for tackling this problem is to design the functional structures that buffer the stress during the charge/discharge processes. Zhang et al. (2010) synthesized a Ni nanocone-array (NCA) supported Si architecture composed of many cylinders with regular domes on top to serve as the anode material for LIBs. In this configuration, Ni NCAs facilitate the charge collection and transport, supporting the electrode structure and acting as the inactive confining buffers. These nanostructured $\mathrm{Si}$ electrodes show an impressive electrochemical performance with a high capacity of around $2400 \mathrm{mAh} / \mathrm{g}$ at $0.2 \mathrm{C}$ rate over 100 cycles with superior capacity retention of $99.8 \%$ per cycle. These Ni NCAs also exhibit an excellent lithium storage capability at high charging and discharging rates of $1 \mathrm{C}$ or $2 \mathrm{C}$ (Figure 32).
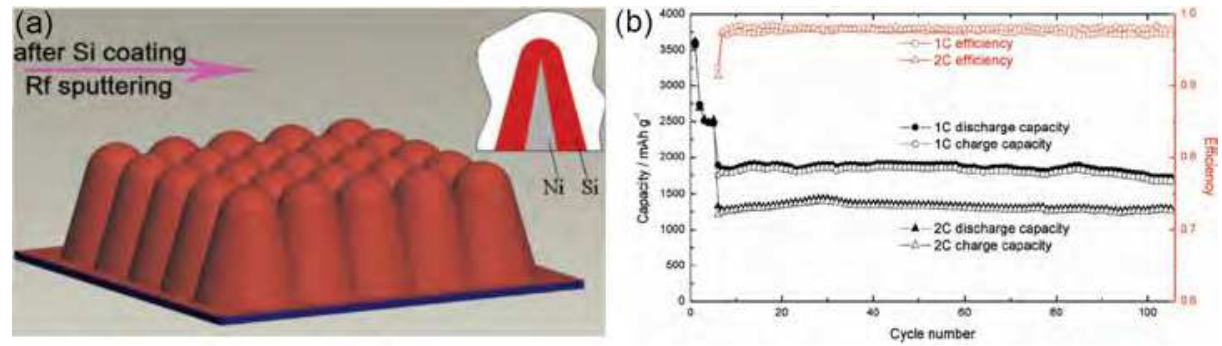

Fig. 32. a) Schematic diagram that illustrates the fabrication of a nickel nanocone-array supported silicon anode architecture; and b) discharge/charge capacity and Coulombic efficiency versus cycle number for a nanostructured $\mathrm{Si}$ electrode at $1 \mathrm{C}$ and $2 \mathrm{C}$ rates after 0.2 $\mathrm{C}$ for 5 cycles with a cut-off voltage of $10 \mathrm{mV}-1.6 \mathrm{~V}$. (Zhang et al., 2010) 
Recently, Krishnan et al. (2011) synthesized a functionally strain-graded C-Al-Si anode composite using DC magnetron sputtering. As shown in Figure 33, the composites consist of an array of nanostructures each comprising an amorphous carbon nanorod ( 170 $\mathrm{nm}$ long) with an intermediate layer of aluminium ( $13 \mathrm{~nm}$ thick) that is finally capped by a silicon nanoscoop ( $\sim 40 \mathrm{~nm}$ thick) on the very top. The gradation in strain arises from the graded levels of volumetric expansion in these three components on alloying with lithium. The introduction of aluminium as an intermediate layer enables the gradual transition of strain from carbon to silicon, thereby minimizing the mismatch at interfaces between differentially strained materials and enabling the stable operation of electrode under high-rate charge/discharge conditions. C-Al-Si composites can provide an average capacity of about $412 \mathrm{mAh} / \mathrm{g}$ with a power output of $100 \mathrm{~kW} / \mathrm{kg}$ continuously over 100 cycles. Even when the power output is as high as $250 \mathrm{~kW} / \mathrm{kg}$, the average capacity over 100 cycles is still at the level of $90 \mathrm{mAh} / \mathrm{g}$.
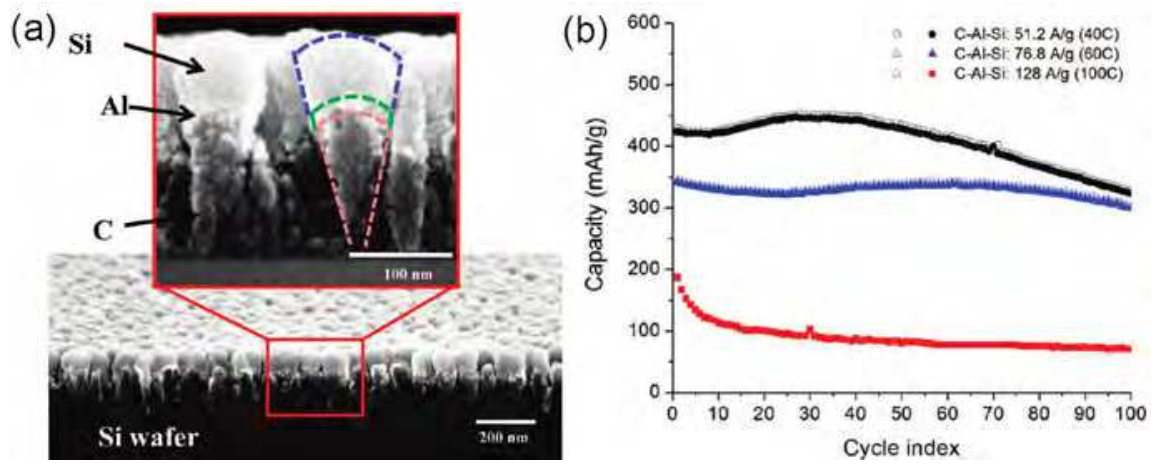

Fig. 33. a) Cross-sectional SEM view of C-Al-Si nanoscoop structures deposited on a Si wafer. A magnified cross-section image is also shown with the $\mathrm{C}, \mathrm{Al}$, and $\mathrm{Si}$ regions demarcated; and b) Capacity as a function of cycle index shown for C-Al-Si electrodes at $51.2,76.8$, and $128 \mathrm{~A} / \mathrm{g}$ over 100 cycles. The empty symbols represent the discharge capacity while the filled symbols represent the charge capacity in each case. (Krishnan et al., 2011)

\section{Summary and outlook}

In this chapter, we have reviewed the recent trends and developments of using heterogeneous nanostructures as the electrode materials for LIBs. It has been illustrated that heterogeneous nanostructured electrodes materials have advantages over the conventional single component nanostructured electrode materials for LIBs, though one has to face some significant challenges before these heterogeneous nanostructured can be large-scale utilized in practical LIBs. There are many novel heterogeneous nanostructured cathode and anode materials that have been reported to show a high rate capability. But the dream is still there as to design and/or develop novel electrodes with much higher performance at high charge/discharge rates.

For example, one has optimized the performance of plenty of LIBs by extensively studying the influences of the morphology, particle size, loading content, and mixing procedure of different components, while the synergic mechanism of heterogeneous nanostructured 
components remains to be further clarified and key variables that determine the interface interaction between different components have to be identified. Over the last five years, tremendous progress has been made in addressing these challenges. Through a survey of those studies from the viewpoints of the synergic mechanism of heterogeneous nanostructured components, one can find that maximizing both ion and electron transportations in the cathodes and anodes while maintaining the good cycling stability can be fundamentally important in designing and developing novel electrodes for HEVs, PHEVs or EVs. Despite the variations of the reported performance, a consistent trend has been emerging that high power density of $60 \mathrm{~kW} / \mathrm{kg}$ and high energy density of $282 \mathrm{Wh} / \mathrm{kg}$ for $\mathrm{SnO}_{2} / \mathrm{V}_{2} \mathrm{O}_{5}$ core/shell composite thin-film cathodes and average capacities of $\sim 412$ $\mathrm{mAh} / \mathrm{g}$ and a power output of $100 \mathrm{~kW} / \mathrm{kg}$ for C-Al-Si composites thin-film anodes with rather impressive cycling lifetimes up to 100 cycles at practical charge/discharge rate can be reproducibly achieved. High rate performance and long cycling lifetimes have most frequently been observed when four critical factors are properly addressed: i) use of nanoscale-dimension electroactive materials that allow a rapid lithium ion diffusion; ii) efficient electronic and ionic conduction from electro-active materials to the current collectors that can be maintained during the cycling; iii) incorporation of void/free space or softer inactive material matrices or additives to accommodate the volume variation; iv) good adhesion between different heterogeneous components by constructing special gradient structure can be formed, which can effectively tolerate the different expansion and contraction efficiency of heterogeneous components during the continual lithium insertion/extraction.

Certainly, it is realized that all current heterogeneous nanostructures have their own drawbacks. For example, heterogeneous nanoarchitectured thin-film electrodes can become mechanically unstable when grown excessively long in the axial direction. This will limit their uses as on-chip power sources for MEMS devices and other applications where the areal footprint is at a premium and a high areal energy density is needed. Here, we tend to propose a future heterogeneous nanoarchitectured thin-film electrode as shown in Figure 34. This proposed heterogeneous nanoarchitectured thin-film electrode is composed of a well ordered branched array with a conformal polymer coating layer grown on a conductive substrate. The backbone is an active electrode material, while the branched is active electrode materials with the role of optimizing the lithium ion/electron transportation or inactive electrode materials to depress the side interaction between electrode and electrolyte. The conformal polymer coating layer acts as a conductive layer and binders. There are a few advantages of this proposed structure: (i) the interconnectivity of the electrode material provides a 3-D continuous lithium ion and electron pathway and can increase the mechanical strength of branched arrays; (ii) the interconnected pores accommodate the volume variations of the electrode material and allow the electrolyte to rapidly penetrate and uniformly contact the electrode material; (iii) 3-D interconnected coating of polymer facilitates a fast electron transfer into the 3-D continuous framework, allowing the electrons to directly transport to the electrode materials due to its conformality, effectively alleviating the stress due to its resiliency that ensures mechanically stability for longer arrays, and acting as a binder to strengthen the adhesion between the branched and backbone materials; and (iv) merits of the material being directly contacted with a conductive substrate, in which electrons can easily transfer from the conductive substrate to the electroactive backbone and branched material as well as to the coating conductive polymer shell. 


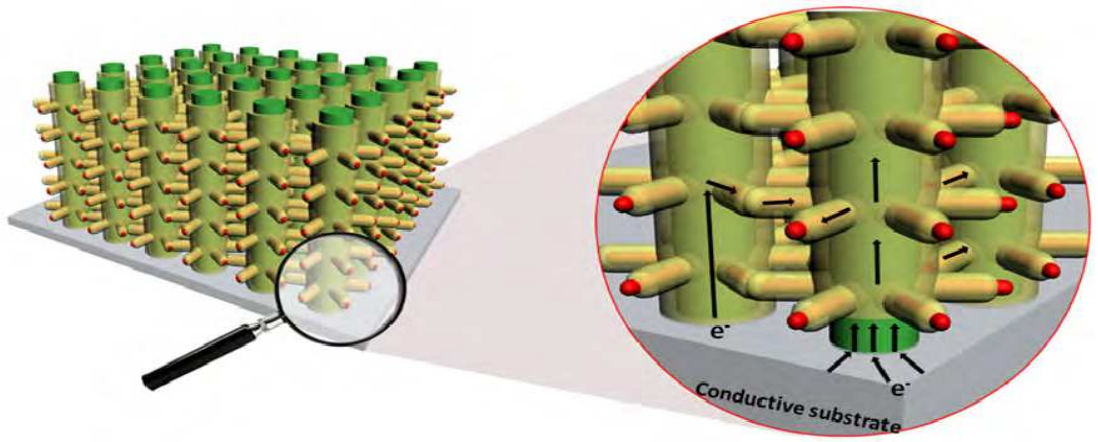

Fig. 34. Future heterogeneous nanoarchitectured thin-film electrodes. The backbone material is in green, the branch material in red, and conductive polymer in yellow.

The progress described here suggests that future research should explore more structurally and compositionally complex hierarchical composite nanostructures with internal void/pore space. Considering the potential large-scale energy applications of LIBs, such as in hybrid and plug-in electric vehicles or electrical power storage, mass production possibility, manufacturability, safety factors, and cost of the heterogeneous nanostructrued materials will also be important to the eventual success in their practical applications.

It is imperative that we as scientists and engineers put all our efforts into exploiting more technologically advanced heterogeneous nanostructures to fulfil the future requirements of LIBs.

\section{Acknowledgment}

This work was financially supported by NSFC (No. 91022018, 21025104), National Basic Research Program of China (No. 2011CBA00501, 2011CB935904), Fujian Program (No. 2009HZ0004-1), and FJIRSM fund (No. SZD09003-1, 2010KL002).

\section{References}

Alcantara, R.; Jaraba, M.; Lavela, P. \& Tirado, J.-L. (2004). X-ray diffraction and electrochemical impedance spectroscopy study of zinc coated $\mathrm{LiNi}_{0.5} \mathrm{Mn}_{1.5} \mathrm{O}_{4}$ electrodes. Journal of Electroanalytical Chemistry, Vol.566, No.1, (May 2004), pp.187192, ISSN 0022-0728

Arrebola, J.; Caballero, A.; Hernan, L. \& Morales, J. (2010). Re-examining the effect of ZnO on nanosized $5 \mathrm{~V} \mathrm{LiNi}_{0.5} \mathrm{Mn}_{1.5} \mathrm{O}_{4}$ spinel: An effective procedure for enhancing its rate capability at room and high temperatures. Journal of Power Sources, Vol.195, No.13, (July 2010), pp. 4278-4284, ISSN 0378-7753

Arrebola, J.; Caballero, A.; Hernan, L.; Morales, J.; Castellon, E.R. \& Barrado, J.-R.-R. (2007). Effects of coating with gold on the performance of nanosized $\mathrm{LiNi}_{0.5} \mathrm{Mn}_{1.5} \mathrm{O}_{4}$ for lithium batteries. Journal of the Electrochemical Society, Vol.154, No.3, (January 2007), pp.A178-A184, ISSN 0013-4651

Arrebola, J.; Caballero, A.; Hernan, L.; Morales, J. \& Castellon, E.-R. (2005). Adverse effect of $\mathrm{Ag}$ treatment on the electrochemical performance of the $5 \mathrm{~V}$ nanometric spinel 
$\mathrm{LiNi}_{0.5} \mathrm{Mn}_{1.5} \mathrm{O}_{4}$ in lithium cells. Electrochemical and Solid State Letters, Vol.8, No.6, (April 2005), pp.A303-A307, ISSN 1099-0062

Bakenov, Z. \& Taniguchi, I. (2010). Electrochemical performance of nanocomposite $\mathrm{LiMnPO}_{4} / \mathrm{C}$ cathode materials for lithium batteries. Electrochemistry Communications, Vol.12, No.1, (January 2010), pp. 75-78, ISSN 1388-2481

Boyano, I.; Blazquez, J.; de Meatza, I.; Bengoechea, M.; Miguel, O.; Grande, H.; Huang, Y. \& Goodenough, J. (2010). Preparation of $\mathrm{C}-\mathrm{LiFePO}_{4} /$ polypyrrole lithium rechargeable cathode by consecutive potential steps electrodeposition. Journal of Power Sources, Vol.195, No.16, (August 2010), pp. 5351-5359, ISSN 0378-7753

Cai, C.; Pol, V.; Guan, D. \& Wang, Y. (2011). Solution processing of $\mathrm{V}_{2} \mathrm{O}_{5}-\mathrm{WO}_{3}$ composite films for enhanced Li-ion intercalation properties. Journal of Alloys and Compounds, Vol.509, No.3, (January 2011), pp. 909-915, ISSN 0925-8388

Cai, J.-J.; Zuo, P.-J.; Cheng, X.-Q.; Xu, Y.-H. \& Yin, G.-P. (2010). Nano-silicon/polyaniline composite for lithium storage. Electrochemistry Communications, Vol.12, No.11, (November 2010), pp. 1572-1575, ISSN 1388-2481

Cao, A.-M.; Hu, J.-S.; Liang, H.-P. \& Wan, L.-J. (2005). Self-assembled vanadium pentoxide $\left(\mathrm{V}_{2} \mathrm{O}_{5}\right)$ hollow microspheres from nanorods and their application in lithium-ion batteries. Angewandte Chemie-International Edition, Vol.44, No.28, (June 2005), pp.4391-4395, ISSN 1433-7851

Chan, C.; Peng, H.; Twesten, R.; Jarausch, K.; Zhang, X. \& Cui, Y. (2007). Fast, completely reversible $\mathrm{Li}$ insertion in vanadium pentoxide nanoribbons. Nano Letters, Vol.7, No.2, (February 2007), pp. 490-495, ISSN 1530-6984

Chew, S.-Y.; Guo, Z.-P.; Wang, J.-Z.; Chen, J.; Munroe, P.; Ng, S.-H.; Zhao, L. \& Liu, H.-K. (2007). Novel nano-silicon/polypyrrole composites for lithium storage. Electrochemistry Communcations, Vol.9, No.5, (May 2007), pp. 941-946, ISSN 13882481

Chen, W.; Qie, L.; Yuan, L.; Xia, S.; Hu, X.; Zhang, W. \& Huang, Y. (2011). Insight into the improvement of rate capability and cyclability in $\mathrm{LiFePO}_{4} /$ polyaniline composite cathode. Electrochimica Acta, Vol.56, No.6, (February 2011), pp. 2689-2695, ISSN 0013-4686

Chen, Z.-H. \& Dahn, J.-R. (2002). Effect of a $\mathrm{ZrO}_{2}$ coating on the structure and electrochemistry of $\mathrm{Li}_{x} \mathrm{CoO}_{2}$ when cycled to $4.5 \mathrm{~V}$. Electrochemcial and Solid State Letters, Vol.5, No.10, (October 2002), pp.A213-A216, ISSN 1099-0062

Choi, J.; Jin, J.; Jung, I.-G.; Kim, J.-M.; Kim, H.-J. \& Son, S.-U. (2011). SnSe 2 nanoplategraphene composites as anode materials for lithium ion batteries. Chemical Communications, Vol.47, No.18, (March 2011), pp.5241-5243, ISSN 1359-7345

Choi, K.; Jeon, J.; Park, H. \& Lee, S. (2010). Electrochemical performance and thermal stability of $\mathrm{LiCoO}_{2}$ cathodes surface-modified with a sputtered thin film of lithium phosphorus oxynitride. Journal of Power Sources, Vol.195, No.24, (December 2010), pp. 8317-8321, ISSN 0378-7753

Chou, S.-L.; Wang, J.-Z.; Choucair, M.; Liu, H.-K.; Stride, J.-A. \& Dou, S.-X. (2010). Enhanced reversible lithium storage in a nanosize silicon/graphene composite. Electrochemistry Communications, Vol.12, No.2, (February 2010), pp.303-306, ISSN 1388-2481

Cui, L.; Shen, J.; Cheng, F.; Tao, Z. \& Chen, J. (2011). SnO 2 nanoparticles@polypyrrole nanowires composite as anode materials for rechargeable lithium-ion batteries. 
Journal of Power Sources, Vol.196, No.4, (February 2011), pp. 2195-2201, ISSN 03787753

Dimesso, L.; Jacke, S.; Spanheimer, C. \& Jaegermann, W. (2011). Investigation on 3dimensional carbon foams $/ \mathrm{LiFePO}_{4}$ composites as function of the annealing time under inert atmosphere. Journal of Alloys and Compounds, Vol.509, No.9, (March 2011), pp. 3777-3782, ISSN 0925-8388

Ding, Y.-L.; Xie, J.; Cao, G.-S.; Zhu, T.-J.; Yu, H.-M. \& Zhao, X.-B. (2011). Single-crystalline $\mathrm{LiMn}_{2} \mathrm{O}_{4}$ nanotubes synthesized via template-engaged reaction as cathodes for high-power lithium ion batteries. Advanced Functional Materials, Vol.21, No.2, (January 2011), pp. 384-355, ISSN 1616-301X

Drezen, T.; Kwon, N.; Bowen, P.; Teerlinck, I.; Isono, M. \& Exnar, I. (2007). Effect of particle size on $\mathrm{LiMnPO}_{4}$ cathodes. Journal of Power Sources, Vol.174, No.2, (December 2007), pp. 949-953, ISSN 0378-7753

Ellis, B.; Lee, K. \& Nazar, L. (2010). Positive Electrode Materials for Li-Ion and Li-Batteries. Chemistry of Materials, Vol.22, No.3, (February 2010 ), pp. 691-714, ISSN 0897-4756

Fan, Y.; Wang, J.; Tang, Z.; He, W. \& Zhang, J. (2007). Effects of the nanostructured $\mathrm{SiO}_{2}$ coating on the performance of $\mathrm{LiNi}_{0.5} \mathrm{Mn}_{1.5} \mathrm{O}_{4}$ cathode materials for high-voltage Liion batteries. Electrochimica Acta, Vol.52, No.11, (March 2007), pp. 3870-3875, ISSN 0013-4686

Fang, H.; Li, L. \& Li, G. (2007). A low-temperature reaction route to high rate and high capacity $\mathrm{LiNi}_{0.5} \mathrm{Mn}_{1.5} \mathrm{O}_{4}$. Journal of Power Sources, Vol.167, No.1, (May 2007), pp. 223227, ISSN 0378-7753

Fang, H.; Li, L. \& Li, G. (2007). Hydrothermal synthesis of electrochemically active $\mathrm{LiMnPO}_{4}$. Chemistry Letters, Vol.36, No.3, (March 2007), pp. 436-437, ISSN 03667022

Fang, H.; Li, L.; Yang., Y; Yan, G. \& Li, G. (2008). Low-temperature synthesis of highly crystallized $\mathrm{LiMn}_{2} \mathrm{O}_{4}$ from alpha manganese dioxide nanorods. Journal of Power Sources, Vol.184, No.2, (October 2008), pp. 494-497, ISSN 0378-7753

Guo, Y.; Hu, J. \& Wan L. (2008). Nanostructured Materials for Electrochemical Energy Conversion and Storage Devices. Advanced Materials, Vol.20, No.23, (December 2008), pp. 2878-2887, ISSN 0935-9648

Ha, H.-W.; Yun, N.-J.; Kim, M.-H.; Woo, M.-H. \& Kim, K. (2006). Enhanced electrochemical and thermal stability of surface-modified $\mathrm{LiCoO}_{2}$ cathode by $\mathrm{CeO}_{2}$ coating. Electrochimica Acta, Vol.51, No.16, (April 2006), pp.3297-3302, ISSN 0013-4686

He, Z.-Q.; Xiong, L.-Z.; Liu, W.-P.; Wu, X.-M.; Chen, S. \& Huang, K.-L. (2008). Synthesis and electrochemical properites of $\mathrm{SnO}_{2}$-polyaniline composite. Journal of Central South University Technology, Vol.15, No.2, (April 2008), pp. 214-217, ISSN 1005-9784

Huang, H.; Yin, S. \& Nazar, L. (2001). Approaching theoretical capacity of $\mathrm{LiFePO}_{4}$ at room temperature at high rates. Electrochemical and Solid State Letters, Vol.4, No.10, (October 2001), pp. A170-A172, ISSN 1099-0062

Huang, X.-H.; Tu, J.-P.; Xia, X.-H.; Wang, X.-L. \& Xiang, J.-Y. (2008). Nickel foam-supported porous $\mathrm{NiO} /$ polyaniline film as anode for lithium ion batteries. Electrochemistry Communications, Vol.10, No.9, (September 2008), pp. 1288-1290, ISSN 1388-2481

Huang, Y. \& Goodenough, J. (2008). High-rate $\mathrm{LiFePO}_{4}$ lithium rechargeable battery promoted by electrochemically active polymers. Chemistry of Materials, Vol.20, No.23, (December 2008), pp. 7237-7241, ISSN 0897-4756 
Hu, S.-K.; Cheng, G.-H.; Cheng, M.-Y.; Hwang, B.J. \& Santhanam, R. (2009). Cycle life improvement of $\mathrm{ZrO}_{2}$-coated spherical $\mathrm{LiNi}_{1 / 3} \mathrm{Co}_{1 / 3} \mathrm{Mn}_{1 / 3} \mathrm{O}_{2}$ cathode material for lithium ion batteries. Journal of Power Sources, Vol.188, No.2, (March 2009), pp.564569, ISSN 0378-7753

Ji, X.; Huang, X.; Liu, J.; Jiang, J.; Lin, X.; Ding, R.; Hu, Y.; Wu, F. \& Li, Q. (2010). Carboncoated $\mathrm{SnO}_{2}$ nanorod array for lithium-ion battery anode material. Nanoscale Research Letters, Vol.5, No.3, (March 2010), pp.649-653, ISSN 1931-7573

Jung, K.-H.; Kim, H.-G. \& Park, Y.-J. (2011). Effects of protecting layer [Li,La] $\mathrm{TiO}_{3}$ on electrochemical properties of $\mathrm{LiMn}_{2} \mathrm{O}_{4}$ for lithium batteries. Journal of Alloys and Compounds, Vol.509, No.12, (March 2011), pp. 4426-4432, ISSN 0925-8388

Kang, H.-B.; Myung, S.-T.; Amine, K.; Lee, S.-M. \& Sun, Y.-K. (2010). Improved electrochemical properties of BiOF-coated $5 \mathrm{~V}$ spinel $\mathrm{Li}\left[\mathrm{Ni}_{0.5} \mathrm{Mn}_{1.5}\right] \mathrm{O}_{4}$ for rechargeable lithium batteries. Journal of Power Sources, Vol.195, No.7, (April 2010), pp. 2023-2028, ISSN 0378-7753

Kim, B.; Kim, C.; Ahn, D.; Moon, T.; Ahn, J.; Park, Y. \& Park, B. (2007). Nanostructural effect of $\mathrm{AlPO}_{4}$-nanoparticle coating on the cycle-life performance in $\mathrm{LiCoO}_{2}$ thin films. Electrochemical and Solid-State Letters, Vol.10, No.2, (December 2006), pp. A32-A35, ISSN 1099-0062

Kim, B.; Kim, C.; Kim, T.-G.; Ahn, D. \& Park, B. (2006). The effect of $\mathrm{AlPO}_{4}$-coating layer on the electrochemical properties in $\mathrm{LiCoO}_{2}$ thin films. Journal of the Electrochemical Society, Vol.153, No.9, (July 2006), pp.A1773-A1777, ISSN 0013-4651

Kim, H.-S.; Kang, S.-H.; Chung, Y.-H. \& Sung, Y.-E. (2010). Conformal Sn coated $\mathrm{TiO}_{2}$ nanotube arrays and its electrochemical performance for high rate lithium-ion batteries. Electrochemical and Solid-State Letters, Vol.13, No.2, (November 2009), pp.A15-A18, ISSN 1099-0062

Koenig, G.-M.; Belharouak, I.; Deng, H.; Sun, Y. \& Amine, K. (2011). Composition-tailored synthesis of gradient transition metal precursor particles for lithium-ion battery cathode materials. Chemistry of Materials, Vol.23, No.7, (April 2011), pp. 1954-1963, ISSN 0897-4756

Koltypin, M.; Pol, V.; Gedanken, A. \& Aurbach, D. (2007). The study of carbon-coated $\mathrm{V}_{2} \mathrm{O}_{5}$ nanoparticles as a potential cathodic material for Li rechargeable batteries. Journal of the Electrochemical Society, Vol.154, No.7, (May 2007), pp. A605-A613, ISSN 00134651

Konarova, M. \& Taniguchi, I. (2008). Preparation of $\mathrm{LiFePO}_{4} / \mathrm{C}$ composite powders by ultrasonic spray pyrolysis followed by heat treatment and their electrochemical properties. Materials Research Bulletin, Vol.43, No.12, (December 2008), pp. 33053317, ISSN 0025-5408

Krishnan, R.; Lu, T.-M. \& Koratkar, N. (2011). Functionally strain-graded nanoscoops for high power Li-ion battery anodes. Nano Letters, Vol.11, No.2, (December 2010), pp. 377-384, ISSN 1530-6984

Lee, H.-W.; Muralidharan, P.; Ruffo, R.; Mari, C.; Cui, Y. \& Kim, D. (2010). Ultrathin spinel $\mathrm{LiMn}_{2} \mathrm{O}_{4}$ nanowires as high power cathode materials for Li-ion batteries. Nano Letters, Vol.10, No.10, (October 2010), pp. 3852-3856, ISSN 1530-6984

Lepage, D.; Michot, C.; Liang, G.; Gauthier, M. \& Schougaard, S. (2011). A Soft Chemistry Approach to Coating of $\mathrm{LiFePO}_{4}$ with a Conducting Polymer. Angewandte ChemieInternational Edition, DOI: 10.1002/anie.201101661, ISSN 1433-7851 
Liang, M. \& Zhi L. (2009). Graphene-based electrode materials for rechargeable lithium batteries. Journal of Materials Chemistry, Vol.19, No.33, (May 2009), pp. 5871-5878, ISSN 0959-9428

Li, N.; Liu, G.; Zhen, C.; Li, F.; Zhang, L.-L. \& Cheng, H.-M. (2011). Battery performance and photocatalytic activity of mesoporous anatase $\mathrm{TiO}_{2}$ nanospheres/graphene composites by template-free self-assembly. Advanced Functional Materials, Vol.21, No.9, (May 2011), pp.1717-1722, ISSN 1616-301X

Li, J.; Klopsch, R.; Stan, M.-C.; Nowak, S.; Kunze, M.; Winter, M. \& Passerini, S. (2011). Synthesis and electrochemical performance of the high voltage cathode material $\mathrm{Li}\left[\mathrm{Li}_{0.2} \mathrm{Mn}_{0.56} \mathrm{Ni}_{0.16} \mathrm{Co}_{0.08}\right] \mathrm{O}_{2}$ with improved rate capability. Journal of Power Sources, Vol.196, No.10, (May 2011), pp.4821-4825, ISSN 0378-7753

Liu, D.-Q.; Liu, X.-Q. \& He, Z.-Z. (2007). The elevated temperature performance of $\mathrm{LiMn}_{2} \mathrm{O}_{4}$ coated with $\mathrm{Li}_{4} \mathrm{Ti}_{5} \mathrm{O}_{12}$ for lithium ion battery. Materials Chemistry and Physics, Vol.105, No.2-3, (October 2007), pp. 362-366, ISSN 0254-0584

Liu, G.-Q.; Kuo, H.-T.; Liu, R.-S.; Shen, C.-H.; Shy, D.-S.; Xing, X.-K. \& Chen, J.-M. (2010). Study of electrochemical properties of coating $\mathrm{ZrO}_{2}$ on $\mathrm{LiCoO}_{2}$. Journal of Alloys and Compounds, Vol.496, No.1-2, (April 2010), pp.512-516, ISSN 0925-8388

Liu, J.; Li, Y.; Ding, R.; Jiang, J.; Hu, Y.; Ji, X.; Chi, Q.; Zhu, Z. \& Huang, X. (2009). Carbon/ZnO nanorod array electrode with significantly improved lithium storage capability. Journal of Physical Chemistry C, Vol.113, No.13, (April 2009), pp.53365339, ISSN 1932-7447

Liu, J. \& Manthiram, A. (2009). Understanding the improvement in the electrochemical properties of surface modified $5 \mathrm{~V} \mathrm{LiMn}{ }_{1.42} \mathrm{Ni}_{0.42} \mathrm{Co}_{0.16} \mathrm{O}_{4}$ spinel cathodes in lithiumion cells. Chemistry of Materials, Vol.21, No.8, (Apirl 2009), pp.1695-1707, ISSN 08974756

Liu, R.; Duay, J. \& Lee, S. (2011). Heterogeneous nanostructured electrode materials for electrochemical energy storage. Chemical Communications, Vol.47, No.5, (November 2010), pp. 1384-1404, ISSN 1359-7345

Lou, X.; Li, C. \& Archer, L. (2009). Designed synthesis of coaxial $\mathrm{SnO}_{2} @$ carbon hollow nanospheres for highly reversible lithium storage. Advanced Materials, Vol.21, No.24, (June 2009), pp. 2536-2539, ISSN 0935-9648

Martha, S.-K.; Markovsky, B.; Grinblat, J.; Gofer, Y.; Haik, O.; Zinigrad, E.; Aurbach, D.; Drezen, T.; Wang, D.; Deghenghi, G. \& Exnar, I. (2009). LiMnPO 4 as an advanced cathode material for rechargeable lithium batteries. Journal of the Electrochemical Society, Vol.156, No.7, (May 2009), pp. A541-A552, ISSN 0013-4651

Murugan, A.; Muraliganth, T. \& Manthiram, A. (2008). Rapid microwave-solvothermal synthesis of phospho-olivine nanorods and their coating with a mixed conducting polymer for lithium ion batteries. Electrochemistry Communications, Vol.10, No.6, (January 2008), pp. 903-906, ISSN 1388-2481

Odani, A.; Pol, V.; Plo, S.; Koltypin, M.; Gedanken, A. \& Aurbach, D. (2006). Testing carboncoated $\mathrm{VO}_{\mathrm{x}}$ prepared via reaction under autogenic pressure at elevated temperature as Li-insertion materials. Advanced Materials, Vol.18, No.11, (June 2006), pp. 14311436, ISSN 0935-9648

Oh, S.-M.; Oh, S.-W.; Yoon, C.-S.; Scrosati, B.; Amine, K. \& Sun, Y.-K. (2010). Highperformance carbon- $\mathrm{LiMnPO}_{4}$ nanocomposite cathode for lithium batteries. 
Advanced Functional Materials, Vol.20, No.19, (October 2010), pp. 3260-3265, ISSN 1616-301X

Oh, Y.; Ahn, D.; Nam, S. \& Park, B. (2010). The effect of $\mathrm{Al}_{2} \mathrm{O}_{3}$-coating coverage on the electrochemical properties in $\mathrm{LiCoO}_{2}$ thin films. Journal of Solid State Electrochemistry, Vol.14, No.7, (July 2010), pp. 1235-1240, ISSN 1432-8488

Ortiz, G.; Hanzu, I.; Lavela, P.; Knauth, P.; Tirado, J. \& Djenizian, T. (2010). Nanoarchitectured $\mathrm{TiO}_{2} / \mathrm{SnO}$ : a future negative electrode for high power density Li-ion microbatteries? Chemistry of Materials, Vol.22, No.5, (March 2010), pp.19261932, ISSN 0897-4756

Ouyang, C.; Zeng, X.; Sijivancanin, Z. \& Baldereschi, A. (2010). Oxidation states of Mn atoms at clean and $\mathrm{Al}_{2} \mathrm{O}_{3}$-covered $\mathrm{LiMn}_{2} \mathrm{O}_{4}(001)$ surfaces. Journal of Physical Chemistry $C$, Vol.114, No.10, (March 2010), pp. 4756-4759, ISSN 1932-7447

Paek, S.-M.; Yoo, E. \& Honma, I. (2009). Enhanced cyclic performance and lithium storage capacity of $\mathrm{SnO}_{2} /$ graphene nanoporous electrodes with three-dimensionally delaminated flexible structure. Nano Letters, Vol.9, No.1, (January 2009), pp. 72-75, ISSN 1530-6984

Padhi, A.; Nanjundaswamy, K. \& Goodenough, J. (1997). Phospho-olivines as positiveelectrode materials for rechargeable lithium batteries. Journal of the Electrochemical Society, Vol.144, No.4, (April 1997), pp. 1188-1194, ISSN 0013-4651

Park, K.-S.; Kang, J.-G.; Choi, Y.-J.; Lee, S.; Kim, D.-W. \& Park, J.-G. (2011). Long-term, highrate lithium storage capabilities of $\mathrm{TiO}_{2}$ nanostructured electrodes using 3D selfsupported indium tin oxide conducting nanowire arrays. Energy $\mathcal{E}$ Enviromental Science, Vol.4, No.5, (May 2011), pp.1796-1801, ISSN 1754-5692

Peng, W.; Jiao, L.; Gao, H.; Qi, Z.; Wang, Q.; Du, H.; Si, Y.; Wang, Y. \& Yuan, H. (2011). A novel sol-gel method based on $\mathrm{FePO}_{4} \cdot 2 \mathrm{H}_{2} \mathrm{O}$ to synthesize submicrometer structured $\mathrm{LiFePO}_{4} / \mathrm{C}$ cathode material. Journal of Power Sources, Vol.196, No.5, (March 2011 ), pp. 2841-2847, ISSN 0378-7753

Posudievsky, O.; Kozarenko, O.; Dyadyun, V.; Jorgensen, S.; Spearot, J.; Koshechko, V. \& Pokhodenko, V. (2011). Characteristics of mechanochemically prepared host-guest hybrid nanocomposites of vanadium oxide and conducting polymers. Journal of Power Sources, Vol.196, No.6, (March 2011), pp. 3331-3341, ISSN 0378-7753

Qiu, M.-C.; Yang, L.-W.; Qi, X.; Li, J. \& Zhong, J.-X. (2010). Fabrication of ordered NiO coated Si nanowire array films as electrodes for a high performance lithium ion battery. Applied Materials \& Interfaces, Vol.2, No.12, (December 2010), pp.3614-3618, ISSN 1944-8244

Reddy, A.-L.-M.; Shaijumon, M.-M.; Gowda, S.-R. \& Ajayan, P.-M. (2009). Coaxial $\mathrm{MnO}_{2}$ /carbon nanotube array electrodes for high-performance lithium batteries. Nano Letters, Vol.9, No.3, (March 2009), pp.1002-1006, ISSN 1530-6984

Sahan, H.; Goktepe, H.; Patat, S. \& Ulgen, A. (2008). The effect of LBO coating method on electrochemical performance of $\mathrm{LiMn}_{2} \mathrm{O}_{4}$ cathode material. Solid State Ionics, Vol.178, No.35-36, (February 2008), pp. 1837-1842, ISSN 0167-2738

Santhanam, R. \& Rambabu, B. (2010). Research progress in high voltage spinel $\mathrm{LiNi}_{0.5} \mathrm{Mn}_{1.5} \mathrm{O}_{4}$ materials. Journal of Power Sources, Vol.195, No.17, (May 2010), pp.5442-5451, ISSN 0378-7753 
Scott, I.; Jung, Y.; Cavanagh, A.; Yan, Y.; Dillon, A.; George, S. \& Lee, S. (2011). Ultrathin coatings on nano-LiCoO $\mathrm{L}_{2}$ for $\mathrm{Li}$-ion vehicular applications. Nano Letters, Vol.11, No.2, (February 2011), pp. 414-418, ISSN 1530-6984

Sides, C.-R. \& Martin, C.-R. (2005). Nanostructured electrodes and the low-temperature performance of Li-ion batteries. Advanced Materials, Vol.17, No.1, (January 2005), pp. 125-128, ISSN 0935-9648

Sun, Y.-K.; Lee, Y.-S.; Yoshio, M. \& Amine, K. (2002). Synthesis and electrochemical properties of $\mathrm{ZnO}$-coated $\mathrm{LiNi}_{0.5} \mathrm{Mn}_{1.5} \mathrm{O}_{4}$ spinel as $5 \mathrm{~V}$ cathode material for lithium secondary batteries. Electrochemical and Solid State Letters, Vol.5, No.5, (May 2002), pp.A99-A102, ISSN 1099-0062

Sun, Y.; Myung, S.; Kim, M.; Prakash, J. \& Amine, K. (2005). Synthesis and characterization of $\mathrm{Li}\left[\left(\mathrm{Ni}_{0.8} \mathrm{Co}_{0.1} \mathrm{Mn}_{0.1}\right)_{0.8}\left(\mathrm{Ni}_{0.5} \mathrm{Mn}_{0.5}\right)_{0.2}\right] \mathrm{O}_{2}$ with the microscale core-shell structure as the positive electrode material for lithium batteries. Journal of the American Chemical Society, Vol.127, No.38, (September 2005), pp. 13411-13418, ISSN 0002-7863

Sun, Y.; Myung, S.; Park, B.; Prakash, J.; Belharouak, I. \& Amine, K. (2009). High-energy cathode material for long-life and safe lithium batteries. Nature Material, Vol.8, No.4, (April 2009), pp. 320-324, ISSN 1476-1122

Takahashi, K.; Wang, Y. \& Cao, G. (2006). Fabrication and $\mathrm{Li}^{+}$-intercalation properties of $\mathrm{V}_{2} \mathrm{O}_{5}-\mathrm{TiO}_{2}$ composite nanorod arrays. Applied Physics A-Materials Science $\mathcal{E}$ Processing, Vol.82, No.1, (January 2006), pp.27-31, ISSN 0947-8396

Thackeray, M.-M.; Kang, S.-H.; Johnson, C.-S.; Vaughey, J.T.; Benedek, R. \& Kackney, S.A. (2007). $\mathrm{Li}_{2} \mathrm{MnO}_{3}$-stabilized $\mathrm{LiMO}_{2}(\mathrm{M}=\mathrm{Mn}, \mathrm{Ni}, \mathrm{Co})$ electrodes for lithium-ion batteries. Journal of Materials Chemistry, Vol.17, No.30, (Apirl 2007), pp.3112-3125, ISSN 0959-9428

$\mathrm{Vu}$, A. \& Stein, A. (2011). Multiconstituent Synthesis of $\mathrm{LiFePO}_{4} / \mathrm{C}$ Composites with Hierarchical Porosity as Cathode Materials for Lithium Ion Batteries. Chemistry of Materials,, DOI: 10.1021/cm201197j, ISSN 0897-4756

Wang, G.; Yang, L.; Chen, Y.; Wang, J.; Bewlay, S. \& Liu, H. (2005). An investigation of polypyrrole- $\mathrm{LiFePO}_{4}$ composite cathode materials for lithium-ion batteries. Electrochimica Acta, Vol.50, No.24, (August 2005), pp. 4649-4654, ISSN 0013-4686

Wang, H.-L.; Cui, L.-F.; Yang, Y.-A.; Casalongue, H.-S.; Robinson, J.-T.; Liang, Y.-Y.; Cui, Y. \& Dai, H.-J. (2010). $\mathrm{Mn}_{3} \mathrm{O}_{4}$-graphene hybrid as a high-capacity anode material for lithium ion batteries. Journal of the American Chemical Society, Vol.132, No.40, (October 2010), pp.13978-13980, ISSN 0002-7863

Wang, H.; Zhang, W.; Zhu, L. \& Chen, M. (2007). Effect of $\mathrm{LiFePO}_{4}$ coating on electrochemical performance of $\mathrm{LiCoO}_{2}$ at high temperature. Solid State Ionics, Vol.178, No.1-2, (January 2007), pp. 131-136, ISSN 0167-2738

Wang, Y. \& Cao, G. (2008). Developments in nanostructured cathode materials for highperformance lithium-ion batteries. Advanced Materials, Vol.20, No.12, (June 2008), pp. 2251-2269, ISSN 0935-9648

Wang, Y.; Wang, Y.; Hosono, E.; Wang, K. \& Zhou, H. (2008). The design of a $\mathrm{LiFePO}_{4} /$ carbon nanocomposite with a core-shell structure and its synthesis by an in situ polymerization restriction method. Angewandte Chemie-International Edition, Vol.47, No.39, (August 2008), pp. 7461-7465, ISSN 1433-7851 
Wang, Y.; Wu, M.; Jiao, Z. \& Lee, J. (2009). Sn@CNT and Sn@C@CNT nanostructures for superior reversible lithium ion storage. Chemistry of Materials, Vol.21, No.14, (July 2009), pp. 3210-3215, ISSN 0897-4756

Winter, M.; Besenhard, J.; Spahr, M. \& Novak, P. (1998). Insertion electrode materials for rechargeable lithium batteries. Advanced Materials, Vol.10, No.10, (July 1998), pp. 725-763, ISSN 0935-9648

Wu, F. \& Wang, Y. (2011). Self-assembled echinus-like nanostructures of mesoporous CoO nanorod@CNT for lithium-ion batteries. Journal of Materials Chemistry, Vol.21, No.18, (March 2011), pp. 6636-6641, ISSN 0959-9428

Wu, H.-M.; Belharouak, I.; Abouimrane, A.; Sun, Y.-K. \& Amine, K. (2010). Surface modification of $\mathrm{LiNi}_{0.5} \mathrm{Mn}_{1.5} \mathrm{O}_{4}$ by $\mathrm{ZrP}_{2} \mathrm{O}_{7}$ and $\mathrm{ZrO}_{2}$. Journal of Power Sources, Vol.195, No.9, (May 2010), pp.2909-2913, ISSN 0378-7753

Wu, P.; Du, N.; Zhang, H.; Yu, J. \& Yang, D. (2010). CNTs@SnO @ @ coaxial nanocables with highly reversible lithium storage. Journal of Physical Chemistry C, Vol.114, No.51, (December 2010), pp. 22535-22538, ISSN 1932-7447

Wu, Z.; Ren, W.; Wen, L.; Gao, L.; Zhao, J.; Chen, Z.; Zhou, G.; Li, F. \& Cheng, H. (2010). Graphene anchored with $\mathrm{Co}_{3} \mathrm{O}_{4}$ nanoparticles as anode of lithium ion batteries with enhanced reversible capacity and cyclic performance. ACS Nano, Vol.4, No.6, (January 2010), pp. 3187-3194, ISSN 1936-0851

Wu, Z.-S.; Ren, W.; Wen, L.; Gao, L.; Zhao, J.; Chen, Z.; Zhou, G.; Li, F. \& Cheng, H.-M. (2010). Graphene anchored with $\mathrm{Co}_{3} \mathrm{O}_{4}$ nanoparticles as anode of lithium ion batteries with enhanced reversible capacity and cyclic performance. ACS Nano, Vol.4, No.6, (June 2010), pp. 3187-3194, ISSN 1936-0851

Xia, H.; Meng, Y.-S.; Lu, L. \& Ceder, G. (2007). Electrochemcial properties of nonstoichiometric $\mathrm{LiNi}_{0.5} \mathrm{Mn}_{1.5} \mathrm{O}_{4-\delta}$ thin-film electrodes prepared by pulsed laser deposition. Journal of the Electrochemical Society, Vol.154, No.8, (May 2007), pp.A737A743, ISSN 0013-4651

Xiao, J.; Choi, D.; Cosimbescu, L.; Koech, P.; Liu, J. \& Lemmon, J.-P. (2010). Exfoliated MoS 2 nanocomposite as an anode material for lithium ion batteries. Chemistry of Materials, Vol.22, No.16, (August 2010), pp. 4522-4524, ISSN 0897-4756

Xiong, H.; Shen, W.; Guo, B.; Bo, S.; Cui, W.; Chen, L.; Li, H. \& Xia, Y. (2011). Anomalous lithium storage in a novel nanonet composed by $\mathrm{SnO}_{2}$ nanoparticles and poly(ethylene glycol) chains. Journal of Materials Chemistry, Vol.21, No.9, (January 2011), pp. 2845-2847, ISSN 0959-9428

Xue, L.; Wei, Z.; Li, R.; Liu, J.; Huang, T. \& Yu, A. (2011). Design and synthesis of $\mathrm{Cu}_{6} \mathrm{Sn}_{5}-$ coated $\mathrm{TiO}_{2}$ nanotube arrays as anode material for lithium ion batteries. Journal of Materials Chemistry, Vol.21, No.9, (January 2011), pp.3216-3220, ISSN 0959-9428

Yamada, H.; Tagawa, K.; Komatsu, M.; Moriguchi, I. \& Kudo, T. (2007). High power battery electrodes using nanoporous $\mathrm{V}_{2} \mathrm{O}_{5}$ /carbon composites. Journal of Physical Chemistry C, Vol.111, No.23, (June 2007), pp. 8397-8402, ISSN 1932-7447

Yang, S.; Feng, X.; Ivanovici, S. \& Mullen, K. (2010). Fabrication of graphene-encapsulated oxide nanoparticles: towards high-performance anode materials for lithium storage. Angewandte Chemie-International Edition, Vol.49, No.45, (September 2010), pp. 8408-8411, ISSN 1433-7851 
Yang, T.; Zhang, N.; Lang, Y. \& Sun, K. (2011). Enhanced rate performance of carbon-coated $\mathrm{LiNi}_{0.5} \mathrm{Mn}_{1.5} \mathrm{O}_{4}$ cathode material for lithium ion batteries. Electrochimica Acta, Vol.56, No.11, (April 2011), pp. 4058-4064, ISSN 0013-4686

Yang, Z.; Du, G.; Guo, Z.; Yu, Xe.; Chen, Z.; Guo, T. \& Liu, H. (2011). TiO2(B)@carbon composite nanowires as anode for lithium ion batteries with enhanced reversible capacity and cyclic performance. Journal of Materials Chemistry, Vol.21, No.24, (May 2011), pp. 8591-8596, ISSN 0959-9428

Yan, J.; Sumboja, A.; Khoo, E. \& Lee, P. (2011). $\mathrm{V}_{2} \mathrm{O}_{5}$ loaded on $\mathrm{SnO}_{2}$ nanowires for high-rate Li ion batteries. Advanced Materials, Vol.23, No.6, (February 2011), pp. 746-750, ISSN 0935-9648

Yi, T.-F.; Zhu, Y.-R.; Zhu, X.-D.; Shu, J.; Yue, C.-B. \& Zhou, A.-N. (2009). A review of recent developments in the surface modification of $\mathrm{LiMn}_{2} \mathrm{O}_{4}$ as cathode material of power lithium-ion battery. Ionics, Vol.15, No.6, (December 2009), pp. 779-784, ISSN 09477047

Yi, T.; Shu, J.; Wang, Y.; Xue, J.; Meng, J.; Yue, C. \& Zhu, R. (2011). Effect of treated temperature on structure and performance of $\mathrm{LiCoO}_{2}$ coated by $\mathrm{Li}_{4} \mathrm{Ti}_{5} \mathrm{O}_{12}$. Surface $\mathcal{E}$ Coatings Technology, Vol.205, No.13-14, (March 2011), pp. 3885-3889, ISSN 02578972

Yu, W.-J.; Hou, P.-X.; Zhang, L.-L.; Li, F.; Liu, C. \& Cheng, H.-M. (2010). Preparation and electrochemical property of $\mathrm{Fe}_{2} \mathrm{O}_{3}$ nanoparticles-filled carbon nanotubes. Chemical Communications, Vol.46, No.45, (October 2010), pp. 8576-8578, ISSN 1359-7345

Zhang, H.-X.; Feng, C.; Zhai, Y.-C.; Jiang, K.-L.; Li, Q.-Q. \& Fan, S.-S. (2009). Cross-stacked carbon nanotube sheets uniformly Loaded with $\mathrm{SnO}_{2}$ nanoparticles: A novel binder-free and high-capacity anode material for lithium-ion batteries. Advanced Materials, Vol.21, No.22, (January 2009), pp.2299-2304, ISSN 0935-9648

Zhang, M.; Lei, D.; Yin, X.; Chen, L.; Li, Q.; Wang, Y. \& Wang, T. (2010). Magnetite/graphene composites: microwave irradiation synthesis and enhanced cycling and rate performances for lithium ion batteries. Journal of Materials Chemistry, Vol.20, No.26, (June 2010), pp. 5538-5543, ISSN 0959-9428

Zhang, S.; Du, Z.; Lin, R.; Jiang, T.; Liu, G.; Wu, X. \& Weng, D. (2010). Nickel nanocone-array supported silicon anode for high-performance lithium-Ion batteries. Advanced Materials, Vol.22, No.47, (December 2010), pp. 5378-5382, ISSN 0935-9648

Zhang, W.-M.; Hu, J.-S.; Guo, Y.-G.; Zheng, S.-F.; \& Zhong, L.-S. (2008). Tin-nanoparticles encapsulated in elastic hollow carbon spheres for high-performance anode material in lithium-ion batteries. Advanced Materials, Vol.20, No.6, (February 2008), pp. 11601165, ISSN 0935-9648

Zhou, X.; Wang, F.; Zhu, Y. \& Liu., Z. (2011). Graphene modified $\mathrm{LiFePO}_{4}$ cathode materials for high power lithium ion batteries. Journal of Materials Chemistry, Vol.21, No.10, (January 2011), pp. 3353-3358, ISSN 0959-9428

Zhou, Y.; Wang, J.; Hu, Y.; O'Hayre, R. \& Shao., Z. (2010). A porous $\mathrm{LiFePO}_{4}$ and carbon nanotube composite. Chemical Communications, Vol.46, No.38, (August 2010), pp. 7151-7153, ISSN 1359-7345

Zhou, Z.-B.; Takeda, M.; Fujii, T. \& Ue, M. (2005). Li $\left[\mathrm{C}_{2} \mathrm{~F}_{5} \mathrm{BF}_{3}\right]$ as an electrolyte salt for $4 \mathrm{~V}$ class lithium-ion cells. Journal of the Electrochemical Society, Vol.152, No.2, (January 2005), pp.A351-A356, ISSN 0013-4651 
Zhu, X.-J.; Zhu, Y.-W.; Murali, S.; Stollers, M.-D. \& Ruoff, R.-S. (2011). Nanostructured reduced graphene oxide $/ \mathrm{Fe}_{2} \mathrm{O}_{3}$ composite as a high-performance anode material for lithium ion batteries. ACS Nano, Vol.5, No.4, (April 2011), pp.3333-3338, ISSN 1936-0851 


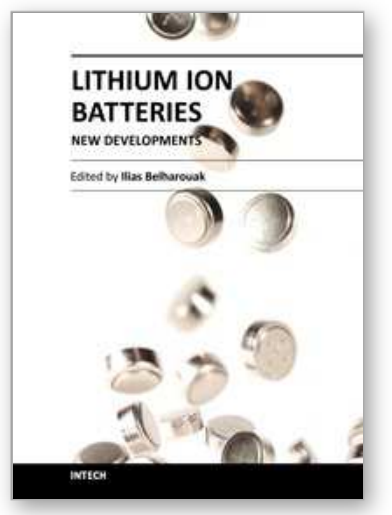

\author{
Lithium lon Batteries - New Developments \\ Edited by Dr. llias Belharouak
}

ISBN 978-953-51-0077-5

Hard cover, 226 pages

Publisher InTech

Published online 24, February, 2012

Published in print edition February, 2012

The eight chapters in this book cover topics on advanced anode and cathode materials, materials design, materials screening, electrode architectures, diagnostics and materials characterization, and electrode/electrolyte interface characterization for lithium batteries. All these topics were carefully chosen to reflect the most recent advances in the science and technology of rechargeable Li-ion batteries, to provide wide readership with a platform of subjects that will help in the understanding of current technologies, and to shed light on areas of deficiency and to energize prospects for future advances.

\title{
How to reference
}

In order to correctly reference this scholarly work, feel free to copy and paste the following:

Xiangfeng Guan, Guangshe Li, Jing Zheng, Chuang Yu, Xiaomei Chen, Liping Li and Zhengwei Fu (2012). Heterogeneous Nanostructured Electrode Materials for Lithium-Ion Batteries - Recent Trends and Developments, Lithium Ion Batteries - New Developments, Dr. llias Belharouak (Ed.), ISBN: 978-953-51-00775, InTech, Available from: http://www.intechopen.com/books/lithium-ion-batteries-newdevelopments/heterogeneous-nanostructured-electrode-materials-for-lithium-ion-batteries-recent-trends-anddevelop

\section{INTECH}

open science | open minds

\section{InTech Europe}

University Campus STeP Ri

Slavka Krautzeka 83/A

51000 Rijeka, Croatia

Phone: +385 (51) 770447

Fax: +385 (51) 686166

www.intechopen.com

\section{InTech China}

Unit 405, Office Block, Hotel Equatorial Shanghai

No.65, Yan An Road (West), Shanghai, 200040, China

中国上海市延安西路65号上海国际贵都大饭店办公楼 405 单元

Phone: +86-21-62489820

Fax: +86-21-62489821 
(C) 2012 The Author(s). Licensee IntechOpen. This is an open access article distributed under the terms of the Creative Commons Attribution 3.0 License, which permits unrestricted use, distribution, and reproduction in any medium, provided the original work is properly cited. 